\title{
4. LE TERRAIN POLITIQUE
}

Beide Systemalternativen PAL und SECAM treten nach Erscheinen des "troisième larron« in eine Phase intensivierter Konkurrenz, die vom Kontext der europäischen (EBU) bzw. internationalen Bemühungen (CCIR) um die Schaffung eines einheitlichen Farbfernsehstandards beeinflußt waren. Der »late comer « PAL setzte vor allem die SECAM-Entwickler unter Druck. $\mathrm{DaB}$ es aber kaum genügt, wirtschaftstheoretische Modelle (first-mover-Vorteile etc.) als ausreichende Erklärungshilfen für die Beschreibung der abgelaufenen Systemkonkurrenz heranzuziehen, geschweige denn mittels dieser Modelle den Ausgang der Kontroverse zu erklären, wird im folgenden Abschnitt zu demonstrieren sein ${ }^{1}$. Schon bevor sich die beiden Systemalternativen bzw. deren Entwickler die Unterstützung ihrer nationalen Industrieverbände sichern konnten, schalteten sich Politiker dies- und jenseits des Rheins in die Farbfernsehfrage ein.

Ziel des folgenden Kapitels ist es, die politische Dimension der PAL-SECAM-Auseinandersetzung auf nationalem, bilateralem und internationalem Boden nachzuzeichnen. Dies geschieht in drei Stufen. Zu Beginn kommt es darauf an, die Bedeutung des Fernsehens als Medium der politischen Öffentlichkeit zu beschreiben. In beiden Ländern setzte sich das Fernsehen als neues Leitmedium der politischen Öffentlichkeit durch und nahm aus diesem Grunde einen prominenten Platz im politischen Diskurs der Nachkriegszeit ein. Dennoch war die Einschätzung der politischen Bedeutung und dementsprechend die staatliche Instrumentalisierung des Fernsehens im Frankreich de Gaulles und in der Adenauer-Republik sehr verschieden. Diese nationalen Differenzen gilt es im folgenden aufzuzeigen.

In einem zweiten Schritt geht es darum, die Farbfernsehkontroverse in den Kontext der deutsch-französischen Beziehungen einzubetten. Die seit dem

1 Die Studie von Uwe-Jean Heuser über das Scheitern der Bemühungen um einen einheitlichen Standard im Bereich des hochauflösenden Fernsehens (HDTV) unternimmt den Versuch, das Scheitern mit wirtschaftstheoretischen Modellen zu untersuchen und zu erklären. Dabei, so die These des Autors, wird aber eher die Unzulänglichkeit der herangezogenen Theorien und Modelle nachgewiesen, als daß ausreichende Erklärungen für das Scheitern angeboten werden. UweJean HeuSEr, Hochauflösendes Fernsehen: Fallstudie und Analyse des internationalen Standardisierungsprozesses, unveröffentlichte Diss. Univ., Köln 1992. Auch Christian Henrich-Frankes Arbeit, welche die Regulierungsproblematiken im Bereich der internationalen Frequenzregelung mittels der sogenannten Neuen Institutionenökonmik analysiert kommt zu dem selbstkritischen SchluB, daß »eindimensionale Erklärung über Kosten-Nutzen-Relationen nicht-ökonomische Wirkungszusammenhänge wie Ideologien, Macht oder Wechselwirkung mit anderen Politikbereichen unbeachtet [läBt], die jenseits des Transaktionskostenarguments einen Einfluß auf das Funkregime bzw. dessen Wandlung nehmen.« Siehe Christian Henrich-Franke, Globale Regulierungsproblematiken in historischer Perspektive. Der Fall des Funkfrequenzspektrums 1945-1988, Baden-Baden 2005, S. 330. 
deutsch-französischen »Freundschaftsvertrag« vom Januar 1963 regelmäßig stattfindenden bilateralen Konsultationen erlauben eine detaillierte Rekonstruktion der Bedeutung, die das Thema Farbfernsehen im Rahmen dieser deutsch-französischen Gespräche einnahm. Die zentralen Akteure dieser politischen Begegnungen, Informationsminister Alain Peyrefitte und der Leiter des Bundespresse- und Informationsamtes Karl-Günter von Hase, haben maßgeblich zur Politisierung der Farbfernsehfrage beigetragen, wenn auch mit durchaus unterschiedlichen Motivationen.

Schließlich gilt es drittens, die Gründe für das Scheitern einer politischen Lösung des Standardisierungskonflikts zu analysieren. Hierbei müssen auBenpolitische Neuorientierungen auf der einen und wirtschaftspolitische Strategien auf der anderen Seite berücksichtigt werden. 


\subsection{Das Fernsehen als neues Leitmedium politischer Öffentlichkeit}

Anläßlich der Eröffnung der Rundfunk- und Phonoausstellung in Düsseldorf am 29. August 1953 hielt der Generaldirektor des Nordwestdeutschen Rundfunks, Adolf Grimme, eine Rede, in der er die Hoffnung äußerte, daß das Fernsehen einen wichtigen Beitrag zur Demokratisierung der deutschen Bevölkerung beitragen werde:

Übrigens, antike Politik! Was diese zur Anteilnahme eines ganzen Volkes machte, kehrt inmitten des Zeitalters der Massen durch das Fernsehen abgewandelt wieder: die Agora, die Versammlung des ganzen Volkes, die direkte Demokratie. GewiB, an einer Sitzung des Bundestages nehmen aktiv auch fernerhin nur die Repräsentanten des Volkes teil. Aber was dort entschieden wird und wie, das wird fortan zum Miterleben für jedermann, und wir gewinnen damit ein Stück unmittelbarer Demokratie zurück. Das Parlament bleibt dann auch Ausdruck des Repräsentativsystems, aber nicht mehr nur. Es tritt ein neues auf und hinzu: das Volk ist mit dabei ${ }^{2}$.

Zwar gibt der Inhalt dieses Zitates weder die Realität der athenischen Demokratie noch die der bundesdeutschen Fernsehlandschaft im Jahre 1953 wieder, doch spricht aus diesen Worten die Hoffnung, das Medium Fernsehen zum wichtigen Bestandteil der politischen Öffentlichkeit in der jungen Bundesrepublik zu machen. Obschon das Fernsehen im Prinzip in demselben institutionellen und legislativen Rahmen wie der Hörrundfunk entwickelt wurde, kam dem Fernsehen eine neue ästhetische und wahrnehmungsstrukturierende Dimension hinzu, die das bisherige Medienerlebnis transzendierte. Hatte bereits das Radio die Trennung von Privatheit und Öffentlichkeit aufgehoben und damit das bürgerliche Modell von Öffentlichkeit, das durch die Vereins und Geselligkeitskultur bestimmt war, in Frage gestellt, wurde nun im privaten Raum der Anschluß an die Öffentlichkeit möglich, ohne daß dieser Anschluß kontrollierbar gewesen wäre ${ }^{3}$. Setzte die bürgerliche Vereinskultur einen ersten "Strukturwandel der Öffentlichkeit « hin zur aufgeklärten bürgerlichen Öffentlichkeit des 19. Jahrhunderts in Gang, kam mit dem Rundfunk ein zweiter Strukturwandel hin zum Zeitalter der Fundamentaldemokratisierung und des politischen Massenmarktes, in dem die modernen Massenmedien immer neue Kommunikationsgemeinschaften am Meinungsund Unterhaltungsmarkt etablierten ${ }^{4}$.

2 Zitiert nach Monika Elsner, Thomas Müller, Peter M. SPangenberg, Zur Entstehung des Dispositivs Fernsehen in der Bundesrepublik Deutschland der fünfziger Jahre, in: Helmut KREUZER, Christian W. Thomson (Hg.), Geschichte des Fernsehens in der Bundesrepublik Deutschland, Bd.1 Perioden, Zäsuren, Epochen, München 1993, S. 43 f.

${ }^{3}$ Inge MARssoleK, Radio in Deutschland 1923-1960. Zur Sozialgeschichte eines Mediums, in: Geschichte und Gesellschaft 27 (2001) 2 S. 207-239, hier S. 212.

4 Jürgen HABERMAS, Strukturwandel der Öffentlichkeit. Untersuchungen zu einer Kategorie der bürgerlichen Gesellschaft, Frankfurt a.M. 1990. Zur kritischen Weiterentwicklung des Konzeptes aus medientheoretischer Perspektive siehe John B. Thompson, The Media and Modernity. A Social Theory of the Media, Cambridge 1995 sowie als konzisen Forschungsïberblick Hans Ver- 
Bernd Weisbrod plädiert zu Recht dafür, jedes Medium in seiner je eigenen Strukturlogik zu betrachten, das heißt, die jedem Medium eigene semantische Logik und diskursive Plastizität herauszuarbeiten. In einem Vergleich des Mediums Photographie mit dem Medium Hörrundfunk macht Weisbrod die unterschiedlichen »Strukturlogiken« deutlich: »Während der besondere optische Wert der photographischen Information in der Illusion der Raumgleichheit bei Zeitungleichheit beruht - man sieht sich zeitversetzt in den Raum hinein - so besteht der akustische Wert der Rundfunkinformation in der Illusion der Zeitgleichheit bei Raumungleichheit - man hört sich gewissermaßen raumversetzt in die Zeit hinein " ${ }^{5}$.

War der spezifische Code des Rundfunkmediums die Einprägung einer unverkennbaren Hörspur, trat mit dem Fernsehen die Dimension bewegter Bilder hinzu. Im Fernsehen fusionierten sozusagen die beiden von Weisbrod beschriebenen Charakteristika der photographischen und tonmäßigen Informationsübertragung zu jenem neuen »Dispositiv« Fernsehen, dessen Qualität am treffendsten mit dem Begriff »televisuelles Dabeisein « umschrieben wird ${ }^{6}$. Vor allem der Live-Charakter des frühen Fernsehens ließ eine neue Kommunikationssituation entstehen, die - ähnlich wie beim Radio - zwischen den Erfahrungsräumen »Öffentlichkeit« und »Privatheit« angesiedelt war. Diese Verschmelzung privater und öffentlicher Erfahrungsräume im Prozeß medialer Teilhabe hat zur Konstruktion einer gänzlich neuen Ebene von medialer Realität geführt, die von Hans Ulrich Gumbrecht als »Fernsehwirklichkeit« beschrieben wird'. "The liveness of events is their dasein: their magical, edged, unfolding, self-disclosing, unpredictable, mood-creating being«, so der

STraeten, The Media and the Transformation of the Public Sphere. A Contribution for a Political Economy of the Public Sphere, in: European Journal of Communication 11 (1996) 3 S. 347-370.

5 WeIsBroD, Medien als symbolische Form der Massengesellschaft, S. 277.

${ }^{6}$ Zum Dispositiv-Begriff, der von Foucault geprägt und von Jean-Louis Baudry im Zusammenhang mit theoretischen Überlegungen zum Kino in den medienwissenschaftlichen Kontext eingebracht wurde, siehe Steinmaurer, Tele-Visionen, S. 14-70; Carsten LenK, Das Dispositiv als theoretisches Paradigma der Medienforschung. Überlegungen zu einer integrativen Nutzungsgeschichte des Rundfunks, in: Mitteilungen des Studienkreises Rundfunk und Geschichte 22 (1996) 1 S. 5-17; Noël NeL, Les dispositifs télévisuels, in: Bourdon, Jost (Hg.), Penser la télévision, S. 59-74 sowie KessLER, Notes on Dispositif. Eine präzise Beschreibung der zentralen Metaphern, die als Charakteristika des Televisuellen benutzt werden, liefert GrIPSRUD, Television, Broadcasting, Flow.

7 Hans Ulrich GumBrecht, »Ihr Fenster zur Welt« oder: Wie aus dem Medium »Fernsehen» die »Fernsehwirklichkeit« wurde, in: Hans-Georg SoEFFner (Hg.), Kultur und Alltag. Soziale Welt, Sonderband Nr. 6, Göttingen 1988, S. 243-250. Zur Theorie der Medien und ihres Einflusses auf Kommunikationsräume und Wirklichkeitsmodelle siehe Klaus MERTEN, Siegfried J. Schmid, Siegfried Weischenberg (Hg.), Die Wirklichkeit der Medien. Eine Einführung in die Kommunikationswissenschaft, Opladen 1994. 
britische Rundfunkhistoriker Paddy Scannell in seiner phänomenologischen Studie des Fernsehens ${ }^{8}$.

Dieser neuen Wirklichkeitsdimension des Mediums Fernsehen muß man sich bewußt sein, will man den Einfluß des Fernsehens auf die politische Öffentlichkeit untersuchen ${ }^{9}$. Im Prozeß der Mediatisierung der Gesellschaft, so Peter Ludes, hat das Fernsehen dem Auge auch im Bereich medialer Wirklichkeitsvermittlung zu jener Vormachtstellung verholfen, den der Sehsinn im natürlichen Wahrnehmungsapparat des Menschen auch einnimmt. Dem Fernsehen kommt demnach eine privilegierte Rolle im "Visualisierungsprozeß« moderner Gesellschaften zu, den Ludes als einen Teilprozeß der »Modernisierung der Moderne $«$ beschreibt ${ }^{10}$.

$\mathrm{Da} B$ auch die Politiker das Fernsehen als Ausdruck medialer Modernisierung begriffen haben, steht außer Zweifel. Dennoch fiel die Würdigung dieses neuen Mediums als Instrument zur Herstellung politischer Öffentlichkeit durchaus unterschiedlich aus. Vor dem Hintergrund der nachfolgenden Darstellung der Politisierung der Farbfernsehfrage macht es Sinn, sich die unterschiedliche parteipolitische oder regierungsmäßige »Nutzbarmachung « des Fernsehen am Beispiel der Bundesrepublik Deutschland und Frankreichs in den fünfziger und sechziger Jahren vor Augen zu führen.

\subsubsection{Bund- oder Ländersache? \\ Grundzüge der Fernsehentwicklung in der Adenauer-Republik}

In einem 1991 veröffentlichten Aufsatz machte der Medienwissenschaftler Knut Hickethier den Vorschlag, die Geschichte des Fernsehens in der Bundesrepublik Deutschland in drei Phasen zu gliedern, wobei er die erste Phase (1948-1963) als jene des »ARD-Monopols« beschrieb ${ }^{11}$. Zu Recht stellt Hik-

8 Paddy Scannell, Television and Modern Life: A Phenomenological Approach, Oxford 1996, S. 92.

${ }^{9}$ Ein Vorschlag zur systematischen Analyse der Beziehung von Öffentlichkeitsstrukturen und Medien im historischen PtozeB findet sich bei FüHRER, HICKETHIER, SCHILDT, Öffentlichkeit Medien - Geschichte, S. 1-38.

10 Peter Ludes, Visualisienung als TeilprozeB der Modernisierung der Moderne, in: KREUZER, THomson (Hg.), Geschichte des Fernsehens in Deutschland, Bd. 1, S. 353-370, hier S. 367. Zum Verhältnis von Hörsinn und Sehsinn bzw. zur Visualisierung des Hörprozesses siehe Andreas FickeRs, Sichtbar hörbar! Radioapparat und Stadt als Knoten im vernetzten Kommunikationsraum, in: Clemens Zimmermann (Hg.), Zentralität und Raumgefüge der GroBstädte im 20. Jahrhundert, Stuttgart 2006, S. 83-103.

11 Knut HickethiER, Phasenbildung in der Fernsehgeschichte - ein Diskussionsvorschlag, in: Helmut Kreuzer, Helmut Schanze (Hg.), Fernsehen in der Bundesrepublik Deutschland: Perioden, Zäsuren, Epochen, Heidelberg 1991, S. 11-37. In Anlehnung an die politische Geschichte der BRD sowie die institutionen- und programmgeschichtliche Entwicklung des Fernsehens schlägt Hickethier folgende drei Phasen vor: 1. Phase: (1948-1963) Das ARD-Monopol; 2. Phase: (1963-1982) ARD und ZDF im Kontrast; 3. Phase: (1982-1989) Öffentlich-rechtliche und 
kethier damit ein wesentliches Merkmal des frühen Fernsehrundfunks in der Bundesrepublik als »Epochenmerkmal « heraus, gab es doch bis zur Gründung des »Zweiten Deutschen Fernsehens « durch den Beschluß der Ministerpräsidenten der Länder am 6. Juni 1961 keine Alternative zum Programm der ARD-Anstalten. Die Formung der bundesdeutschen »Fernsehnation« lag bis zum Start des Programmbetriebs des ZDF im April 1963 somit in der alleinigen Macht und Verantwortung der ARD-Anstalten ${ }^{12}$.

Wenn auch die Bedeutung dieser Monopolstellung im Bereich der Programmverantwortung aus kulturgeschichtlicher Sicht nicht unterschätzt werden darf, waren in der Phase der institutionellen Konsolidierung des Fernsehrundfunks in der Bundesrepublik andere Fragen von zentraler Bedeutung für die Entwicklung der bundesdeutschen Fernsehlandschaft. Charakteristisches Merkmal der frühen Entwicklungsphase des Fernsehens in der Bundesrepublik war die Auseinandersetzung zwischen dem Bund und den Ländern um die verfassungsrechtlich nicht eindeutig definierten Kompetenzen im Bereich des Rundfunks ${ }^{13}$. Wie bereits geschildert war die strukturelle Form, in der der Wiederaufbau des Rundfunks in Deutschland nach dem Ende des Zweiten Weltkriegs stattfand, ein Spiegel der unterschiedlichen Interessen der alliierten Besatzungsmächte. Resultat der oftmals divergierenden alliierten Interessen war eine Rundfunklandschaft, in der den Ländern die Kulturhoheit und damit letztlich die Rundfunkhoheit zugesprochen worden war, der Post jedoch - und damit einer Bundesbehörde - besondere Rechte in der Fernmeldetechnik eingeräumt wurden ${ }^{14}$.

Wie Hans Bausch in seiner Studie zur Rundfunkpolitik nach 1945 formulierte, war der Konflikt zwischen Bund und Ländern aus diesem Grund »so

kommerzielle Konkurrenz. Hickethiers Beschreibung der ersten Phase als Monopolphase der ARD deckt sich mehr oder minder mit John Ellis Charakterisierung der Frühphase des Fernsehens als »age of scarcity«. Siehe EluIs, Seeing Things.

12 Die kulturhistorische Bedeutung dieses Phänomens der »Fernsehnation « wird von Monika Bernold beispielhaft für Österreich analysiert. Siehe BERNOLD, Fernsehen ist gestern.

${ }^{13} \mathrm{Zu}$ den juristischen Fragen des Aufbaus des Fernsehrundfunks in der Bundesrepublik siehe Hans Brack, Günther HerrmanN, Hans-Peter Hillig (Hg.), Organisation des Rundfunks in der Bundesrepublik Deutschland 1948-1962, Hamburg 1962. In diesem Band befindet sich ein Anhang mit den wichtigsten Satzungen, Gesetzestexten und Staatsverträgen zum Rundfunk in der Bundesrepublik Deutschland. Siehe außerdem Hans BRACK, Organisation und wirtschaftliche Grundlagen des Hörfunks und des Fernsehens in Deutschland, Schriftenreihe des Instituts für Rundfunkrecht an der Universität Köln, Bd. 2, München 1968.

14 BausCH, Rundfunkpolitik nach 1945, in: DeRs. (Hg.): Rundfunk in Deutschland, Bd. 3, S. 13-160. Siehe auch die Aufsätze von Winfried Lerg »Über die Entstehung der deutschen Rundfunktopografie«, Klaus Pabst »Kulturlandschaften als Alibi: Strukturfragen der frühen Sendegesellschaften« sowie Wolf Bierbach »Besatzungszonen und Länder. Föderale und zentralistische Rundfunkanstalten « in dem Sammelband von Walter FörsTER (Hg.), Rundfunk in der Region. Probleme und Möglichkeiten der Regionalität, Annalen des Westdeutschen Rundfunks, Bd. 6, Köln 1983. 
gut wie vorprogrammiert «. Nachdem die Bemühungen um ein Bundesrundfunkgesetz der Adenauer-Regierung im Jahre 1953 am Widerstand der Alliierten gescheitert waren, ein zweiter Anlauf in Form von Bund-Länder-Verhandlungen auch durch Verweigerungen der CDU-geführten Länder vereitelt worden war, setzte Adenauer nach Erringung der absoluten Mehrheit bei der Bundestagswahl 1957 zu einem dritten Anlauf an. Die im Deutschlandvertrag des Jahres 1955 wiedererlangte Souveränität hatte dem Bund auch die Funkhoheit übertragen, so daß Adenauer verfassungsrechtlich und innenpolitisch gestärkt in eine neue Verhandlungsrunde mit den Ländern eintreten konnte.

Neben den veränderten innen- wie außenpolitischen Rahmenbedingungen waren es aber auch wirtschaftliche und kulturelle Faktoren, welche die Bundesregierung zum Handeln drängten. Zum einen war 1957 die erste Teilnehmermillion des bundesdeutschen Fernsehens erreicht worden, die den Bedeutungsanstieg des Mediums aus wirtschaftlicher wie gesellschaftlicher Ebene eindrucksvoll dokumentierte. Zum anderen drängte die deutsche Wirtschaft angeregt vom amerikanischen und englischen Beispiel - auf eine bundesrechtliche Regelung der Sendezeiten für die kommerzielle Fernsehwerbung. Vor allem der Aufbau eines kommerziellen zweiten Fernsehprogramms in Großbritannien (ITV) zeigte, daß ein privatrechtliches Programm neben einem öffentlich-rechtlichen Programm (dem der BBC) erfolgreich bestehen konnte $^{15}$. Doch die Vorstöße von Bundesinnenminister Schröder, den Aufbau eines zweiten Fernsehprogramms zur bundesstaatlichen Angelegenheit zu machen, trafen auf den erbitterten Widerstand der Landesregierungen, die ihrerseits beschlossen, ein zweites Fernsehprogramm in Form eines Fernsehverbandes auf Länderebene zu entwickeln (Kieler Beschlüsse vom 19. und 20. Juni 1959). Da eine einvernehmliche Lösung nicht in Aussicht schien, setzte die Bundesregierung auf eine "privatwirtschaftliche Lösung «, die auf den vielversprechenden Namen »Freies Fernsehen GmbH« getauft wurde. Am 25. Juli 1960 unterzeichnete Bundeskanzler Adenauer zum Entsetzen vieler Fernsehjournalisten und Intendanten der Landesrundfunkanstalten den Vertrag zur Gründung der »Deutschland-Fernsehen $\mathrm{GmbH}{ }^{16}$.

Hans Bausch, damals Intendant des Süddeutschen Rundfunks (SDR), kritisierte das Vorgehen des Bundeskanzlers während eines Interviews in der Tagesschau scharf als Angriff auf die Pressefreiheit und warnte vor den Folgen für »Gesellschaft« und »politisches Leben« in der Bundesrepublik ${ }^{17}$. Der Ministerpräsident von Hessen, Dr. Georg August Zinn, sprach gar von einem

15 HickethiER, Geschichte des deutschen Fernsehens, S. 115.

16 Zum Thema »Deutschland-Fernsehen GmbH« siehe Florian KaIN, Das Privatfernsehen, der Axel Springer Verlag und die deutsche Presse. Die medienpolitische Debatte in den sechziger Jahren, Münster u.a. 2003, sowie Rüdiger STEINmeTZ, Freies Fernsehen. Das erste privat-kommerzielle Fernsehprogramm in Deutschland, Konstanz 1996.

17 BAUSCH, Rundfunkpolitik nach 1945, S. 419. 
»Husarenstreich« und verglich das Vorgehen Adenauers mit der Politik des Reichskanzlers Franz von Papens gegen Preußen im Jahre 1932 ${ }^{18}$ !

Tatsächlich bewies die Satzung der "Deutschland-Fernsehen $\mathrm{GmbH}$ «, daß sie als eine vom Bund beherrschte privatrechtliche Gesellschaft konzipiert war, und das Wort vom »Adenauer-Fernsehen « war bald in aller Munde. Doch der politische Widerstand gegen Adenauers Pläne ließ nicht lange auf sich warten. Bereits am 19. August reichte das Land Hamburg eine Klage gegen das Vorgehen Adenauers beim Bundesverfassungsgericht in Karlsruhe ein, der sich wenig später die Länder Hessen, Bremen und Niedersachsen anschließen sollten. Als der ehemalige SDR-Intendant und vehemente Verfechter der Rundfunkhoheit der Länder, Hans Bausch, 1980 seine Studie zur "Rundfunkpolitik in Deutschland nach 1945 « vorlegte, war die Empörung über das damalige Vorgehen Adenauers in seinen Worten immer noch lebendig. Er schreibt:

Wenn es die Beteiligten nicht eines Tages schonungslos offenlegen, wird das Spiel, das zwischen dem frühen Winter 1958 und dem späten Winter 1961 zwischen Unternehmern und Bundesregierung gespielt wurde, historisch niemals voll und ganz auszuleuchten sein. [...] Die Periode der rundfunkpolitischen sIrrungen, Wirrungen، endete exakt um die Mittagsstunde des 28. Februar 1961, als das Bundesverfassungsgericht zu Karisruhe sein für den Gang der Rundfunkgeschichte entscheidendes $>$ Fernseh-Urteil verkündete $^{19}$.

Das von Bausch auch als "Magna-Charta des bundesrepublikanischen Rundfunks bezeichnete Urteil des Bundesverfassungsgerichts verbot jedenfalls das »Adenauer-Fernsehen« und bestätigte die Rundfunkhoheit der Länder, schrieb den öffentlich-rechtlichen Status des Fernsehens fest und zwang den Bund zur Aufgabe seiner Pläne eines staatsnahen Fernsehprogramms. Dieses Urteil wird zu Recht auch als politische Niederlage Adenauers gedeutet, dessen politischer Stern nach der gescheiterten Kandidatur für das Amt des Bundespräsidenten im Jahre 1959 den Zenit überschritten hatte ${ }^{20}$.

Das »Fernseh-Urteil« ist mit Sicherheit das populärste Beispiel zur Demonstration des Verhältnisses, welches Bundeskanzler Adenauer mit der Presse pflegte. Zwar sollte die »Spiegel-Affäre« die Schlagzeilen um das „Fernseh-Urteil« in den Schatten stellen ${ }^{21}$, doch müsse es nachdenklich stimmen, so Kurt Koszyk, »daß nicht das Schicksal einzelner Journalisten zu verfassungsrechtlicher Überprüfung der Praktiken des Bundeskanzlers führte,

18 Ibid. S. 422.

19 Ibid. S. 422 und 305.

20 Siehe Heinrich KÜPPERS, Adenauer und Altmeier im Fernsehstreit 1958-1961, in: Vierteljahreshefte für Zeitgeschichte 35 (1987) S. 625-659.

21 Zur Spiegel-Affäre siehe Christoph Klessmann, Zwei Staaten, eine Nation. Deutsche Geschichte 1955-1970, Bonn 1988, S. 162-166 sowie ausführlich KaIN, Das Privatfernsehen. 
sondern erst sein Zugriff auf das wirksamste Massenmedium unserer Tage, das Fernsehen ${ }^{22}$. Adenauers Ambitionen im Bereich der Pressepolitik beschränkten sich aber nicht auf das neue Medium Fernsehen.

Die in den fünfziger Jahren unbestritten mächtigste Rolle im Prozeß der politischen Meinungsbildung übten die Zeitungen aus. Mit dem Aufbau des Bundespresse- und Informationsamtes, das dem Bundeskanzleramt direkt unterstellt war, schuf sich Konrad Adenauer bzw. die Bundesregierung ein "Hör- und Sprachrohr«, mit dem Ziel, eine zentrale Informationsstelle für alle die Regierung betreffenden Informationen zu etablieren ${ }^{23}$. Der Geschäftsverteilungsplan des Bundespresse- und Informationsamtes vom Juni 1951 sah sieben Inlands- sowie acht Auslandsreferate vor, zwei Referate für die allgemeine Verwaltung sowie sechs Arbeitsgruppen für die Abteilungen Archiv, Bibliothek und amtliche Publikationen. Das Amt verfügte über Millionenbeträge, »nicht zuletzt zur Beeinflussung genehmer Presseorgane, zu denen bis 1954 auch die rechtsradikale >Deutsche Soldaten-Zeitung` gehörte $\ll^{24}$.

Es verwundert daher nicht, daß die politischen Magazinsendungen im Fernsehen immer wieder ins Kreuzfeuer amtlicher Kritik gerieten, was aber kaum als alleiniges Privileg der Adenauer-Ära gelten kann. In einem 1966 publizierten Aufsatz mit dem Titel "Der Kritiker lebt gefährlich. Aber: Mut ist kein Berufsrisiko mehr « schrieb Joachim Fest, zu dieser Zeit Chefredakteur des Fernsehpolitmagazins »Panorama«:

Zu sprechen ist aber auch von einer anderen Schwierigkeit des Sprechers im Fernsehen, die sich anzeigt in den Protesten und Interventionen von außen, denen er sich unablässig ausgesetzt sieht. Die Industrie und die Gewerkschaften, die Kirchen, die Vertriebenen, die Parteien und großen Verbände verfolgen das Programm mit eigens angesetzten Beobachtern, geben teilweise eigene Korrespondenzen heraus und scheuen gelegentlich auch vor nachdrücklichen Interventionen nicht zurück ${ }^{25}$.

Überraschender als diese Verteidigungsrhetorik für die Pressefreiheit ist Fests anschließende Bemerkung, die auf die "hierzulande verbreitete Aversion gegen Kritik und Auffassungsgegensatz« anspielt:

Insgesamt sind es aber noch immer vielmehr moralische Gründe, die dazu führen, daB der Spielraum redaktioneller Freiheit bisweilen beengt scheint: das heißt, verantwortlich dafür sind weni-

${ }^{22}$ Kurt KoszyK, Presse und Pressekonzentration in den 50er Jahren, in: SCHILDT, Sywottek (Hg.), Modernisierung im Wiederaufbau, S. 449.

23 Walter Kordes, Hans Polmann, Das Presse- und Informationsamt der Bundesregierung, Düsseldorf ${ }^{9}$ 1985; Horst O. WALKer, Das Presse- und Informationsamt der Bundesregierung. Eine Untersuchung zu Fragen der Organisation, Koordination und Kontrolle der Presse- und Öffentlichkeitsarbeit der Bundesregierung, Frankfurt a. M. 1982.

24 Arnulf Baring, Am Anfang war Adenauer, München 1984, S. 84, hier zitiert nach KoszYK, Presse und Pressekonzentration in den 50er Jahren, S. 447.

25 Joachim FEST, Der Kritiker lebt gefährlich. Aber: Mut ist kein Berufsrisiko mehr, in: Arbeitgeber 1966, S. 664 f., hier zitiert nach KLEsSManN, Zwei Staaten, eine Nation, S. 519. 
ger die Interventionen von außen, sondern die eher freiwilligen Verzichthaltungen im Inneren, die dumpfe Nachgiebigkeit gegenüber dem allgemeinen Konformitätsdruck. Das ist, was man `Gefälligkeitsdemokratie von unten r nennen könnte. Sie vor allem verspieit, gedankenlos oder opportunistisch sich anpassend, die journalistische Bewegungsfreiheit ${ }^{26}$.

Damit sprach Fest das Phänomen der Selbstzensur an, das besonders im Bereich des Fernsehjournalismus zu Beginn des Fernsehens häufig zu beobachten war, sei es aus Gründen der satzungsmäßigen Programmleitlinien der „öffentlich-rechtlichen" Rundfunkanstalten, sei es - wie Fest betont - aus mangelnder Streitkultur ${ }^{27}$. Allerdings war dies kein genuin bundesdeutsches Phänomen, wie ein Zitat des bekannten französischen Fernsehjournalisten Léon Zitrone zeigt. Auf das Problem der staatlichen Zensur angesprochen, antwortete Zitrone: »Ich beherrsche vier Sprachen: Französisch, Englisch, Russisch und Gehorsamkeit ${ }^{28}{ }^{\text {! }}$

Die staatlich verordneten oder selbstauferlegten Formen der Zensur vermochten die Attraktivität des Mediums Fernsehens jedoch in keiner Weise zu schmälern. Die Fernsehteilnehmerzahlen in der Bundesrepublik stiegen in der zweiten Hälfte der fünfziger Jahre rapide an, von 1958 bis 1972 mit einer durchschnittlichen Zuwachsrate von ca. 1,3 Millionen pro Jahr. War die erste Phase der Fernsehwahrnehmung durch Gaststättenbesuche oder Schaufensteransichten geprägt, begann um 1958 der massive Einzug des Fernsehgeräts in die privaten Haushalte. Bedingung für diese Verschiebung war auch die Preispolitik der Rundfunkunternehmen. Diese hatten zunehmend mit der Konkurrenz des boomenden Versandhandels zu kämpfen, so daß 1956 bereits Empfangsgeräte unter 600 Mark zu haben waren ${ }^{29}$. Steigende Einkommen und gleichzeitig fallende Empfängerpreise führten dazu, daß 1960 bereits jeder vierte Haushalt der Bundesrepublik mit einem Fernsehempfänger ausgestattet war und das Fernsehen zur liebsten »Freizeitbeschäftigung « der Deutschen aufsteigen konnte.

Damit leitete der Fernsehrundfunk jene Epoche neuer Häuslichkeit ein, die der amerikanische Kulturwissenschaftler Raymond Williams treffend als

26 Ibid.

27 Zur Geschichte der politischen Fernsehmagazine und zum Stand des investigativen Fernsehjournalismus siehe Gerhard LAMPE, Panorama, Report und Monitor. Geschichte der politischen Fernsehmagazine 1957-1990, Konstanz 2000. Zur Rolle des Mediums Fernsehen im demokratischen Aufbau der Bundesrepublik siehe Nicolas PETHEs, "Don't talk back « oder Fernsehdemokratie? Die Selbstbeschreibung der Gesellschaft im Fernsehdiskurs der frühen Bundesrepublik, in: Schneider, Spangenberg (Hg.), Medienkultur der 50er Jahre, S. 213-226, sowie Fickers, Radio und Fernsehen als nationale Sozialisierungsinstanzen.

28 Jérôme Bourdon, Censorship and Television in France, in: Historical Journal of Film, Radio and Television 18 (1998) 2 S. 231-235, hier S. 232.

291954 lagen die Durchschnittspreise bei 1500 Mark für einen s/w-Empfänger mit einer Bildröhre von $36 \mathrm{~cm}$ Durchmesser. 
"mobile Privatisierung « beschrieben hat ${ }^{30}$. Wie Axel Schildt bemerkt, wurde diese Wandlung des Familienlebens zur »neuen Häuslichkeit« vor allem in der stärkeren Anwesenheit des Mannes im Heim sichtbar, was von der Mehrzahl der Fernsehzuschauer als »familienbindend « begrüßt wurde ${ }^{31}$. Die Folgen dieser Verschiebung abendlicher Vergnügungsaktivitäten von »außen« nach »innen « waren aber nicht nur familiärer oder sozialer Natur. Sie machten sich auch in Form massiver Finanzeinbußen in der Kino-, Kneipen- oder Tanzlokalbranche bemerkbar. Anfang der sechziger Jahre war das Fernsehen endgültig zum neuen massenmedialen Leitmedium aufgestiegen und damit nicht nur zum gesellschaftlichen Faktor ersten Ranges, sondern auch zum Objekt der politischen Willensbildung aufgestiegen ${ }^{32}$. Wie sah im Vergleich zur Bundesrepublik die Implementierung des Fernsehrundfunks in Frankreich aus?

\subsubsection{Fernsehen in Frankreich 1945-1969: "Télécratie» statt Mediendemokratie}

Anders als in Deutschland, wo die alliierten Besatzungsmächte die Organisation des Rundfunks im Wiederaufbau übernahmen, mußten die Franzosen nach der Libération selbst über die Zukunft des Rundfunks bestimmen. Auch wenn die französischen Fernsehtechniker, wie im ersten Kapitel beschrieben, auf die technischen Anlagen des »Fernsehsenders Paris« zurückgreifen und so bereits 1945 wieder mit Fernsehsendungen beginnen konnten, wurde der Fernsehrundfunk von den politisch Verantwortlichen dieser schwierigen Zeit vollkommen ignoriert. »A la Libération «, so Jérôme Bourdon, »les gouvernants ont d'autres soucis que la télévision ${ }^{33}$. Dafür war der Hörfunk um so tiefer in die politischen Wirren der Nachkriegszeit eingebunden. Wie der Rundfunkjournalist Jean Quéval 1946 bemerkte, habe es den Anschein, daß der Direktor des französischen Rundfunks Ministerrang habe: "La France change-t-elle de gouvernement, aussitôt la radio doit changer de directeur « ${ }^{34}$ ! Dies hatte mit dem unklaren Statut der "Radiodiffusion Française (RDF) zu tun, das lediglich durch zwei Regierungserlasse vom 9. August 1944 und 23.

\footnotetext{
30 Raymond Williams, Television. Technology and Cultural Form, London 1975. Zum Thema "private mobilization « und »domestication« siehe besonders SPIGEL, Make Room For TV.

31 SchILDT, Der Beginn des Fernsehzeitalters, in: DERS., SrwotTEK (Hg.), Modernisienung im Wiederaufbau, S. 477-492; Christina BarTz, Die Masse allein zu Hause. Alte Funktionen und neue Medien, in: Schneider, Spangenberg (Hg.), Medienkultur der 50er Jahre, S. 109-122.

32 Konrad Dussel, Vom Radio- zum Fernsehzeitalter. Mediumumbrüche in sozialgeschichtlicher Perspektive, in: Axel SchiLdt, Detlef Siggfried, Karl Christian Lammers (Hg.), Dynamische Zeiten. Die 60er Jahre in den beiden deutschen Gesellschaften, Hamburg 2000, S. 673-694.

33 Bourdon, Haute Fidélité, S. 29.

34 Jean Quéval, zitiert nach Bourdon, Haute Fidélité, S. 29.
} 
März 1945 definiert war und dessen Aufgabe sich in der Funktion eines offiziellen Sprachrohrs der Regierung erschöpfte. Erst am 4. Februar 1949 wurde die RDF per Regierungsdekret zur "Radiodiffusion Télévision française « (RTF), die jedoch immer noch nicht über ein exakt definiertes juristisches Statut verfuigte, auch wenn sie ein eigenes Budget erhielt. De facto und de jure blieb die RTF der finanziellen und politischen Kontrolle des Staates untergeordnet.

Es dauerte bis zum Jahre 1953, bis das Fernsehen die ernste Aufmerksamkeit einiger politisch Verantwortlicher fand und das französische Parlament am 31. Dezember 1953 schließlich einen Fünfjahresplan zur Entwicklung des Fernsehens beschloB. Auch in Frankreich war die Live-Übertragung der Krönungsfeierlichkeiten der englischen Königin Elisabeth II (Juni 1952) der Durchbruch in der öffentlichen Wahrnehmung der Möglichkeiten des Fernsehens. Dennoch hatte die enge Verbindung des Fernsehens mit den Regierungsinteressen in der politisch labilen Vierten Republik dazu geführt, daß die Fernsehentwicklung in Frankreich im Vergleich zu anderen Nationen stark gebremst worden war:

Quant aux responsables de politiques de la IV République, s'ils n'ignorent pas l'existence de la télévision et son irréversible développement - alors même que la France en ce domaine se caractérise par un retard non négligeable au regard de la situation anglaise -, ils débattent, âprement partagés, sur le statut juridique et économique dont il conviendrait de doter l'instance ayant en charge l'organisation, la production et la réalisation d'émissions ${ }^{35}$.

Der von Marie-Françoise Lévy angesprochene Rückstand der französischen Fernsehentwicklung zeigt sich auch, wenn man die Verbreitungsgeschwindigkeit der Fernsehempfänger, das heißt deren Einzug in die privaten Haushalte betrachtet. Pierre Albert weist darauf hin, daß das Erreichen der 1-Million-Empfängergrenze in Frankreich doppelt so lange gedauert hat wie in England oder Deutschland. In Großbritannien war diese Zahl fünf Jahre nach Wiederaufnahme des regelmäBigen Programmbetriebes erreicht (1951). Die 10-Millionen-Grenze wurde 1960 erreicht. In der BRD, wo der Programmbetrieb erst 1952 startete, war die 1-Millionen-Grenze 1957, die 10-Millionen-Grenze 1964 erreicht. Setzt man den regelmäßigen Programmbetrieb in Frankreich mit Beginn der 819-Zeilennorm im Jahre 1949 an, dauerte es bis zur ersten Million zehn Jahre, bis zum Erreichen der 10-Millionen-Grenze 20 Jahre $^{36}$.

Auch in Frankreich war die erste Phase der Verbreitung des Fernsehens nicht jene des privaten Fernsehkonsums, sondern die des Gemeinschaftsempfangs in Cafés oder »Télé-Clubs«, die das Fernsehen besonders im ländlichen

35 Marie-Françoise LÉvy, Introduction, in: DIEs. (Hg.), La Télévision dans la République. Les années 50, Paris 1999, S. $11 \mathrm{f}$.

36 Albert, Remarques sur la lenteur du développement de la télévision en France. 
Raum zu einer Art privaten Kinoveranstaltung machten ${ }^{37}$. Die beiden Fernsehjournalisten Jean Quéval und Jean Thévenot faßten 1957 die Ursachen und Gründe zusammen, die ihrer Meinung nach für den Rückstand der französischen Entwicklung verantwortlich waren:

La TV, pour eux [die französische Regierung, A.d.V.], ce n'était d'abord qu'une curiosité scientifique [...], puis une sorte de Guignol pour grandes personnes un peu demeurées. Mais, quand ils eurent pris connaissance de sa puissance et de son efficacité possibles et même déjà vérifiées, ils entendirent en faire leur jouet et faire de ceux qui assument les charges grandes ou petites de l'exploitation leurs marionettes ${ }^{38}$.

Auch wenn die Programmverantwortlichen der RTF, allen voran Programmdirektor Jean d'Arcy, nicht müde wurden, die kulturpolitische Bedeutung des neuen Mediums zu propagieren ${ }^{39}$, fristete das Fernsehen in Frankreich während der IV. Republik ein eher klägliches Dasein. Das absolute Monopol des Staates im Bereich des Fernsehrundfunks wurde zu keinem Zeitpunkt von einer der vierzehn Regierungen in Frage gestellt: "La tutelle de l'État sur l'information audiovisuelle«, so Jérôme Bourdon, »a vraiment valeur de dogme intangible ${ }^{40}$. Erst mit dem Fernsehstatut vom 4. Februar 1959, das die RTF in eine öffentliche Anstalt mit industriellem und wirtschaftlichen Charakter verwandelte, konnte sich das Fernsehen aus dem "cadre structurant" des Vorläufers Radio lösen und eine eigene Identität als neues Leitmedium entwickeln ${ }^{41}$.

Zwar änderte sich an der staatlichen Bevormundung des Fernsehens auch mit dem Beginn der IV. Republik nichts, dennoch markierte der Beginn der Präsidentschaft Charles de Gaulles einen fundamentalen Wandel der Stellung des Fernsehens in der politischen Öffentlichkeit Frankreichs. Dieser Wandel manifestierte sich zum einen durch die juristischen und institutionellen Veränderungen, deren Eckdaten die schon erwähnte Umwandlung der RTF in eine öffentlich-rechtliche Anstalt 1959 und die erneute Umwandlung zur

37 Zu den Télé-Clubs siehe LÉvy, La création des télé-clubs, in: Dies. (Hg.), La télévision dans la République, S. 107-132. Zur Rezeptionsgeschichte des Fernsehens siehe Anne-Marie SoHN, Pour une histoire de la société au regard des médias, S. 287-306.

38 Jean QuÉval, Jean ThÉvenot, TV, Paris 1957, S. 178, hier zitiert nach Bourdon, Haute Fidélité, S. 38.

39 Auf einer UNO-Konferenz im März 1955 sprach Jean d'Arcy davon, daß das Fernsehen mehr sei als die bloße Übertragung eines Spektakels ins Heim. Vielmehr eröffnete es die einmalige Möglichkeit, »de vaincre le temps et la distance par l'image«. Die Fernsehkamera, so d'Arcy, sei vielmehr ein sinstrument de vérité et d'authenticité extraordinaire«. Zitiert nach BouRDoN, Haute Fidélité, S. 31.

40 Ibid. S. 39. Eine vergleichende Übersicht zum Stand der historischen Forschung im Bereich der Fernsehnachrichtensendungen findet sich bei Andreas FicKers, Bernadette KESTER, Veel nieuws - weinig geschiedenis. Een historisch-historiografisch essay over internationaal televisienieuws, in: Tijdschrift voor Mediageschiedenis 8 (2005) 2 S. 111-142.

41 Stéphane OlivesI, Histoire politique de la télévision, Paris 1998, S. $114 \mathrm{f}$. 
ORTF (Office de radiodiffusion télévision française) im Jahre 1964 sind $^{42}$. Zum anderen sorgte der Ausbau der Sendezeit (2 451 Stunden im Jahr 1958; 5232 Stunden im Jahr 1968) und der Senderreichweiten bzw. der Empfangsdichte (1958 erfaßte der Sender Paris nur 30\% der Bevölkerung; 1969 deckte das erste Programm 95\%, das zweite Programm 82\% der Bevölkerung ab) in den 1960er Jahren für eine flächendeckende Versorgung der Franzosen mit den staatlichen Fernsehprogrammen. Die schleichende Entwicklung des Fernsehens während der IV. Republik vor Augen, mag diese »décollage de la télévision « in den sechziger Jahren erstaunen.

Tatsächlich ist dieser Wandel ohne eine Analyse der Rolle, welche die Person von Charles de Gaulle in diesem Prozeß eingenommen hat, nicht verständlich. Die Bedeutung, die der französische Präsident dem Medium Fernsehen von Beginn seiner Amtszeit im Elysée-Palast zugemessen hat, ist im europäischen Vergleich beispiellos. Jacques Manier, der viele Fernsehauftritte de Gaulles geplant und organisiert hat, brachte die Bedeutung de Gaulles für die Entwicklung des französischen Fernsehens auf den Punkt: »Il a fallu $>$ l'incident de Gaulle` pour que l'image retienne à nouveau toute l'attention politique ${ }^{43}$. »Le premier téléspectateur de la France«, wie de Gaulle von "Le Monde« Journalist Romain Gary genannt wurde, war sich der Bedeutung des Fernsehens im öffentlichen und damit politischen Leben Frankreichs von Anfang an bewußt. Wie erklärt sich dieses Bewußtsein de Gaulles angesichts der eher zögerlichen bis feindlichen Reaktionen, die andere Staatsmänner dem Medium Fernsehen Ende der fünfziger Jahre entgegenbrachten ${ }^{44}$ ?

Jérôme Bourdon, unbezweifelt der beste Kenner der Fernsehgeschichte der de Gaulle-Ära, weist zurecht auf die Vertrautheit des Generals mit dem Medium Rundfunk hin. De Gaulles Rundfunkansprachen aus London an das französische Volk während des Zweiten Weltkrieges hatten legendären Charakter und brachten de Gaulle den Spitznamen »Général Micro« ein ${ }^{45}$. Die Stimme des »Freien Frankreichs«, die während des Krieges täglich von 20.25 bis $20.30 \mathrm{Uhr}$ von der BBC über den Äther gesendet wurde, begründete de Gaulles Ruf als meisterhaften Rhetoriker, und die zahlreichen Dankesbriefe, die dem Sender aus dem Heimatland zugingen, stärkten de Gaulles Selbstvertrauen als oberster Widerstandskämpfer der Franzosen. Im ersten Band seiner "Mémoires de guerre« schreibt er: "Tous les huit jours environ, je parlais

42 Die langwierigen politischen und personellen Auseinandersetzungen, die mit der Diskussion um das Statut der RTF bzw. ORTF verbunden waren, werden im Detail in der Arbeit von Jérôme Bourdon »Histoire de la télévision sous de Gaulle« rekonstruiert.

43 Jacques MANIER, "La meilleure image du monde...«, in: Bulletin du Comité d'histoire de la télévision 24 (juin 1992) S. 26.

$44 \mathrm{Zu}$ den Reaktionen der britischen, kanadischen und australischen Ministerpräsidenten auf das Fernsehen nach 1945 siehe Colin, Seymour-Ure, Prime Ministers Reactions to Television, in: Media, Culture \& Society (1989) S. 309 f.

45 Siehe Bourdon, Haute Fidélité, S. 53. 


\section{à travers le monde. à travers}

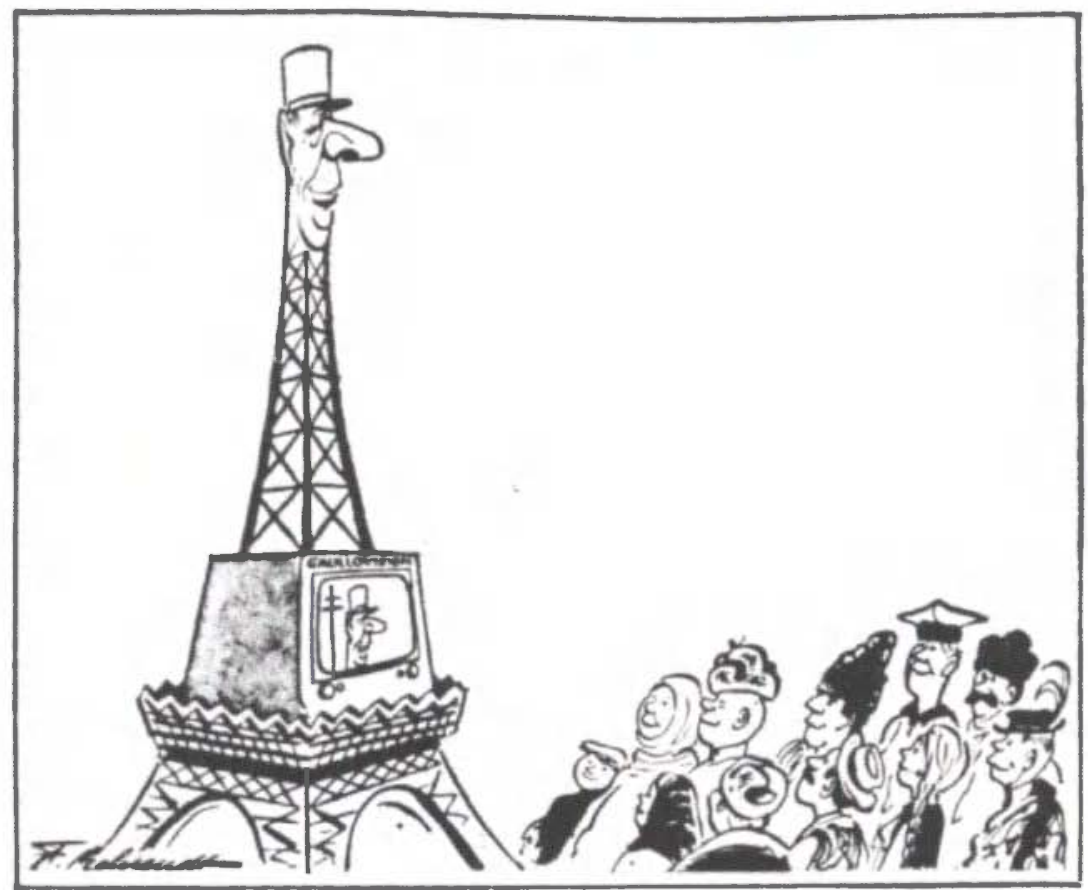

Television on couleur jusquid I Oural... (. Die Welwoche s).

Abb. 16: „La Gaullovision" oder: „Television en couleur jusqu'à l'Oural", aus: Archiv des Deutschen Museums München, Nachlaß Walter Bruch, Signatur NL 101, Nr. 123.

moi-mème, avec l'emouvante impression d'accomplir, pour des millions d'auditeurs qui m'ècoutaient dans l'angoisse à travers d'affreux brouillages, une espèce de sacerdoce " ${ }^{46}$. Man ist geneigt, de Gaulles Selbstverständnis als »Rundfunkprediger« nahtlos auf dessen Fernsehauftritte zu übertragen, die ihn gewissermaßen zum »Fernsehpriester « machten. In seinen »Memoiren der Hoffnung « bringt de Gaulle sein Verhältnis zum Fernsehen auf den Punkt:

Mais c'est au peuple lui-meme, et non seulement à ses cadres, que je veux ètre lié par les yeux et les oreilles. Il faut que les Français me voient et m'entendent, que je les entende et les voie. La telévision et les voyages publics m'en donnent la possibilité. Or, voìci que la combinaison du micro et de l'écran s'offre à moi au moment meme où l'innovation commence son foudroyant développement. Pour etre présent partout, c'est là soudain un moyen sans égal [...] Par le son et par l'image, je suis proche de la nation ${ }^{4}$.

46 Charles de Gaulle, Mémoires de guerre. Bd. 1, L'appel (1940-1942), Paris 1954, S. 132.

47 Charles DE Gaulle, Mémoires d'espoir, Bd. 1, Le renouveau, Paris 1970, S. 301. 
$\mathrm{Daß}$ de Gaulle die mediale Nähe zum Volk auch praktizierte, beweisen alleine die 32 Fernsehansprachen, die der Staatspräsident in den ersten zwei Jahren seiner Amtszeit inszenierte. Bei aller Liebe zum Volk ging es de Gaulle aber vor allem darum, das Fernsehen als Mittel der politischen Machtausübung einzusetzen. Dies um so mehr, als er die Bedeutung der anderen Massenmedien als Instrumente der politischen Meinungsbildung im Vergleich zum Fernsehen deutlich abstufte. Seinem Informationsminister Alain Peyrefitte gestand de Gaulle im März 1964:

La télévision prend une place de plus en plus grande dans la vie d'aujourd'hui. Elle grignote sans cesse le cinéma, la radio, les journaux. Elle finira par les réléguer dans un coin, quand elle sera passée à la couleur. C'est le grand moyen de communication de demain, avec les individus comme avec les masses: pour l'information, pour la culture, pour l'enseignement, pour la formation professionelle, pour les loisirs, elle va se substituer à tous les moyens traditionnels. Ce sera l'instrument qui forgera l'esprit public. [...] Qui tient la télévision tient un pays ${ }^{48}$.

Die Abbildungen machen deutlich, daß de Gaulles Fernsehauftritte das Resultat einer genauen Vorbereitung waren, in der Rhetorik und Gestik exakt aufeinander abgestimmt waren. Hatte sich de Gaulle durch die zahlreichen Rundfunkansprachen jene meisterhafte Wortwahl und Betonung zu eigen gemacht, die seinen Ruf als politischen Redner begründeten, muBte er den Auftritt vor der Fernsehkamera erst noch lernen.

Wie Jérôme Bourdon berichtet, war es der Pionier der französischen Werbewirtschaft, Marcel Bleustein-Blanchet, der sich gegenüber Vertrauten des Präsidenten entsetzt über die erste Fernsehansprache de Gaulles am 13. Juni 1958 äußerte. De Gaulle müsse den Blick in die Kamera richten und mehr Körpersprache einsetzen, so Bleustein-Blanchet: »Quand on est le Général de Gaulle, on n'entre pas comme ça chez les gens « ${ }^{49}$. Ähnliche Kritik äußerten auch Philippe Ragueneau und Pierre Sabbagh, enger Vertrauter des Generals der eine, Fernsehregisseur der andere. »Enfin«, so Bourdon, »une anecdote, jamais confirmée [jamais démentie non plus, so Bourdon in der Fußnote,

48 Peyrefirte, C'était de Gaulle, S. $525 \mathrm{f}$. Ein ähnliches Zitat de Gaulles wird in einem Schreiben des WDR-Intendanten Klaus von Bismarck wiedergegeben. Dort heißt es: „General de Gaulle glaubt anscheinend, daß man die Einflüsse der durchweg kritischen Presse durch den Gebrauch des Fernsehens für die Zwecke der Regierung ausgleichen müsse (in Paris kursiert eine Äußerung über den Informationsminister [sic!] >Mon cher Peyrefitte, la télévision, c'est l'État‘». Siehe «Vertrauliche Information über die RTF (Radiodiffusion Télévision Française), Köln, 23.04. 1963, in: Bundesarchiv Koblenz, Signatur B 145/4514, Deutsch-französische Zusammenarbeit auf dem Gebiet des Rundfunks und Fernsehens, Bd. 1, Nr. 954.

49 Marcel Bleustein-Blanchet, La rage de convaincre, zitiert nach Jean-Pierre Guichard, De Gaulle et les mass media. L'image du Général, Paris 1985, S. 130. 

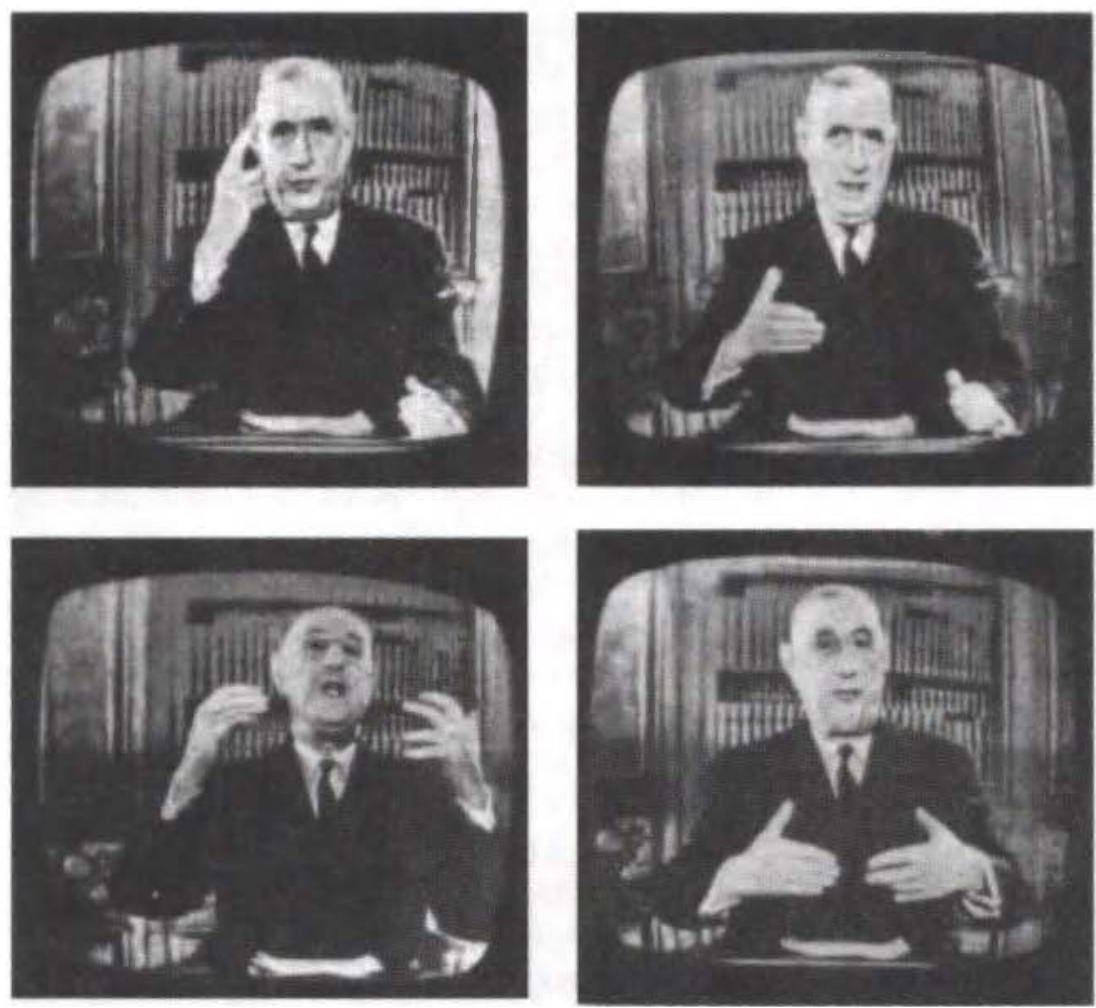

Abb. 17: De Gaulle als „Fernsehpriester«. Bildserie aus: Der Spiegel, Nr. 24 (1965) S. 58.

A.d.V.], veut qu'un sociétaire de la Comedie Française se soit rendu à l'Ėlysée donner des leçons de diction $\aleph^{50}$.

Fest steht, daß de Gaulle seine Fernsehauftritte sehr rasch so perfekt inszenierte, daß sie die Fernsehzuschauer in ihren Bann zogen. Jean-Pierre Guichard, der die mediale Wirkung de Gaulles bis ins kleinste Detail mittels semiotischer, psycholgischer und mediensoziologischer Theorien studiert hat, kommt zu dem überzeugenden Urteil, daß die Erscheinung de Gaulles auf dem Fernsehbildschirm die Zuschauer nur selten unberührt gelassen habe, sie statt dessen fast immer zu einer Stellungnahme, zu einer mehr oder weniger bewußten Interpretation des Gesehenen aufgefordert habe. Indem de Gaulle die direkte Ansprache (»Françaises, Français«), das bewußte Miteinbeziehen der Zuschauer (»C'est pourquoi je me tourne vers vous...«) oder gar die direkte Aufforderung zur Reaktion (»Aidez-moi!«) gezielt in seine Fernseh-

50 Bourdon, Haute Fidélité, S. 55. Siehe auch die Zeitzeugenaussagen von Philippe Ragueneau, Alexandre Tarta, Jacques Manier und Jean-Louis Guillaud, die ihre Erinnerungèn an die Fernsehauftritte de Gaulles vor und hinter der Kameerra wiedergèbèn in: „De Gaullè, homme de télévision«, in: Bulletin du Comité d'histoire de la télévision 24 (1992) S. 3-26. 
rhetorik eingebaut habe, sei es ihm gelungen, eine persönliche, privilegierte Kommunikationssituation mit jedem einzelnen der Millionen von Fernsehzuschauern aufzubauen. "Finalement«, so Guichard, "la télévision, par l'image et par le son, s'avère un excellent vecteur et même un vecteur essentiel sous la $\mathrm{V}^{\mathrm{e}}$ République du message gaullien, qui vient la pluspart du temps sous forme d'un appel, solliciter chaque citoyen dans l'intimité de son être, c'est-à-dire dans sa conscience et dans son âme «" ${ }^{51}$.

Es $m u B$ an dieser Stelle darauf verzichtet werden, weiter auf die interessante Frage der Beziehung von medialer Kompetenz und politischer Wirkmächtigkeit einzugehen ${ }^{52}$. Es steht außer Zweifel, daß die Bedeutung der medialen Wirkung der Persönlichkeit de Gaulles in der Einschätzung seiner politischen Rolle nicht unterschätzt werden darf. Bisherige Darstellungen de Gaullescher Politik lassen audiovisuelles Quellenmaterial bei ihren Analysen jedoch vollkommen unbeachtet ${ }^{53}$.

Zusammenfassend kann man sagen, daß de Gaulle die »épreuve cathodique ${ }^{54}$ des beginnenden Fernsehzeitalters wie wohl kaum ein anderer europäischer Staatsmann in den sechziger Jahren gemeistert hat. An de Gaulle manifestiert sich in Europa damit erstmals das in den USA schon seit den frühen fünfziger Jahren feststellbare Phänomen der »Personifizierung « der politischen Macht, der Substitution des politischen Programms zugunsten des einzelnen politischen Akteurs: »La promotion, par la télévision, de l'imagerie, du spectaculaire et de la personnalisation en politique, a pour corollaire un certain recul des idéologies et une déprogrammation. [...] A la télévision, la prestation de sl'acteur< politique a, autant, sinon plus, d'importance que la teneur idéologique de ses déclarations verbales ${ }^{55}$. Die Inszenierung der Person de Gaulles, des »Generals«, zum zentralen Akteur französischer Politik folgte dem Ziel, über die Darstellung der Einzigartigkeit der Symbolfigur de Gaulle die Einigkeit ganz Frankreichs zum Ausdruck zu bringen. De Gaulle war Frankreich und Frankreich de Gaulle - »das Vaterbild kommt frei Haus ${ }^{56}$ !

51 Guichard, De Gaulle et les mass media, S. 139.

52 Eine kompakte und gut strukturierte Analyse des Verhältnisses de Gaulle/Massenmedien auf deutsch liefert Daniela HoYer, Charles de Gaulle und die Massenmedien. Wie ein Politiker Presse und Rundfunk instrumentalisierte, Mainz 1998.

53 Siehe beispielsweise die Studien von Serge Berstein, Histoire du Gaullisme, Paris 2001 und Maurice VAïssE, La grandeur: Politique étrangère du général de Gaulle 1958-1969, Paris 1998.

54 "L'épreuve cathodique«, so Stéphane Olivesi, „devient une condition première d'existence sur la - les - scène(s) politique(s). « OLIVEsI, Histoire politique de la télévision, S. 141.

55 Guichard, De Gaulle et les mass media, S. 114.

56 In einem ausführlichen De Gaulle-Porträt wies Spiegel-Chefredakteur Rudolf Augstein 1965 auf die zentrale Bedeutung des Fernsehens als Medium der politischen Selbstdarstellung de Gaulles hin. Augstein ging sogar so weit, de Gaulle in einer Reihe mit Mussolini, Hitler und Castro zu nennen: "Wahr ist, daB Napoleon WI. nicht das Fernsehen hatte. Hitler und Mussolini hat- 
Die institutionelle und personalpolitische Organisation des Rundfunks in Frankreich machte dieses Medium zum vollwertigen Instrument de Gaullescher Politik. Zum »Handlanger« der Umsetzung der politischen Vorgaben de Gaulles im Rundfunkbereich wurde "sein« Informationsminister Alain Peyrefitte $^{57}$. In den vier Jahren (April 1962 bis Januar 1966), in denen Peyrefitte die Position des Informationsministers innehatte - übrigens eine ungewöhnlich lange Zeit für diesen als »Schleudersitz « bekannten Posten -, verstand er es auf gekonnte Weise, sowohl die eigenen als auch die Interessen de Gaulles in äuBerst effektiver Art und Weise zu vertreten. Sich selbst als »liberalen Gaullist « verkaufend, entwickelte sich Peyrefitte hinter den verschlossenen Türen der ORTF zum obersten Zensor des französischen Fernsehens, »contrôlant personnellement les moindres rouages de la RTF ${ }^{58}$.

Zwar rühmt sich Peyrefitte in seinem Werk »Le mal Français« dafür, die Klingelknöpfe am Schreibtisch seines Vorgängers abgeschafft zu haben, die es erlaubten, die verantwortlichen Direktoren der RTF jederzeit zum Rapport beim Minister erscheinen zu lassen ${ }^{59}$. Als $»$ Kompensation « dafür baute er jedoch den »Service des liaison interministérielles pour l'information« (SLII) auf, der Schritt für Schritt zur zentralen informationspolitischen Kontrollagentur der Regierung ausgebaut wurde ${ }^{60}$. Durch diese Behörde wurde Alain

ten noch nicht das Fernsehen. Castro hat (und nutzt) das Fernsehen. Aber schon zu Hitlers und Mussolinis Zeiten galt, daß ein >Mann der Vorsehung sicht von innen gestürzt werden kann, wenn er das Radio und die Presse beherrscht. Heute genügt vielleicht schon das Fernsehen. Das >Vaterbild، kommt frei Haus.« Rudolf Augstein, Die Ziege des Herrn Seguin. Charles de Gaulle und sein Gaullismus, in: Der Spiegel 24 (1965) S. 40-63, hier S. 60.

57 Die Institution des Informationsministeriums geht auf ein Dekret des französischen Präsidenten Paul Reynaud vom 1. April 1940 zurück, wurde aber schon im Juni von der Vichy-Regierung abgeschafft und durch das »Hochkommissariat für Propaganda« ersetzt. Unter der Leitung de Gaulles wurde nach der Libération durch zwei Ordonnanzen vom 23. Oktober 1944 und 19. Oktober 1945 emeut ein Informationsministerium geschaffen, das gewissermaßen die Fortsetzung des »Commissariat à l'information« antrat, welches in Algier unter der Exilregierung de Gaulles existiert hatte. Während der IV. und V. Republik wechselten sich die Bezeichnungen »Ministre de l'information« oder »Secrétaire d'État de l'information« mehrfach ab, ohne daß sich damit an der Kompetenz des jeweiligen Amtsinhabers etwas geändert hätte. Siehe Emil HuGHEs, Le ministère de l'information en France, in: Revue politique des idées et des institutions 17 (1955) S. 513-520. Zur Person Alain Peyrefittes siehe den leicht hagiographisch angehauchten Artikel von Pierre De Borsdefrre, Alain Peyrefitte, le Tocqueville du XX $\mathrm{XX}^{\mathrm{e}}$ siècle, in: Revue des deux mondes 10 (1999) S. 128-137.

58 Bourdon, Histoire de la télévision sous de Gaulle, S. 96.

59 Alain Peyrefitte, Le Mal Français, Paris 1976, S. 69.

${ }^{60}$ Nach Zustimmung des Ministerrats wurde der SLII am 31. Juli 1963 im Rahmen eines Finanzgesetzes gegründet und dem Informationsminister unterstellt. Dem SLII wurde eine dreifache »Mission« zugewiesen: 1) eine organische Verbindung zwischen den verschiedenen Ministerien herzustellen, um die offizielle Informationspolitik der Regierung zu koordinieren; 2) für eine engere Kooperation mit den staatlichen Medienanstalten (Presse, Hörfunk, Fernsehen) zu sorgen; 3) die Öffentlichkeitsarbeit der Regierung durch eigene Publikationen zu begleiten. Die täglichen (!) Konferenzen des SLII - Peyrefitte selber nahm einmal wöchentlich an einer Sitzung 
Peyrefitte zum »bestinformierten Regierungsmitglied«, was nicht unbedingt zur Popularität des Informationsministers bei seinen Kollegen sowie jenen Vertretern des Hör- und Fernsehfunks beitrug, die an den täglichen Sitzungen des SLII teilnehmen mußten.

Ohne weiter auf die Funktionsdetails des SLII eingehen zu wollen, hatte Peyrefitte bzw. die französische Regierung mit dieser interministeriellen Behörde einen effektiven Apparat zur Kontrolle der staatlichen Informationspolitik geschaffen, dessen Kompetenzen weit über jene des bundesdeutschen Presse- und Informationsamtes hinaus gingen. Diese direkte politische Kontrolle des französischen Rundfunks schlug sich nicht zuletzt in der Personalpolitik der RTF nieder. So gelang es Peyrefitte, die Behörde Schritt für Schritt mit gaullistischen Gefolgsmännern zu besetzen, die eine »Intervention von oben « durch vorauseilenden Gehorsam überflüssig machten ${ }^{61}$. Das von Fest für die Bundesrepublik beschriebene Phänomen der Selbstzensur kann demnach durchaus auf die französischen Verhältnisse übertragen werden.

Wie tief die enge Verzahnung regierungspolitischer Interessen mit der Struktur des Rundfunks im Bewußtsein der politisch Verantwortlichen auch nach de Gaulles Abtritt im Jahre 1969 noch war, zeigt ein Zitat seines Amtsnachfolgers Georges Pompidou, der auf einer Pressekonferenz am 21. September 1973 erklärte: "Qu'on le veuille ou non - et je sais qu'il y en a qui ne me croient pas - le journaliste de télévision n'est pas un journaliste comme les autres. Il a des responsabilités supplémentaires. Qu'on le veuille ou non, la télévision est considérée comme la Voix de la France, et par les Français et par l'étranger « ${ }^{62}$.

Nicht alle Franzosen teilten diese Auffassung. Der Journalist Claude Durieux nahm 1976 in seinem aufsehenerregenden Buch »La Télécratie « kein Blatt vor den Mund. »La bande à Peyrefitte«, so Durieux, habe die ORTF während zehn Jahren mit einer Politik eingeschleuster Mittelsmänner be-

teil, dienten als "Lagebesprechung, in denen jeder Teilnehmer erfuhr, was bei seinen Kollegen [aus den anderen Ministerien, A.d.V.] geschah «. Siehe HOYER, Charles de Gaulle und die Massenmedien, S. 91-102.

61 In einem Schreiben des WDR-Intendanten Klaus von Bismarck vom 23.04.1963 heißt es diesbezüglich: »Besonders die Arbeit der Abteilung Information für Radio und Fernsehen der RTF (Journal Parlé, Journal Télévisé) unter M. Gérard wird in der französischen Öffentlichkeit allgemein als die eines Regierungsbulletins bezeichnet. M. Gérard verfügt über direkte persönliche Verbindungen zum Élysée (M. Chameau, M. Lefranc). Er ist wahrscheinlich ein besonders markantes, aber keineswegs das einzige Beispiel dafür, wie die RTF durch Selbstkontrolle und Selbstzensur eine Kontrolle von außen ergänzt und z. T. ersetzt: Die Gaullisten aller Schattierungen in der Direktion der RTF versuchen, Interventionen >von oben« überflüssig zu machen. « Siehe «Vertrauliche Information über die RTF (Radiodiffusion Télévision Française), Köln, 23.04.1963, in: Bundesarchiv Koblenz, Signatur B 145/4514, Deutsch-französische Zusammenarbeit auf dem Gebiet des Rundfunks und Fernsehens, Bd. 1, Nr. 954.

62 Bourdon, Histoire de la télévision sous de Gaulle, S. 17. Zur Rolle Pompidous in der PALSECAM-Affaire siehe FickERS, »Pourquoi ne feraient-ils pas un procès à Telefunken?«. 
herrscht - von Meinungsfreiheit keine Spur ${ }^{63}$. Diese regierungspolitische Instrumentalisierung des Fernsehens in Frankreich wirkte sich natürlich auch auf die Erwartungshaltungen der Zuschauer aus. Das Fernsehen wurde von kritischen Intellektuellen immer wieder als totalitäres Machtinstrument beschimpft. Das zentrale Medium politischer Auseinandersetzung blieb in Frankreich daher die Presse ${ }^{64}$.

Vergleicht man die Situation des Rundfunks in Frankreich und Deutschland in den fünfziger und sechziger Jahren miteinander, so wird deutlich, daß die Bemühungen darum, das neue Leitmedium Fernsehen politisch zu instrumentalisieren, sowohl in der Adenauer-Republik als auch in der IV. Republik und der Amtszeit de Gaulles zentrales Merkmal des informationspolitischen Selbstverständnisses der beiden Regierungen war $^{65}$. In der Bundesrepublik verhinderte die föderale Rundfunkorganisation letztlich den Aufbau eines "Staatsfernsehens«, während der direkte politische Zugriff auf den Rundfunk in Frankreich aufgrund des fehlenden juristischen Statuts der RTF bzw. ORTF nie in Frage gestellt wurde. Trotz des Interesses, das Bundeskanzler Adenauer dem Fernsehen entgegen brachte, wurde die Bedeutung des Fernsehens für die politische Öffentlichkeitsarbeit von den meisten bundesrepublikanischen Politikern verkannt. Der damalige "deutsche Informationsminister « und spätere Intendant des ZDF, Karl Günther von Hase, merkte im Interview an, daß das Fernsehen im Bewußtsein der deutschen Politiker nicht annähernd die Bedeutung gehabt habe wie bei den französischen Kollegen. Eindeutiges Indiz hierfür sei auch, da $B$ das Farbfernsehen nie Thema einer Kabinettssitzung in Bonn gewesen se $^{66}$. Selbst wenn dieses BewuBtsein vorhanden gewesen wäre, zeigt das Beispiel der »Deutschland-Fernsehen GmbH « deutlich, daß die Landesrundfunkanstalten die Versuche einer bundespolitischen Einflußnahme erfolgreich abwehrten.

In Frankreich dagegen war das Fernsehen bis Mitte der siebziger Jahre Medium der regierungspolitischen Interessen, die staatliche Rundfunkorganisation wurde zum Sprachrohr gaullistischer Botschaften und stand unter direkter Kontrolle des französischen Informationsministeriums. Wie der Intendant des WDR, Klaus von Bismarck, in einer »vertraulichen Information über die RTF« im April 1963 mitteilte, dürfe die Bezeichnung der RTF als

63 Claude Durieux, La Télécratie, Paris 1976.

64 Zum Beziehungsgeflecht von Politik und Medien in Frankreich siehe die Überblicksdarstellungen von Fabrice D'Alemeida, Christian Delporte, Histoire des médias en France de la Grande Guerte à nos jours, Paris 2003; Jean-Noël JEAnNeney, Une histoire des médias des origines à nos jours, Paris 2001; Bernard LAMIZET, Histoire des médias audiovisuels, Lonrai 1999. 65 Johannes Georg Müller, Staats- und ParteieneinfluB auf die Rundfunkanstalten in Frankreich und Deutschland - Eine vergleichende Analyse, Frankfurt a. M. u.a. 1987.

66 So die Aussage von Karl-Günther von Hase im Interview mit dem Autor, Bonn, 14.06. 2000. 
»établissement publique« nicht zu der Annahme verleiten, daß man es mit einer selbständigen Anstalt zu tun habe:

Während das Regierungspersonal seit 1958 nur in Nuancen gewechselt hat, sind die oberen Ränge der RTF häufig ausgewechselt worden. In der IV. Republik wechselten die Regierungen, aber das leitende Personal der RTF blieb. [...] Die gegenwärtige Organsiation der RTF kennzeichnet demnach ein hierarchisch-bürokratischer Aufbau mit strenger Unterordnung der RTF unter das Informationsministerium, die Regierung und den Élysée-Palast, aus deren Mitte dauernd das Recht der direkten Intervention beansprucht wird ${ }^{67}$.

Trotz dieser strukturellen Differenzen im Bereich der institutionellen Ausprägung und politischen Einbettung des Rundfunks in beiden Ländern läßt sich aber eine funktionelle Gemeinsamkeit des Fernsehens nicht abstreiten. In beiden Ländern nahm das Fernsehen eine wichtige Stellung in der medialen Konstruktion eines nationalen Erfahrungsraumes ein. Als "nationale Sozialisierungsinstanz ${ }^{68}$ übte das neue Leitmedium diesseits wie jenseits des Rheins die Funktion eines identitätsstiftenden Kommunikationsraumes aus, der bloße Akt des Fernsehens wurde zur symbolischen Teilnahme an einer Fernsehwirklichkeit, die - als Resultat des technopolitischen Nationalismus im Bereich der Fernsehnormen - fast ausschließlich eine rein nationale Erfahrungsgemeinschaft war. "La télévision«, so Évelyne Cohen, »donne à voir aux Français le spectacle du contact entre le peuple et le chef de l'État, elle crée entre les Français un véritable langage national, devient un véhicule privilégié du sentiment national et de la communauté nationale ${ }^{69}$. Es ist wohl diese im Begriff der »Fernsehnation« zum Ausdruck kommende privilegierte Beziehung zwischen Fernsehen und Gesellschaft, welche den Wunsch staatlicher bzw. regierungspolitischer Einflußnahme auf dieses Medium verständlich macht.

Auch wenn sich Alain Peyrefitte der strukturellen Differenzen zwischen seinem Amt und dem seines bundesdeutschen Kollegen Karl-Günther von Hase bewußt war ${ }^{70}$, begannen bereits Ende des Jahres 1963 Gespräche zwischen diesen beiden Akteuren zum Thema Farbfernsehen im Rahmen der regelmäßigen deutsch-französischen Konsultationen, wie sie im »Freundschaftsvertrag« vereinbart worden waren. Diese Gespräche, die das Thema

67 Siehe »Vertrauliche Information über die RTF (Radiodiffusion Télévision Française), Köln, 23.04. 1963, in: Bundesarchiv Koblenz, Signatur B 145/4514, Deutsch-französische Zusammenarbeit auf dem Gebiet des Rundfunks und Fernsehens, Bd. 1, Nr. 954.

68 FICKERs, Radio und Fernsehen als nationale Sozialisierungsinstanzen?

${ }^{69}$ Évelyne CoHEN, Télévision, pouvoir et citoyenneté, in: LÉvy (Hg.), La télévision dans la République, S. 23-42, hier S. 32 .

70 In einem Brief von Alain Peyrefitte an Georges Pompidou vom 27. Januar 1964 heiBt es: »J'ai déjà eu l'occasion de m'en entretenir avec le Secrétaire d'État à l'Information allemand, M. Von Hase, mais sa position dans le gouvernement allemand et l'organisation particulière de la télévision en Allemagne limitent ses possibilités d'intervention dans ce domaine." In: Archives nationales, Signatur F-41/2310. 
Farbfernsehen auf die oberste politische Ebene der deutsch-französischen Beziehungen hoben, werden im folgenden detailliert nachgezeichnet, da sie den Schlüssel zum Verständnis der Politisierung der PAL-SECAM-Kontroverse bilden. 


\subsection{Das Farbfernsehen im Zeichen der deutsch-französischen Freundschaft}

Über die Entstehungsgeschichte, Bedeutung und Wirkung des deutsch-französischen "Freundschaftsvertrages « ist so viel publiziert worden, daß an dieser Stelle auf eine Würdigung dieser Annäherung verzichtet werden kann ${ }^{71}$. Unter Punkt II. A 2 des Vertrages wird aufgeführt: »Die auf dem Gebiet des Informationswesens bereits bestehende Zusammenarbeit wird zwischen den beteiligten Dienststellen in Bonn und Paris und zwischen den Vertretungen in Drittstaaten fortgeführt und ausgebaut«. Der Vertrag sah vor, daB regelmäßige Konsultationen (alle drei Monate) stattfinden sollten, abwechselnd auf deutschem und französischem Boden. Bereits im Mai 1963 fand daraufhin ein erstes Treffen zwischen den Verantwortlichen der französischen (RTF) und bundesdeutschen (ARD) Rundfunkanstalten statt. Auf der anschließenden Sitzung der Gremienvorsitzenden der ARD am 22. Mai bedankte sich der Leiter des Bundespresse- und Informationsamtes, Karl-Günther

71 Per Fischer, Der diplomatische ProzeB der Entstehung des deutsch-französischen Vertrages von 1963, in: Vierteljahreshefte für Zeitgeschichte 41 (1993) S. 101-116. Eine detaillierte Beschreibung des Zustandekommens des Élysée-Vertrages findet sich bei LAPPENKüPER, Die deutsch-französischen Beziehungen sowie bei BaumanN, Begegnung der Völker? und Corine Defrance, Ulrich Pfeil (Hg.), Der Élysée-Vertrag und die deutsch-französischen Beziehungen, 1945-1963-2003, München 2005. Knapper, prägnanter und in eine längerfristige Perspektive des deutsch-französischen Verhältnisses eingebettet ist die Darstellung von Gilbert ZiEBURA, Die deutsch-französischen Beziehungen seit 1945. Mythen und Realitäten, Stuttgart ${ }^{2} 1997$. Einen generellen Überblick liefert die Sondernummer der Zeitschrift Dokumente/Documents: Die deutsch-französischen Beziehungen: Chronologie und Dokumente 1948-1999, Bonn 1999. Aus deutscher Perspektive siehe Martin Koopmann, Das schwierige Bündnis. Die deutsch-französischen Beziehungen und die Außenpolitik der Bundesrepublik Deutschland, 1958-1965, BadenBaden 2000. Aus innenpolitischer Sicht siehe Reiner MARCowitz, Option für Paris? Unionsparteien, SPD und Charles de Gaulle 1958-1969, München 1996. Aus französischer Perspektive mit dem Schwerpunkt Sicherheitspolitik siehe Georges-Henri Soutou, L'Alliance incertaine: les rapports politico-stratégiques franco-allemands 1954-1996, Paris 1996 sowie Pierre GuILlEn, La question allemande - 1945 à nos jours, Paris 1996. Aus amerikanischer Perspektive siehe Eckart ConZe, Die gaullistische Herausforderung. Die deutsch-französischen Beziehungen in der amerikanischen Europapolitik 1958-63, München 1995. Einen längsschnittartigen Überblick über die deutsch-französischen Beziehungen liefert der Sammelband von Peter ScHöTtLER, Patrice VeIt, Michael Werner (Hg.), Plurales Deutschland - Allemagne Plurielle (Festschrift für Étienne François), Göttingen 1999. Zur Rolle der internationalen Beziehungen im deutsch-französischen Verhältnis siehe Klaus MülleR, Dieter BAECHLER (Hg.), Dritte in den deutsch-französischen Beziehungen, München 1996. Eine einführende Übersicht in das komplexe deutsch-französische Gefuige der sechziger Jahre vor dem Hintergrund europäischer Politik liefert der von Band von Wilfried LoTH, Robert Picht (Hg.), De Gaulle, Deutschland und Europa, Opladen 1991. Die Bedeutung der Pariser Verträge für die deutsch-französischen Beziehungen werden ausfuhrlich dargestellt in dem Sammelband von Helène Miard-Delacroix, Rainer HudemanN (Hg.), Wandel und Integration. Die Pariser Verträge von 1954 im ProzeB der deutsch-französischen Annäherung der Nachkriegszeit, München 2005. 
von Hase, für die gelungene Vorbereitung des Treffens seitens der ARD. Die Franzosen hätten den Verlauf und das Ergebnis der Tagung positiv aufgenommen. Auf dem Gebiet des Hörfunks und des Fernsehens könne nach Meinung der Bundesregierung eine vertrauensvolle Zusammenarbeit zustandekommen. Die Bundesregierung sehe bei diesen Gesprächen ihre Rolle darin, als »Beobachter und Vermittler « zu dienen ${ }^{72}$.

Vielleicht war von Hases Bedürfnis, als »Beobachter und Vermittler« tätig zu werden auch von dem Gefühl motiviert, daß einige der Intendanten der Landesrundfunkanstalten keine besonders hohe Meinung von ihren französischen Kollegen hatten. So war der WDR-Intendant und ARD-Vorsitzende, Klaus von Bismarck, im April 1963 zu seinen Kollegen der RTF nach Paris gereist und berichtete seinen Intendantenkollegen am 23. April 1963:

Herr Bordaz [Generaldirektor der R.T.F., A.d.V.] - am Tage meines Besuches in seiner Zeit-Disposition offenbar durch die Fernseh-Ansprache de Gaulles im besonderen zur Rolle eines eifrigen Befehls-Empfängers degradiert - macht einen schwachen Eindruck. Neu war mir, daB die Spitze der RTF von einem >Kabinett Bordaz ' gebildet wird, d.h. von drei politisch bestimmten engsten Mitarbeitern des General-Direktors, die dieser sich auswählt (die also auch mit ihm gehen würden!). Diese Spitze steht über den Direktoren. [...] Die Herren in der Spitze der RTF waren wenig oder gar nicht liber die Struktur des Rundfunks und Fernsehens in der Bundesrepublik orientiert ${ }^{73}$.

Karl-Günther von Hases Selbstverständnis als »Vermittler« war vielleicht auch aus diesem Grunde beim Thema Farbfernsehen notwendig. Bereits beim Treffen von Peyrefitte und von Hase am 22. November 1963 in Paris schlug Alain Peyrefitte seinem deutschen Gesprächspartner vor, die nationalen Rundfunkanstalten beider Länder zu einer Zusammenarbeit auf dem Gebiet des Farbfernsehens zu bewegen. Beweisen zahlreiche spätere Dokumente, $\mathrm{da} B$ von Hase von diesem Zeitpunkt an tatsächlich an einer deutsch-französischen Gemeinschaftsaktion im Geiste des "Freundschaftsvertrages" gelegen war, war die Initiative Peyrefittes von vornherein Teil einer politischen Strategie: »M. von Hase«, so Informationsminister Peyrefitte in einem Brief an den Außenminister Couve de Murville vom 24. Dezember 1963, "a manifesté le désir que les responsables allemands des services de télévision aient des consultations sur ce sujet avec leurs collègues français. J'ai prié le Directeur Général de la RTF d'envoyer une mission de spécialistes en Allemagne pour tenter de convaincre les Allemands de la supériorité du procédé français et les amener à porter leur choix sur celui-ci ${ }^{74}$.

72 Siehe Niederschrift der Sitzung der Gremienvorsitzenden vom 22.5.1963 in Baden-Baden, in: Historisches Archiv des WDR, Signatur: WDR/II ARD/5. Tag (Prot.), 1963-1969; Gremiensitzung.

73 Schreiben Klaus von Bismarcks an die Intendanten der Landesrundfunkanstalten (persönlichvertraulich), Hamburg, 23.04. 1963, in: Bundesarchiv Koblenz, Signatur B 145/4514, Deutschfranzösische Zusammenarbeit auf dem Gebiet des Rundfunks und Fernsehens, Bd. 1, Nr. 954.

74 Brief von Peyrefitte an Couve de Murville, 24. Dezember 1963, in: Archives nationales, Signatur F-41/2310. 
Sah Peyrefitte die Aufgabe der Experten der RTF also darin, die deutschen Kollegen der ARD von der Überlegenheit des SECAM-Systems zu überzeugen, versicherten sich von Hase und von Bismarck in gegenseitigem Einvernehmen, daß »bei der Erarbeitung und Einführung einer europäischen Norm keine einseitigen nationalen Interessen ausschlaggebend sein dürfen $\aleph^{75}$. Dieses Bekenntnis zur unpolitischen, rein auf technischen Kriterien basierenden Urteilsbildung in der Farbfernsehsystemfrage war bis zur Wiener CCIR-Konferenz im April 1965 das handlungspolitische Credo sämtlicher bundesdeutscher Behörden, die an der Normdiskussion beteiligt waren. Sowohl die Landesrundfunkanstalten als auch die zuständigen Ministerien (Post- und Fernmeldewesen, Wirtschaftsministerium und Bundespresse- und Informationsamt) waren sich darin einig, daß »die Frage des Farbfernsehens in der BRD nicht nach politischen, sondern ausschließlich nach fachlichen und technischen Gesichtspunkten « beurteilt werden durfte ${ }^{76}$.

Nicht selten waren diese Bekenntnisse zur unpolitischen und rein technisch-wissenschaftlich motivierten Handlungsweise aber mit Bemerkungen versehen, die von einer unterschwelligen Aversion gegen die französischen Bemühungen zur politischen "propagation « des SECAM-Systems zeugen. Besonders beliebt war dabei der Verweis auf die frühere "Fehlentscheidung" der Franzosen, als diese das 819-Zeilensystem in »anti-europäischer« Gesinnung eingeführt hätten ${ }^{77}$. Sogar der Papst, so Dr. Hans Stercken, Leiter des Frankreichreferats im Bundespresse- und Informationsamt, zeige sich besorgt über die mögliche Spaltung der europäischen Fernsehlandschaft ${ }^{78}$ !

75 Brief von Klaus von Bismarck an Karl-Günther von Hase, Köln, 24. Dezember 1963, und Antwortschreiben von Hase an Bismarck, 7. Januar 1964, in: Bundeszwischenarchiv Bonn, Signatur B 145/1356.

76 Siehe beispielhaft das Schreiben des Bundespostministers Stücklen an Wirtschaftsminister Schmücker vom 4. Mai 1964, in dem Stücklen die Politisierung der Frage durch Herrn Peyrefitte kritisiert. In: Bundeszwischenarchiv Bonn, Signatur B 145/1356.

77 Siehe beispielhaft den Vermerk des Leiters des Fernsehreferats im Bundespresse- und Informationsamt, Dr. Matern, vom 26. Juni 1964 in Bonn: »Die Entscheidung über das beste Normverfahren kann nicht aus politischen Gründen erzwungen werden. Es hat schon einmal eine Fehlentscheidung gegeben, als Frankreich sich für das 819-Zeilen-System entschied«. In: Bundeszwischenarchiv Bonn, Signatur B 145/1356.

$78 »$ Er [Pietro Quaroni, ehemaliger italienischer Botschafter in Bonn und 1964 Vorsitzender des Verwaltungsrates der RAI, A.d.V.] wies darauf hin, da $B$ er bei einem Besuch des Papstes auch mit diesem über die Gefahren bereits gesprochen habe, die sich bei der Anwendung unterschiedlicher Systeme in Europa ergeben könnten. Der Papst habe sich hier sehr sorgenvoll gezeigt, insbesondere wohl wegen der Konsequenz, daß das österreichische und das deutsche Fernsehen in Ungarn, der Tschechoslowakei sowie in der SBZ nicht mehr empfangen werden könnten«. Vermerk von Dr. Hans Stercken, Bonn, 9. November 1964, in: Bundeszwischenarchiv Bonn, Signatur B 145/1356. Abgesehen davon, daB die obigen Behauptungen aus technischer Sicht falsch sind, rührte die Sensibilität des Heiligen Vaters für Fragen der Standardisierung in der Fernsehtechnik vielleicht daher, daß der Vatikan 1950 das französische 819-Zeilensystem eingeführt hatte, das ihm von Frankreich "geschenkt« worden war! Stercken selbst korrespondierte Ende 1964 
Bemühte man sich auf bundesdeutscher Seite demnach darum, die Diskussion um die zukünftige europäische Farbfernsehnorm auf der Ebene wissenschaftlich-technischer Argumente zu halten, wurde das Thema Farbfernsehen in Frankreich zusehends auf die Ebene außen- und wirtschaftspolitischer Interessen gehoben. Bereits im Januar 1964 wandte sich Informationsminister Alain Peyrefitte in einem ausführlichen Schreiben an den Premierminister Georges Pompidou, um diesem seine Ansichten über die politische Dimension der Farbfernsehfrage darzulegen. Peyrefitte zeigte sich überzeugt davon, daß der Erfolg des SECAM-Systems im wesentlichen davon abhängig sei, ob es gelingen werde, die Deutschen auf die SECAM-Seite zu ziehen. Genau darauf habe er in den bisherigen Gesprächen mit Karl-Günther von Hase hingearbeitet, doch habe dieser keinen Einfluß auf den öffentlich-rechtlichen Rundfunk in der Bundesrepublik noch auf die deutsche Rundfunkindustrie. Aus diesem Grunde hielt Peyrefitte es für ratsam, die Sache entsprechend »höher« anzusiedeln, nämlich auf Ebene der Regierungschefs beider Länder:

C'est pourquoi je pense qu'il serait très souhaitable qu'une intervention du gouvernement français auprès du gouvernement allemand soit faite dans les prochains jours pour marquer, sur le plan général des rapports entre les deux pays, l'intérêt qui s'attacherait à voir un accord se réaliser entre les industriels et les techniciens français et allemands pour l'adoption du procédé SECAM. Si vous partagiez cette manière de voir, je souhaiterais très vivement qu'il vous soit possible d'intervenir, par lettre, auprès du Chancelier Erhard, afin de faire connaître notre position et lui demander si son Gouvernement pourrait faire sa part à l'industrie allemande de son vou de voir un accord se réaliser entre les techniciens et les industriels compétents en Allemagne et en France $^{79}$.

Zwar war es nach Meinung von Peyrefitte vor allem Sache der Industrie auf eine Einigung mit Telefunken hinzuwirken, doch könne eine gewisse politische Rückendeckung in dieser Angelegenheit durchaus förderlich sein. Eines war auch Peyrefitte von Anfang an klar: daß es im Bereich der Farbfernseh-

mit Pater Superior Schmitz vom Radio Vatican über die Farbfernsehfrage und bemühte sich, diesem Kontakt keine offiziellen politischen Weihen zu geben. Dennoch wies er auf die gemeinsamen Interessen der Bundesregierung und des Vatikans hin: »Das Unternehmen [der Kontakt des Bundespresse- und Informationsamtes mit dem Staatssekretariat des Vatikans, A.d.V.] war auch weniger als ein diplomatisches Manöver vorgesehen, sondern gründete sich vielmehr auf die Überzeugung, da $\beta$ die Kirche an den mit der Frage verbundenen seelsorgerischen Problemen Anteil nehme und gerade daher umso eher in der Lage gewesen wäre, als höhere moralische Autorität die politischen und technischen Auseinandersetzungen zu beseitigen. Nur diese Intervention der Kirche, sozusagen also in eigener Sache, interessiert uns, weil wir glauben, daß dieses Anliegen mit dem unsrigen übereinstimmt. Ich brauche nicht darauf zu verweisen, daß die augenblicklichen Spannungen zwischen Paris und Bonn nur noch verkompliziert werden könnten, wenn die Franzosen den Eindruck gewinnen würden, daß wir die Autorität des Staatssekretariats mißbrauchen, um eine im Endergebnis für sie vielleicht ungünstige Regelung herbeizuführen«. Brief von Dr. Hans Stercken an Pater Superior Schmitz, Bonn, 19. Dezember 1964, in: Bundeszwischenarchiv Bonn, Signatur B 145/1356.

79 Brief von Alain Peyrefitte an Georges Pompidou, Paris, 27. Januar 1964, in: Archives nationales, Signatur F-41/2310. 
technologie - im Gegensatz zur früheren s/w-Entwicklung - keinem Land möglich sein werde, einen nationalen Alleingang zu riskieren:

Il est presque certain, étant donné l'énormité des moyens industriels à mettre en jeu et l'avènement de l'Eurovision et de la Mondovision, qu'aucune nation europsenne ne pourra s'aventurier sans risque à faire cavalier seul et à adopter un procédé qui ne serait pas celui retenu par les autres nations. [...] L'exemple de la France, qui joue en Europe le rôle de franc-tireur, avec son 819-lignes, définition qu'elle a dâ abandonner pour la deuxième chaîne, est révélateur en la matière $^{80}$.

Wenige Wochen später war das Farbfernsehen erstmals Thema einer Ministerratssitzung, über die Peyrefitte in seiner de Gaulle-Biographie ausführlich berichtet. De Gaulle bekräftigte Peyrefitte in seinen Bemühungen, dem SECAM-System international Geltung zu verschaffen. "Cette affaire de la télévision en couleurs est importante. Elle va être symbolique. L'Europe serat-elle capable, oui ou non, de relever le défi«, so de Gaulle zu Peyrefitte ${ }^{81}$. Für de Gaulle genoß die Farbfernsehfrage seit diesem Zeitpunkt oberste politische Priorität. Es ist gerade jene enge Verzahnung der Farbfernsehfrage mit den politischen Visionen des französischen Staatspräsidenten, welche die PAL-SECAM-Kontroverse zum Spiegel seines außenpolitischen Kurswechsels machte, der unter dem Schlagwort »Europa vom Atlantik bis zum Ural« oder »détente-entente-coopération« bekannt wurde.

Die außenpolitischen Intentionen, die de Gaulle mit dem SECAM-System verband, blieben auch dem wichtigsten europäischen »Gegenspieler« Frankreichs nicht verborgen - den Briten. Auch wenn die folgende Quelle aus der Zeit der Wiener Konferenz im März 1965 stammt und daher der Entwicklung zeitlich vorgreift, wird sie im folgenden ausführlich zitiert, da sie die britische Einschätzung der de Gaulleschen SECAM-Politik auf den Punkt bringt:

He [de Gaulle, A.d.V.] recently informed the Directeur Economique at the Quai d'Orsay that the adoption of SECAM was at present at greater importance to him than the French campaign to avoid the formation of a MLF [multi lateral force, A.d.V.]. [...] While at first sight it may appear strange that despite his other preoccupations General de Gaulle should be paying such attention to this matter, there is no reason to doubt the explanation the French themselves are giving us, namely that the General sees in the Russion adoption of SECAM the first concrete stop towards the rapprochement [Unterstreichung im Original] with Russia which is now a the centre of his policy. In short SECAM has now become for the French the symbol of Franco-Russian collaboration, much as the Concorde is for Anglo-French collaboration ${ }^{82}$.

Wie erklärt sich der außenpolitische Kurswechsel de Gaulles, dessen oberste außenpolitische Maxime vor kurzem noch die deutsch-französische Aussöh-

80 Siehe die sechsseitige NNote concernant la télévision en couleur«, die dem Brief von Peyrefitte an Pompidou vom 27. Januar 1964 beigefügt ist. In: Archives nationales, Signatur F-41/2310.

81 Peyrefitte, C'était de Gaulle, Bd. 2, S. 525.

82 Telegramm vom britischen Botschafter Sir P. Reilly in Paris an das Foreign Office in London, Paris, 30. März 1965, in: PRO, Signatur INFU/848. 
nung und ein europapolitisches Zusammengehen beider Staaten gewesen war? Zahlreiche Faktoren hatten das kurz aufgeblühte deutsch-französische Verhältnis bereits kurz nach der feierlichen Unterzeichnung des deutsch-französischen Freundschaftsvertrages in den Augen de Gaulles wieder welken lassen: $\mathrm{Zu}$ den wichtigsten zählten mit Sicherheit die dem Vertrag vor der Ratifizierung vom deutschen Bundestag vorangestellte »Präambel« sowie der Kanzlerwechsel vom »Gaullisten« Adenauer zum »Atlantiker« Erhard. Bereits vor dem vereinbarten Rücktritt Adenauers im Oktober 1963 rechnete man im Élysée-Palast damit, daß sich die deutsch-französischen Beziehungen nach dem Amtsantritt Erhards abkühlen würden.

Als im Juni 1963 der amerikanische Präsident zu Besuch in der Bundesrepublik war, berichtete der französische Botschafter in Bonn, Roland de Margerie, über Kennedys Rede in der Paulskirche zu Frankfurt am Main: »Mais il est clair qu'il [Kennedy, A.d.V.] ne peut manquer d'exercer au moins pour un temps, une action profonde sur la plupart des ministres du cabinet fédéral, et sur M. Erhard en particulier, dont la télévision laissait voir les applaudissements enthousiasmés. Seul M. Adenauer reste irréductiblement à l'abri de ces séductions et de ces blandices « ${ }^{83}$.

De Gaulle machte aus seiner Enttäuschung über die in seinen Augen gescheiterte deutsch-französische Annäherung keinen Hehl und verglich den Élysée-Vertrag bereits während der Ratifizierungsdebatte im französischen Parlament mit Rosen und jungen Mädchen, die beide nur kurze Zeit blüh$\operatorname{ten}^{84}$. Auf einer Pressekonferenz vom 23. Juli 1964 wurde de Gaulle noch deutlicher und beklagte, daß der Vertrag zwar zu regelmäßigen und durchaus angenehmen Kontakten zwischen den Regierungen und Verwaltungen beider Länder geführt habe, „daß aber der französisch-deutsche Vertrag bis zur Stunde nicht $\mathrm{zu}$ einer gemeinsamen Haltung geführt hat ${ }^{85}$. Der britische Botschafter in Berlin, General Peel Yates, kommentierte die unterschiedlichen Positionen Erhards und de Gaulles im Juni 1965 sehr treffend, als er schrieb: "De Gaulle was very much disappointed with the way the FrancoGerman Treaty was working. He complained that the French and Germans were not on the same wavelength: the French had regarded the Treaty as a political matter, the Germans had made it a sentimental one ${ }^{86}$.

\footnotetext{
83 Bericht von Roland de Margerie an das Quai d'Orsay, in: Archives du MAE, Signatur: Europe 1961-70, sous-série R.F.A., Nr. 1600.

84 „Verträge sind wie Rosen und junge Mädchen - sie haben ihre Zeit«, zitiert nach: „Deutschland - Frankreich. Ein neues Kapitel ihrer Geschichte (1948-1988). Chronologie«, hg. von der Zeitschrift Dokumente und dem Deutsch-Französischen Institut Ludwigsburg, Bonn 1988, S. 37.

85 Ibid. S. 39.

86 Telegramm von General Peel Yates, britische Botschaft in Berlin, an das Foreign Office in London, Berlin, 11. Juni 1965, in: PRO, Signatur PREM 13/899.
} 
Deutlichstes Zeichen für den außenpolitischen Kurswechsel de Gaulles ${ }^{87}$ war der Rückzug der französischen Atlantik- und Ärmelkanalflotte aus den Verbänden der NATO im Juni 1963, die offizielle Aufnahme diplomatischer Beziehungen mit der kommunistischen Republik China im Januar 1964 sowie die »Politik des leeren Stuhls« in Brüssel (1. Juli 1965 bis 31. Dezember 1965), da die französischen Forderungen im Bereich der Agrarpolitik auf Widerstand der EWG-Partner stießen ${ }^{88}$. Genau in diese Phase außenpoliti-

87 Es scheint ratsam, vom außenpolitischen Kurswechsel de Gaulles und nicht der französischen Regierung zu sprechen, da das französische Außenministerium durchaus divergierende Interessen vertrat. Außenminister Couve de Murville tat sich vor allem mit de Gaulles Annäherung an die Sowjetunion schwer, wofür er von de Gaulle scharf kritisiert wurde. Von de Gaulle über die Stimmung im Quai d'Orsay unterrichtet, die eindeutig in Richtung eines Arrangements mit der Bundesrepublik in Fragen des Farbfernsehens wies, erwiderte de Gaulle: »Bon sang, mais qu'estce qu'on leur a fait à ces gens du Quai d'Orsay? Ils ne peuvent pas admettre que la France gagne! [...] Vous avez des types qui n'ont qu'une idée en tête, c'est qu'il faut s'arranger avec les Allemands. Ils ont tout fait pour ça. Alors que le procédé allemand n'existe que si nous voulons bien qu'il existe! [De Gaulle spielt hier auf die angebliche Patentabhängigkeit des PAL-Systems von SECAM an, A.d.V.] C'est une manie de ce sacre Quai d'Orsay. Pourquoi? La négociation qui réussit, à leurs yeux, c'est une négociation dans laquelle la France disparaît. C'est une tare qu'ils ont dans le sang «. Zitiert nach Peyrefitte, C'était de Gaulle, Bd. 2, S. $537 \mathrm{f}$.

88 Während sich unter dem amerikanischen Präsidenten Kennedy und dem russischen Präsidenten Chruschtschow Anzeichen einer "Entspannung des weltpolitischen Klimas abzeichneten, war es de Gaulles Europapolitik, die innerhalb Europas und auch weltweit immer wieder für Irritationen sorgte. Die amerikanische Politik des »grand design«, innerhalb derer Europa eine »atlantic partnership « im Sinne einer »Allianz für den Fortschritt « angeboten wurde, widersprach de Gaulles Europapolitik, in der Frankreich als "grande nation au premier rang« eine führende Rolle spielen sollte. Frankreichs Ablehnung des englischen Beitrittsgesuchs zur EWG am 14.1.1963 war ein deutliches Zeichen in diese Richtung. Das >Außen-Vorlassen sollte eine Amerikanisierung Europas verhindern, die sich aus der Sicht de Gaulles durch die englisch-amerikanische »special relationship« ergeben müßte. Frankreichs Bemühungen konzentrierten sich in der Folge auf ein Werben um Deutschland als Partner für ein meuropäisches Europa« und später auf eine stärkere Einbeziehung der Sowjetunion als politischen und wirtschaftlichen Verbündeten Frankreichs. Mit dem Amtsantritt Erhards als Bundeskanzler und unter dem Einfluß des Außenministers Gerhard Schröder wechselte die politische Spitze der Bundesrepublik jedoch vom Lager der »Gaullisten« in das Lager der »Atlantiker«. Hatte der Élysée-Vertrag unter dem "Gaullisten « Adenauer noch auf den Vorrang der deutsch-französischen Beziehungen verwiesen, so sah sich Erhard durch die wachsenden französisch-amerikanischen Spannungen gezwungen, die deutsche Politik auf Kosten dieses Vertrags neu zu definieren. Es waren vor allem verteidigungspolitische Interessen und die damit verbundene "deutsche Frage«, die den Handlungsspielraum der bundesdeutschen Außenpolitik einengten. Zusammenfassend kann man sagen, daß die französische Diplomatie Mitte der sechziger Jahre darauf abzielte, durch die Lockerungen der Bindungen Frankreichs an die europäische und atlantische Gemeinschaft und die Annäherung an die Sowjetunion mehr Bewegungsfreiheit zu gewinnen, um so eine Sonderstellung der "grande nation « in Europa zu erhalten. Solange Deutschland geteilt blieb und sich die hegemonialen Bestrebungen der Sowjetunion auf Mitteleuropa richteten, sah die Bundesrepublik aber in den USA den eigentlichen Garanten ihrer Sicherheit und - neben der Sowjetunion - den wichtigsten Faktor, den es bei der Wiedervereinigungspolitik zu berücksichtigen galt. 
scher Neuorientierung fiel auch die verschärfte Politisierung der Farbfernsehfrage in Frankreich.

Nachdem auf der CCIR-Tagung in London im April 1964 erstmals auch Vertreter der OIRT an der Diskussion um die europäische Farbfernsehnorm teilgenommen hatten, war man sich auf französischer Seite sicher, daß die Sowjetunion eine Schlüsselrolle bei der definitiven Systemwahl einnehmen würde. In einem Brief berichtete der Generaldirektor der CFT, Henri Peyroles, seinem indirekten Vorgesetzten Maurice Ponte von der Londoner Tagung. »Il est possible«, so Peyroles Überzeugung, »de gagner définitivement cette affaire dans les prochains mois. Tout le monde le souhaite - soit par conviction ou intérêt, soit par lassitude ${ }^{89}$. Um die sowjetischen Fernsehtechniker von den Vorteilen des SECAM-Systems zu überzeugen, reiste sowohl CSF-Chef Maurice Ponte als auch ORTF-Generaldirektor Robert Bordaz im Juni 1964 nach Moskau. Wie der Sonderbeauftragte der französischen Regierung in Moskau, François de Laboulaye, in mehreren Schreiben an Außenminister Couve de Murville berichtete, waren die Russen sehr am französischen System interessiert, doch schreckte sie der im Vergleich zum NTSCSystem höhere Empfängerpreis ein wenig $a b^{90}$.

Die französischen Aktivitäten in Moskau blieben auch den bundesdeutschen Stellen nicht verborgen. So informierte Walter Bruch seinen Vorgesetzten Werner Nestel über "Gerüchte«, daß die französische Regierung mit SECAM ein »Kompensationsgeschäft« mit den Russen plane: »Es hat meines Erachtens nichts mit dem technischen Interesse der Russen zu tun «, so Bruch. »Es scheinen reine politische Abkommen. Daher müßte unser Besuch in Moskau oder ein Besuch der Russen bei uns in Hannover durch Einladung der Bundesregierung erfolgen ${ }^{91}$. Während die offizielle Einschaltung der Bundesregierung in die Farbfernsehfrage zugunsten von PAL ein frommer Wunsch von Walter Bruch bleiben sollte, brachte in Frankreich der Präsident persönlich die SECAM-Sache ins Rollen. Als Peyrefitte ihm im Oktober 1964 berichtete, daß die französische elektrotechnische Industrie von vielen ausländischen Beobachtern nicht als wirklich konkurrenzfähig mit der bundesdeutschen angesehen werde, reagierte de Gaulle mit Entsetzen: »Pour

${ }^{89}$ Brief von Peyroles an Ponte, 24.04.1964, in: Archives du CHTV/NA, Nachlaß Michel Dubail.

90 In einem Brief von Cantacuzene (Attaché Scientifique à l'Ambassade français de Moscou) an Peyroles vom 25. Juni 1964 heiBt es: "Les Soviétiques reconnaissent que le système français est techniquement le meilleur, mais ils sont sensibles à la différence de prix impliquée par cette différence de qualité. « Cantacuzene glaubt aber nicht daran, daß der Preis die Sowjets letztlich von einem besseren System abschrecken werde. In: Archives du CHTV/INA, Nachlaß Michel Dubail.

91 Brief von Bruch an Nestel, Hannover, 10.06.1964, in: Archiv des Deutschen Museums München, NL 101, Nr. 202. 
les autos, ou les avions, ou les hélicoptères, les Allemands ne font pas mieux que nous, ou font moins bien! Et notre métro de Montréal? Et nos camions en Chine? Pourquoi ne ferions-nous pas de téléviseurs aussi bien qu'eux ${ }^{92}$ ?

De Gaulle empfiehl seinem Informationsminister daraufhin, den sowjetischen Botschafter in Paris, Winogradow, aufzusuchen, allerdings ohne das Quai d'Orsay von diesem Treffen zu informieren. Da Peyrefitte bereits mehrfach Einladungen zu Besuchen in die Sowjetunion bekommen hatte, schien ihm nun der richtige Zeitpunkt gekommen, einen Besuch in Moskau mit einer Werbeaktion für das SECAM-System zu verbinden. Anfang November wurden im Informationsministerium die entsprechenden Kontakte geknüpft, und Peyrefitte gestand seinem Kabinettschef Jean-Jacques de Bresson in einer persönlichen Note:

Je suis de plus en plus persuadé que nous ne pourrons l'emporter dans l'affaire de la télévision en couleurs que par l'intermédiaire des Russes. Or, je rappelle que nous devons avoir à cet égard un rôle de leader, dont $\mathrm{j}$ 'ai été chargé au Conseil des Ministres. [...] Vinogradov me relance sans cesse pour aller en Russie. Ne peut-on monter un voyage sérieux, qui pourrait emporter le morceau avant le congrès de Vienne, où la décision doit étre prise entre Européens? [...] Notre procédé l'emportera si les Russes et les démocraties orientales prennent position en sa faveur à Vienne ${ }^{93}$.

Mit dieser Meinung stand Peyrefitte nicht alleine da. Auch Maurice Ponte war der Überzeugung, daß ein stärkeres Engagement seitens der politischen Institutionen in Moskau eine entsprechende Wirkung haben werde. In den Gesprächen zwischen Peyrefitte und Ponte Ende November 1964 tauchte auch erstmals ein Faktor auf, der in der zukünftigen Strategie der Franzosen eine entscheidende Rolle spielen sollte: die $\mathrm{DDR}^{94}$. »Il [M. Ponte, A.d.V.]

92 PeyrefitTe, C'était de Gaulle, Bd. 2, S. 527.

93 Note d'Alain Peyrefitte à J. J. de Bresson, Paris, 6.11.1964, in: Archives du MAE, Affaires Économiques et Financières, Affaires Générales, Nr. 220a.

94 Obwohl eine entsprechende Quellenarbeit bereits verrichtet war, wurde eine eingehende Analyse der Rolle der DDR in der deutsch-französischen Auseinandersetzung um den Farbfernsehstandard in diese Arbeit nicht mit aufgenommen. Dies liegt darin begriundet, daß der Autor das von der DFG geförderte Forschungsprojekt am Lehrstuhl für Geschichte der Technik der RWTH Aachen nach einem Jahr verlieB um eine Stelle als Assistent am Lehrstuhl für Neueste Geschichte des Historischen Instituts der RWTH Aachen anzunehmen. Während die vorliegende Arbeit sich primär mit der deutsch-französischen Dimension der PAL-SECAM-Kontroverse beschäftigt, hat sich der Nachfolger des Autors im DFG-Projekt explizit auf der Rolle der DDR konzentriert. Siehe Gerald GlauBITz, Die PAL-SECAM-Kontroverse in der DDR. Die politisch-ideologische Instrumentalisierung der Farbfernsehfrage durch den ostdeutschen Staat zwischen 1965 und 1969, Berlin u. a. 2003. Zur Rolle der DDR siehe zudem die Arbeiten von Ulrich PrEIL, Die »anderen " deutsch-französischen Beziehungen. Die DDR und Frankreich 1949-1990, Köln 2004; Ders., Von der Politisierung eines technischen Wettstreits in den deutsch-französischen Beziehungen: Die PAL-SECAM-Kontroverse, in: Revue d'Allemagne et des pays de langue allemande 37 (2005) 1 S. 45-64. 
considère lui aussi«, so berichtete Peyrefitte seinem Kabinettschef de Bresson nach einem Gespräch mit Ponte am 13. November 1964, »que la meilleure manière de forcer la main des Allemands est d'entraîner les Russes; les pays de l'Est, y compris la DDR qui a une position clef ${ }^{95}$. Als de Gaulle Peyrefitte am 19. November schließlich empfahl, einen »Délégué interministériel« für die SECAM-Frage zu ernennen, wurde die Farbfernsehfrage ganz offiziell zu einer Angelegenheit mit oberster nationaler Priorität erklärt ${ }^{96}$. Am 27. Januar 1965 ernannte Alain Peyrefitte den bisher in Moskau als "Chargé d'Affaires de la France en URSS « aktiven François de Laboulaye zum »Ministre Plénipotentiaire« und zum Präsidenten der neu gegründeten Gesellschaft FRANTECO (Association pour la promotion et la diffusion du procédé français de télévision en couleur) ${ }^{97}$. Die FRANTECO hatte den Status einer $100 \%$ staatlichen Gesellschaft, deren Gründungsmitglieder der Informationsminister, der Generaldirektor der ORTF sowie der Präsident der Compagnie Française de Télévision (CFT) waren. Das Budget der FRANTECO stammte zu gleichen Teilen aus dem Informationsministerium und der ORTF und sollte von einem staatlichen Wirtschaftsprüfer, der auch für die ORTF zuständig war, kontrolliert werden ${ }^{98}$.

In einer Note vom 2. September 1965 faßte Philippe Olivier, Kabinettsmitglied von Alain Peyrefitte, die zentrale Motivation zusammen, welche die französische Politik dazu bewogen hat, sich der SECAM-Frage in dieser Weise anzunehmen:

95 Gesprächsnotiz von Peyrefitte über Gespräch mit Ponte bestimmt für de Bresson, Paris, 13.11. 1964, in: Archives du MAE, Affaires Economiques et Financières, Affaires Générales, Nr. 219 a.

\% »Si vous n'avez pas un délégué interministériel qui vous soit personellement rattaché, qui soit pleinement responsable sous votre autorité, qui ne fasse rien d'autre que de penser à ça toute la journée et de joindre tous les fils, ça ne marchera jamais.« De Gaulle, zitiert nach PEYrefrTte, C'était de Gaulle, Bd. 2, S. 529.

97 Siehe Brief von Alain Peyrefitte an François de Laboulaye, Ministre Plénipotentiaire, 27. Januar 1965: "J'ai l'honneur de vous faire savoir, qu'en accord avec le Ministre des Affaires Étrangères, le Ministre des Finances, le Ministre de l'Industrie et le Ministre des Postes et Télécommunications, j'ai décidé de vous charger sous mon autorité, de la mission de coordonner l'ensemble des actions menées par la France pour la diffusion du procédé français de télévision en couleurs. «, in: Archives nationales, Signatur F-41/2310.

98 In der Bekanntmachung der FRANTECO durch den Informationsminister Alain Peyrefitte am 21. Januar 1965 heiBt es: »J'ai l'honneur de vous faire connaitre qu'à l'issue des délibérations du Conseil des Ministres du mercredi, 13 janvier, une 'Association pour la promotion et la diffusion du procédé français de télévison en couleurı vient d'étre créé. Cette association comprend à titre de membres fondateurs: l'État français représenté par le Ministre de l'Information, l'Office de Radiodiffusion-Télévision Française représenté par son Directeur Général et la Compagnie Française de Télévision représentée par son Président Directeur Général. Je vous serais obligé de bien vouloir envisager de soumettre cette association dont le budget comporte une cotisation de l'État et une cotisation de l'ORTF au contrôle financier du contrôleur d'État de l'ORTF ${ }^{\prime}$, in: Archives nationales, Signatur F-41/2310. 
C'est au mois de décembre 1964 que le gouvernement français décide de faire de l'adoption du procédé SECAM par les pays européens, sans exclure bien entendu les autres, une affaire d'intérêt national. [...] Le SECAM est un procédé de haute qualité, il intéresse une industrie pilote de notre économie, son adoption par le continent européen tout entier constituerait un succès industriel et technique certes, mais essentiellement politique de première grandeur pour notre pays ${ }^{99}$.

Eindeutig wurde SECAM als Aushängeschild und Symbol französischer grandeur definiert und zum »champion national« stilisiert, was auf der internationalen Bühne deutlich demonstriert werden sollte. Doch die Zeit drängte. Die entscheidende CCIR-Konferenz in Wien fand bereits im April 1965 statt, so daß den Franzosen nicht mehr allzuviel Zeit blieb, wollten sie die Sowjetunion auf die Seite der SECAM-Anhänger ziehen. Denn auch in London oder Washington war man sich der Schlüsselfunktion der Sowjetunion im europäischen Entscheidungsprozeß bewußt und scheute weder Mühen noch Kosten, letztere von der Überlegenheit des NTSC-Systems zu überzeugen. Bereits im September 1964 berichtete CFT-Direktor André Danzin während eines Aufenthaltes in Moskau davon, daß die BBC vor Ort ständig daran arbeite, den sowjetischen Technikern die Schwachstellen des SECAM-Systems zu demonstrieren ${ }^{100}$. War der Besuch von Peyrefitte in Moskau ursprünglich bereits Ende Dezember 1964 geplant, wurde er kurzfristig auf Mitte Januar 1965 verschoben, da zu diesem Zeitpunkt sowohl Fachleute von der BBC und Ingenieure der RCA das NTSC-System in Moskau vorführten.

Die Sowjetunion war sich ihrer Rolle als entscheidender technopolitischer Akteur im europäischen Standardisierungsprozeß bewußt und spielte geschickt auf dem diplomatischen Klavier, um aus der Lage des »Umworbenen « in der Farbfernsehfrage optimales politisches und industrielles Kapital zu schlagen. Wie auch den Franzosen bald klar wurde, ging es der Sowjetunion weniger um die Frage der Adoption der technisch besten Systemalternative - insofern es sie überhaupt gab -, sondern um die Verknüpfung der Farbfernsehfrage mit dem AbschluB eines möglichst umfassenden technischwissenschaftlichen Kooperationsabkommens mit einem kapitalistischen Staat, um so in den Besitz wichtigen technischen oder industriellen Know-Hows zu gelangen.

99 Note von Phillip Olivier, confidentiel, Paris, 2.09.1965, 21 maschinengeschriebene Seiten, hier S. $1 \mathrm{f}$., in: Archives du MAE, Affaires Économiques et Financières, Affaires Générales, Nr. 220c. Bei dieser Note handelt es sich um ein Dokument, welches die politische Bedeutung des SECAM-Systems auf eindrucksvolle Weise belegt und die strategische Vorgehensweise der Regierung Schritt für Schritt aufführt und argumentativ begründet.

100 "D'après les renseignements que nous avons pu avoir, la foi des Russes dans le procédé SECAM est systématiquement combattue par la BBC qui exerce une action quasi permanente sur place et ne fait état que des infériorités du procédé sans jamais mettre en evidence ses supériorités«. Brief von Danzin an Peyroles, Moskau, 20.10.1964, in: Archives du CHTV/NA, Nachlaß Michel Dubail. 
So teilte der stellvertretende Vorsitzende des Komitees für Koordinierung der Wissenschaft und Technik in der Sowjetunion, Dïzermen M. Gwischiani, dem Generaldirektor der CFT, Henri Peyroles, bei dessen Moskau-Visite im November 1964 mit: „Cette affaire de télévision doit être l'occasion et le point de départ d'une collaboration plus large: à égalité technique c'est l'étendu du champ de collaboration, attaché à chaque système, qui décidera du choix ${ }^{101}$. Peyroles schluBfolgerte, daB man den Russen SECAM wohl nur dann »schmackhaft« machen könne, wenn es mit einem Paket anderer Zutaten versehen werde, zu denen er Meßgeräte, Verzögerungsleitungen, Farbröhren, Halbleiterbauelemente wie Transistoren und Dioden und sogar eine komplette Fabrik zur Halbleiterproduktion zählte.

Diese "Zutaten" waren nicht unproblematisch, da einige von ihnen auf der COCOM-Liste standen, so beispielsweise Geräte für die magnetische Aufzeichnung von Fernsehbildern oder Hochfrequenz-Meßgeräte ${ }^{102}$. Machte man sich im Informationsministerium ${ }^{103}$ und vor allem im Außenministerium $^{104}$ ernsthafte Gedanken über eine eventuelle Verletzung der COCOM-Bestimmungen im Falle eines breiter angelegten wissenschaftlich-technischen Abkommens mit der Sowjetunion, hatte General de Gaulle für diese Bedenken nur wenig Verständnis: »Eh bien, il n'y a qu'à violer le Cocom! Et puis

101 Reisebericht von Peyroles über seine Moskaureise vom 19.-26. November 1964, 5 maschinengeschriebene Seiten, Paris, 27. November 1964, in: Archives du CHTV/INA, NachlaB Michel Dubail.

102 Das COCOM (Coordinating Committee on East-West Trade Policy) war ein direktes Produkt des Kalten Krieges. Gegründet 1950 mit Sitz in Paris basierte es auf einer Art »gentlemen's agreement« ohne völkerrechtliche Grundlage. Die rechtliche Bindung existierte lediglich in Form bilateraler Verträge. 1994 wurde das COCOM offiziell aufgelöst. Zur Geschichte und wirtschaftspolitischen Bedeutung des COCOM siehe Gary K. BERTsCH (Hg.), Controlling East-West Trade and Technology Transfer. Power, Politics and Policies, Durham 1988.

103 So fand am 2. März 1965 unter der Leitung des Kabinettschefs von Peyrefitte, Jean-Jacques de Bresson, ein Treffen zwischen den Herren Brosse (Kabinettsmitglied des Premierministers), Laboulaye (als Président de l'Association pour la télévision en couleurs), Admiral Salmon und Fregattenkapitän Blanc (als Vertreter des Secrétaire Général de la Défense Nationale), Jordan (AuBenministerium), Richer (Beigeordneter von Laboulaye) und Thibau (Conseiller technique im Kabinett von Peyrefitte) statt, bei dem es hauptsächlich um die Frage ging, wie man - im Falle eines generelleren Kooperationsabkommens zwischen sowjetischen Stellen und der CSF/CFT - die Bestimmungen des COCOM umgehen konnte. Die von Maurice Ponte erstellte Liste mit den entsprechenden Materialien wurde aber von allen Beteiligten als mehr oder minder unproblematisch angesehen. Siehe Note sur la Télévision en couleurs, réunion chez de Bresson, 2.3.1965, in: Archives du MAE, Affaires Économiques et Financières, Affaires Générales, Nr. 219a.

104 So wies M. Jordan vom MAE in einem Telegramm an die französische Botschaft in Moskau darauf hin, daß das Gerät für die magnetische Bildaufzeichnung, das für die Farbfernsehvorführungen gebraucht werde, auf der Liste der COCOM-Güter stehe! Es dürfe also nur von den französischen Technikern benutzt werden. Die Amerikaner hätten es bei ihren Vorfuhrungen in Moskau sogar jeden Abend mit in die amerikanische Botschaft genommen! Siehe Telegramm von Jordan an die französische Botschaft in Moskau, Paris, 10.12.1964, in: Archives du MAE, Affaires Économiques et Financières, Affaires Générales, Nr. 219 a. 
d'ailleurs, tout le monde le viole tous les jours, à commencer par les Anglais. Ce machin a été inventé par les Américains pour nous ficeler « ${ }^{105}$.

In seiner Einschätzung lag de Gaulle richtig. Selbst die Amerikaner diskutierten darüber, die COCOM-Bestimmungen zu lockern, um den Sowjets das NTSC-System schmackhaft zu machen ${ }^{106}$ ! Drei Tage vor seiner Reise nach Moskau erbat sich Peyrefitte noch eine »Spezialaudienz« bei de Gaulle, um mit diesem die letzten Einzelheiten der Reise abzuklären. De Gaulle zeigte sich guter Dinge, da Winigradow ihm am ersten Januar positive Signale bezüglich eines französisch-sowjetischen Abkommens übermittelt habe. De Gaulle entließ Peyrefitte mit den weihevollen Worten: "Cette affaire de la télévision en couleurs peut jouer un rôle pionnier. C'est l'affaire de la Force multilatérale en petit: si le procédé américain triomphe, la colonisation américaine va encore progresser en Europe $\ll{ }^{107}$.

In Moskau traf Peyrefitte sowohl mit dem Vorsitzenden des Komitees für Koordinierung der Wissenschaft und Technik, Roudniev, als auch mit Premierminister Alexeij Kossygin zusammen. Während letzterer den Eindruck machte, daB er sehr an einem schnellen »accord de principe« interessiert sei, wies Roudniev mehrfach auf die langjährigen Erfahrungen und Vorarbeiten hin, die die sowjetischen Fernsehexperten durch das Experimentieren mit dem amerikanischen Farbfernsehsystem gewonnen hätten. Falls es zu einer Kooperation zwischen Frankreich und der Sowjetunion komme, müsse diesen Vorarbeiten entsprechend Rechnung getragen werden. Insgesamt zogen aber alle Beteiligten ein positives Fazit des Peyrefitte-Besuches in Moskau. Botschafter Baudet schickte noch während der Anwesenheit Peyrefittes in Moskau am 9. Januar ein Telegramm nach Paris, in dem er die symbolische Bedeutung des Treffens hervorhob: »Il est clair au demeurant que pour $\mathbf{M}$. Roudnev, comme pour M. Gvichiani, et encore plus peut-être pour M. Kossyguine, cette coopération dans le domaine de la télévision en couleurs a une valeur de symbole. Dans leur esprit, elle s'inscrit même comme un premier pas dans une voie qui mène au-delà de la technique vers la politique ${ }^{108}$.

Diese Worte muBten wie Musik in de Gaulles Ohren klingen, der das Telegramm Baudets ebenfalls gelesen hatte. Am 27. Januar traf de Gaulle erneut mit Botschafter Winigradow in Paris zusammen. Im Anschluß an dieses Treffen berichtete de Gaulle seinem Informationsminister, Winogradow habe ihn erneut auf die zahlreichen Gemeinsamkeiten der französischen und so-

105 Zitiert nach Peyrefitre, C'était de Gaulle, Bd. 2, S. 535.

106 Telegramm von Baudet, frz. Botschaft in Moskau, an das Quai d'Orsay, Moskau, 10.2.1965, in: Archives du MAE, Affaires Économiques et Financières, Affaires Générales, Nr. 219a.

107 Zitiert nach Peyrefitte, C'était de Gaulle, Bd. 2, S. 530.

108 Telegramm von Baudet an das MAE, Moskau, 9. Januar 1964, 3 maschinengeschriebene Seiten, hier S. 3, in: Archives du MAE, Affaires Économiques et Financières, Affaires Générales, Nr. 219a. 
wjetischen Positionen bezüglich vieler außenpolitischer Fragen hingewiesen (Laos, Abrüstung, UNO, NATO) und vorgeschlagen, nun einen Schritt weiter zu gehen. In den Aufzeichnungen, die Alain Peyrefitte von diesem Gespräch machte, heißt es:

L'Union Soviétique ne demande qu'à aller de l'avant: un premier exemple, un premier pas [...] pourrait être effectué très prochainement dans le domaine de la télévision en couleurs. [...] Le Général de Gaulle a pris acte des paroles de M. Vinogradov, s'en est félicité et a estimé que la télévision en couleurs constituait bien le premier exemple d'une coopération franco-soviétique $^{109}$.

Das SECAM-System, soviel stand nun fest, sollte zum Symbol des neuen auBenpolitischen Kurses de Gaulles werden. Ein Symbol, das die technische Dimension der französisch-sowjetischen Kooperation bewußt transzendieren sollte und international als Zeichen des neuen europapolitischen Kurses wahrgenommen werden sollte. Während einer Sitzung im Informationsministerium am 1. März wurde schlieBlich die definitive Taktik der Franzosen festgelegt, um erstens zu einem Abkommen mit der Sowjetunion zu kommen (»solution minimale«) und zweitens in Wien das SECAM-System als europäischen Farbfernsehstandard durchzusetzen (»l'objectif maximae«) $)^{110}$. Schien eine französisch-sowjetische Einigung auf politischer Ebene damit so gut wie besiegelt, versuchten die sowjetischen Verhandlungspartner alle Trümpfe auszuspielen, die ihnen beim Verhandlungsproze $B$ zur Verfügung standen. Geschickt nutzten die sowjetischen Politiker vor allem den Zeitfaktor aus. Ziel der französischen Bemühungen war es, einen offiziellen französisch-sowjetischen Kooperationsvertrag noch vor Eröffnung der CCIR-Konferenz in Wien zu erreichen, die am 24. März 1965 begann. Nur so hatte die französische Strategie Aussicht auf Erfolg, auf dem Wege eines Abkommens mit der Sowjetunion auch sämtliche Satellitenstaaten - darunter besonders die DDR - für SECAM zu gewinnen und somit ein symbolisches Übergewicht in Wien zu erreichen.

Anfang März 1964 spitzten sich die Verhandlungen in Moskau zu. Grund für diese Zuspitzung waren die sowjetischen Forderungen, die sich wie folgt

109 Note von Alain Peyrefitte, 27.1.1965, in: Archives du MAE, Affaires Economiques et Financières, Affaires Générales, Nr. 219a.

110 Unter dem Vorsitz von Alain Peyrefitte versammelten sich alle zentralen Akteure der SECAM-Propagation am 1. März 1965 im Informationsministerium, um, wie es im originalen Wortlaut heiBt, zu einer »définition de la tactique à suivre avant et jusqu'à la conférence de Vienne« zu gelangen. Anwesend waren neben Peyrefitte sein Kabinettschef de Bresson, CSFChef Maurice Ponte, François Laboulaye als FRANTECO-Chef sowie Jacques Thibau, Technischer Berater im Informationsministerium. Während des Treffens wurden die taktischen Schritte der nächsten Verhandlungsrunde mit der Sowjetunion sowie das anschließende Vorgehen in Wien definiert. Siehe »Note sur la télévision en couleurs, réunion du $1^{\text {er }}$ mars $1965 \ll, 4$ maschinegeschriebene Seiten, in: Archives du MAE, Affaires Économiques et Financières, Affaires Générales, Nr. 219a. 
zusammenfassen lassen: 1. Übernahme des SECAM-Systems nur unter der Bedingung, da $B$ parallel zu diesem Abkommen ein erweitertes Abkommen zur wissenschaftlich-technischen Zusammenarbeit abgeschlossen wurde (»accord intergouvernemental«); 2. Für das SECAM-System würden keinerlei Lizenzgebühren zu zahlen sein; 3. Die UdSSR müsse das Recht haben, in Eigenverantwortung Weiterentwicklungen am SECAM-System zu machen. Als Gegenleistung bot die sowjetische Seite die Unterstützung des SECAM-Systems in Wien an, d.h. die Übernahme der Garantie, daß alle Satellitenstaaten ebenfalls für SECAM votieren würden ${ }^{111}$.

Aus verhandlungstheoretischer Sicht hatten die Russen selbstverständlich die besseren Karten. So wiesen sie des öfteren darauf hin, daß sowohl die Amerikaner als auch die Briten ihnen mehrfach eine volle materiell-technische Unterstützung für den Aufbau einer Farbfernsehindustrie zugesagt hätten, falls man sich für das NTSC-System entscheide. Selbst die Vorteile des SECAM-Konkurrenten PAL wurden mehrfach angemahnt, doch hatte man selbst bei der CFT den Eindruck, daß es sich dabei lediglich um verbale Aufrüstung im Verhandlungskampf handelte ${ }^{12}$. Für die CFT bzw. CSF stellten die sowjetischen Forderungen jedoch ein nicht unerhebliches Problem dar. Hatte Maurice Ponte gehofft, den Russen das SECAM-System für 200 Millionen französische Franken verkaufen zu können, forderten diese die Benutzung der SECAM-Patente zum Nulltarif. Der von Ponte in Moskau mit den Verhandlungen betraute François Demichel faßte die Verhandlungsposition seiner sowjetischen Gesprächspartner treffend zusammen:

Par contre, Moscou entend monnayer sa position d'arbitre et en tirer tous les avantages matériels possibles. [...] L'attitude des milieux soviétiques n'a rien de surprenant pour quelqu'un qui est averti de leurs méthodes de négociations. Il ne s'agit de rien d'autre que de prendre une position qui est susceptible de diminuer les prétentions en matière commerciale et financière des interlocuteurs ${ }^{113}$.

Damit unterschied sich Demichels Einschätzung nur wenig von der des britischen Botschafters in Moskau, der nach einem Gespräch mit Laboulaye nach London telegrafierte: "The Russians will presumbly keep the French guessing until they have got them tied up as they want on offers of technical assistance, supply of components etc. ${ }^{114}$.

11 Siehe Telegramm (très urgenvdiffusion réservée) von Baudet, französische Botschaft in Moskau, an das Quai d'Orsay, Moskau, 5.3.1965, 4 maschinegeschriebene Seiten, in: Archives du MAE, Affaires Économiques et Financières, Affaires Générales, Nr. 219a.

112 "La concurrence du PAL est souvent avancée, mais j'ai eu l'impression d'une arme de négociation «. So André Danzin in seinem Moskauer Reisebericht vom 20. Oktober 1964, in: Archives du CHTV/INA, NachlaB Michel Dubail.

113 Brief von Demichel an Ponte, Paris, 22.2.1965, 3 maschinegeschriebene Seiten, hier S. 1 und 2, in: Archives du CHTV/INA, NachlaB Michel Dubail.

114 Telegramm der britischen Botschaft in Moskau an das Foreign Office/London, Moskau, 12.3.1965, in: PRO, Signatur FO 371/181313. 
War die erste sowjetische Forderungen aus Sicht der zuständigen politischen Stellen in Paris kein Problem, muBte für den Verzicht auf Lizenzgebühren aus Sicht der CFT erst eine entsprechende Kompensation gefunden werden. Dies gelang dadurch, daß man dem Kooperationsabkommen einen später nicht veröffentlichen »Annexe« beifügte, in dem zahlreiche Geschäfte zwischen der CSF und sowjetischen Betrieben im Bereich der Studiotechnik, Halbleitertechnik sowie im Bereich der Farbröhrenproduktion vereinbart wurden. Diese vertraglich festgelegten Geschäftsverbindungen, so die Hoffnung des CSF-Präsidenten Maurice Ponte, würden einer Kompensation des Verzichts auf Lizenzgebühren für das SECAM-System gleichkommen.

Unerwartet heikel gestalteten sich jedoch die Verhandlungen über den letzten Punkt der sowjetischen Forderungen, die Frage der Weiterentwicklung des SECAM-Systems. Weiß man um den weiteren Verlauf der Farbfernsehkontroverse, so erscheint gerade dieser Punkt in einem anderen Licht, als ihn die Beteiligten zum Zeitpunkt der Verhandlungen sahen. Wie Baudet in einem ausführlichen Telegramm aus Moskau vom 6. März 1965 berichtete, drohten die Verhandlungen am Wortlaut einer einzigen Formulierung $\mathrm{zu}$ scheitern. Der sowjetische Verhandlungsleiter Dïzermen Gwischiani hatte vorgeschlagen, folgende Formulierung als Grundlage des Vertragstextes anzunehmen: »le système franco-soviétique sur la base du SECAM $\ll$. Henri Peyroles dagegen forderte, daß man eine präzisere Definition des Systems festschreiben müsse, die zum Beispiel »le procédé SECAM avec son standard « lauten könne. Die von Gwischiani geforderten Weiterentwicklungen, so Peyroles, könnten sich auf entsprechende Elemente wie Aufzeichnungsgeräte, Kameras oder Transcodiereinrichtungen beziehen. $\mathrm{Zu}$ dieser exakten Definition war Gwischiani aber nur unter dem Umstand bereit, daß die Sowjetunion auf sämtliche Zahlungen zur Einführung des SECAM-Systems verzichten könne. Am 6. März 1965, auf dem Höhepunkt der Verhandlungen in Moskau, telegrafierte FRANTECO-Chef François de Laboulaye dem Informationsminister:

Le vice-président du KNIR [Gwischiani, A.d.V.] a, en effet, lié l'acceptation d'une formule aussi précise à une concession considérable sur le plan financier (gratuite). En contrepartie de cette gratuité il s'est dit prêt à se rallier à une formule du type suivant: ১Les parties sont convenues de réunir leurs efforts pour l'étude de la mise en exploitation du système de télévision en couleurs SECAM et coopéront dans la création sur la base de ce système à un ensemble télévision en couleurs commun franco-soviétique' ${ }^{115}$.

Tatsächlich einigte man sich schließlich auf die salomonische Formulierung »sur la base du procédé SECAM et de son standard«. Wie sich zeigen wird, wurde die »Basis« des Standards von den sowjetischen Technikern bereits

115 Telegramm von Laboulaye an Peyrefitte, Moskau, 6.03.1965, 4 maschinegeschriebene Seiten, hier S. 3, in: Archives du MAE, Affaires Économiques et Financières, Affaires Générałes, Nr. 219a. 


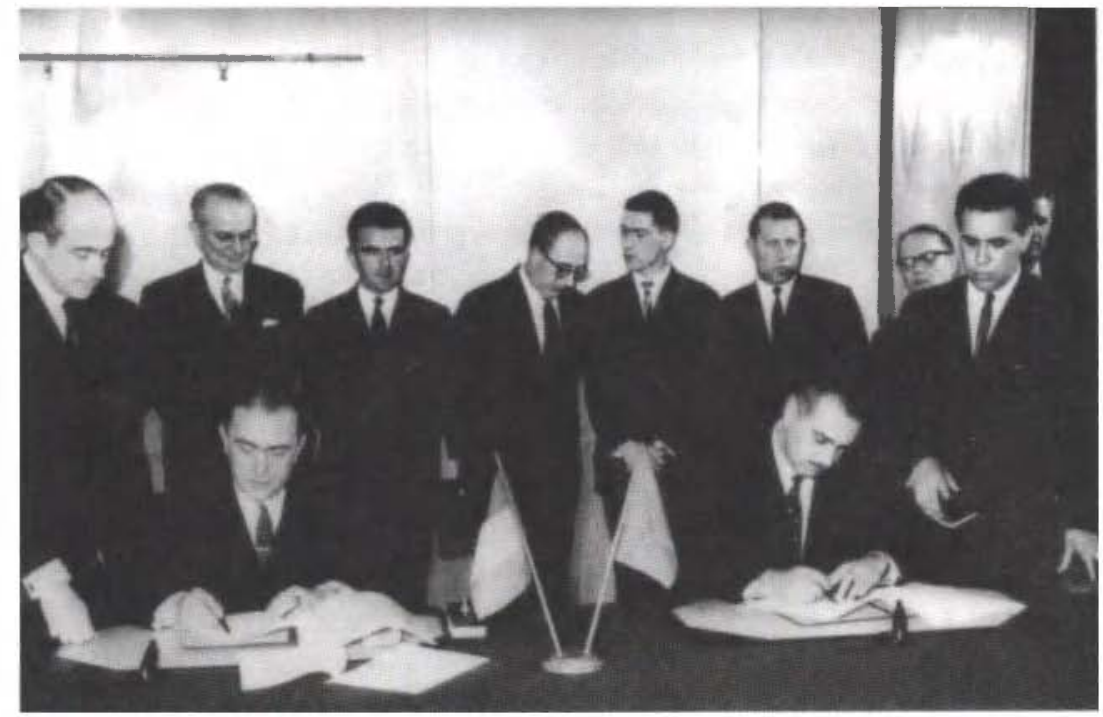

Abb. 18: Unterzeichnung des französisch-sowjetischen Farbfernsehabkommens durch den Vorsitzenden des sowjetischen Komitees für Koordinierung der Wissenschaft und Technik (KNIR), Dizermen M. Gwischiani, und den Kabinettschef von Informationsminister Alain Peyrefitte, JeanJacques de Bresson am 22. März 1965 in Paris. Auch Alain Peryerfitte (3.v.l.) sowie der CSFVorstandsvorsitzende Maurice Ponte (2.v.l.) waren zugegen. Aus: Archives du CHTVINA, Nachlaß Michel Dubail.

wenige Wochen nach der feierlichen Unterzeichnung des französisch-sowjetischen Abkommens am 22. März 1965 in Paris durchaus kreativ ausgelegt. $\mathrm{Da} B$ es letztlich zu einem erfolgreichen Vertragsabschluß zwischen Frankreich und der Sowjetunion kam, war unzweifelhaft der politischen Dimension des Abkommens geschuldet. Sowohl von französischer als auch von sowjetischer Seite war es die symbolische Dimension des Abkommens, welche die wirtschaftlichen und industriellen Vereinbarungen in ihrer Bedeutung überwog. Sowohl die Amerikaner als auch die Briten hatten bis zur Unterzeichnung des französisch-sowjetischen Abkommens zahlreiche Versuche unternommen, um die sowjetischen Behörden vom NTSC-System zu überzeugen. Allerdings wurden die Initiativen des wichtigsten amerikanischen Akteurs, Dr. George Brown von der RCA, von den entsprechenden politischen Stellen in Washington wenig gefördert ${ }^{116}$. Die britische Botschaft berichtete sogar

116 George Brown, ... and Part of which I Was. Recollections of a Research Engineer, Princeton 1982. Siehe besonders Kapitel 14 »The Russians are coming«. Knackpunkt der Gespräche mit der RCA war für die Russen vor allem die Frage der »shadow-mask «-Patente. Im Gegensatz zu den Franzosen war die RCA nicht bereit, auf die Lizenzeinnahmen bei der Röhrenproduktion zu verzichten. 
darüber, daß das State Department die Einreise von Brown in die Sowjetunion verzögert habe, um entsprechende Kontakte vor Wien zu vermeiden ${ }^{117}$.

Im Gegensatz zu den USA, wo die politisch Verantwortlichen den Technologietransfer in die Sowjetunion ablehnten, war es im britischen Fall die Rundfunkindustrie, die sich wenig begeistert über industrielle Kontakte mit der Sowjetunion auf dem Fernsehgebiet zeigte. Erst recht nicht, wenn es darum ging, SECAM als möglichen europäischen Standard zu unterstützen: "There is no British manufacturing interested in SECAM $\ll$, so die knappe Mitteilung des Foreign Office an die britische Botschaft in Paris ${ }^{118}$. Alle britischen Farbfernsehhersteller würden NTSC den Vorzug geben. Dagegen wären sowohl die BBC als auch das britische Postministerium bereit gewesen, "to give every practicable assistance to their Russian counterparts ${ }^{119}$. Generell war bei der britischen Radioindustrie aber eine gewisse Zurückhaltung bezüglich der Förderung russischer Initiativen sichtbar. Besonders Mullard, neben Thorn die einzige englische Firma, die zu diesem Zeitpunkt die serienmäßige Herstellung von Farbfernsehröhren beherrschte, war sehr zurückhaltend $^{120}$. Wie Mullard betonte, würde eine Zusammenarbeit bedeuten, daß man den Russen ermöglichte, einen zehnjährigen Technikrückstand zu überbrücken $^{121}$ !

117 »In the State Committee's discussion with RCA, Dr. Brown has repeatedly referred the necessity of State Department approval and the State Department had, in fact, delayed the entry of the RCA demonstration unit into the USSR from Finland. What guarantee was there that such hindrances could be avoided in future? Dr. Brown of RCA, alone on the Amercan side, was the only one to have made any proposals«. Telegramm von Trevelyan, britische Botschaft in Moskau, an das Foreign Office in London, Moskau, 12.03.1965, in: PRO, Signatur BT 11/6433.

118 Telegramm vom Foreign Office an die britische Botschaft in Paris, 8.03.1965, in: PRO, Signatur BT 11/6433.

119 Telegramm vom Foreign Office an die britische Botschaft in Moskau, 10.03.1965, in: PRO, Signatur BT 11/6433.

$120 »$ As regards the transmission end Marconi are enthousiastic to supply all that might be required and Rank-Bush-Murphy are also eager to quote for certain items of equipment. But at the receiver end where the Russians have so far shown the most interest and have suggested that they would like to help in setting up colour tube factories, Mullard and Thorn, the makers of the colour tubes, have made only a guarded response in view of the magnitude of the task of closing the 10-year gap between Russian technology and our own.« Telegramm vom Foreign Office an die britische Botschaft in Moskau, 10.03. 1965, in: PRO, Signatur BT 11/6433.

121 Einzige Ausnahme in der britischen Rundfunkindustrie war Marconi. In einem Brief von D. G. Smee (Assistant General Manager von Marconi in GB) an J. Leckie (Ministry of Technology) vom 25.02.1965 sagte Smee der britischen Regierung seine volle Unterstïtzung furr die Promotion von NTSC seitens Marconi zu: "You will see from all of this that our policy is to prosecute this business as wholeheartedly as we can within the framework of, fundamentally, British Government decisions. We are able and willing to provide the Russian authorities with every type of support - engineering planning, supply of equipment, training of engineers, etc. - to the maximum extend in which we are permitted by British Government regulations and to the need to negociate satisfactory commercial contracts «. In: PRO, Signatur BT 11/6433. Dagegen wandte sich F. E. Jones, General Manager von Mullard Ltd., in einem Brief vom 23. Februar 1965 an J. 
Auch auf deutscher Seite war man vor Wien aktiv geworden, um für eine positive Stimmung für PAL zu sorgen. Im Gegensatz zu den Franzosen, Briten oder Amerikanern konzentrierten sich die Bemühungen von Telefunken nicht auf die Sowjetunion, sondern auf die Ostblockstaaten Polen und Tschechoslowakei sowie die Skandinavischen Länder. So berichtete Werner Nestel seinen Vorstandskollegen von Telefunken über seine Reisen nach Stockholm, Oslo und Helsinki, die das Ziel verfolgt hatten, »Einfluß zu nehmen auf eine skandinavische Vorentscheidung « ${ }^{122}$. Wenige Wochen später machte sich auch Bruch zu einer PAL-Webetour in die Ostblockstaaten Polen und Tschechoslowakei auf. In Warschau, wo Bruch am 15. März zu Gast beim Institut für Post- und Fernmeldewesen war, schaute sich auch der stellvertretende Minister und Präsident der polnischen Akademie der Wissenschaften die PAL-Vorführungen an. Bruch berichtete: »Die Polen waren sehr SECAMfreundlich und die polnisch-französischen Beziehungen sind ja auch sehr viel besser als die polnisch-deutschen.[...] Zusammenfassend kann man sagen, $\mathrm{da}$ B sowohl in Prag wie auch in Warschau [...] mit unerhörten Anstrengungen in Form von technisch-politischen Unterhaltungen mehr von mir erreicht wurde, als ich eigentlich erwartet habe ${ }^{123}$.

Kurz vor Beginn der Wiener CCIR-Konferenz hatten somit sowohl die Anhänger des NTSC-Systems (USA und GB) als auch die SECAM- und PAL-Fraktionen keine Mühen und Kosten gescheut, den Boden der Wiener Verhandlungsbühne hinter den offiziellen Kulissen der CCIR durch Werbeund Überzeugungsarbeit vorzubereiten. Doch bevor das Parkett der Wiener Verhandlungsbühne betreten werden kann, müssen zuerst jene Reaktionen beschrieben werden, die das zwei Tage vor Beginn der CCIR-Konferenz in Wien publik gemachte französisch-sowjetische Abkommen in der Welt der

Leckie, Staatssekretär im Ministerium für Technologie, um diesem die Zurückhaltung Mullards in Fragen des Techniktransfers mit der Sowjetunion mitzuteilen: »[...] there are many things that we as tube makers would give priority to in front of assistance to the Russians, for the competition in the whole field of electronics is extremely great, especially from the USA, and it is proving as much as we can do with our limited technical expertise to continue to play an important part in the home market against American competition, and to build up a useful export activity. However, if the Government think that it would be in the national interest to divert some of our efforts to giving technical assistance to the Russians, then of course, we would do so«. In: PRO, Signatur BT 11/6433.

122 Protokoll der Vorstandssitzung vom 23.2.1965 in Berlin, in: AEG-Telefunken-Archiv, Deutsches Technikmuseum Berlin, Signatur GS/VS 038.

123 Vom 17. bis 24. Februar war Bruch mit einer kleinen Telefunken-Mannschaft in Prag, vom 25. Februar bis zum 2. März in Warschau. Siehe die beiden »Kurzberichte über eine Demonstrationsreise nach Prag /bzw. Warschau«, die Bruch am 15. März 1965 anfertigte. In: Archiv des Deutschen Museums München, Signatur NL 101, Nr. 202. Bruch beschreibt die Atmosphäre in Prag als "menschlich recht freundlich«, es habe aber Tage gedauert, bis er die technischen Vorbehalte gegenüber PAL »durch Diskussionen, Vorträge und Demonstrationen auftauen konnte «. 
Farbfernsehexperten und der politischen Öffentlichkeit ausgelöst hatte. Wie sich zeigt, sollte der Nachhall der Explosion dieser »diplomatischen Bombe« die Diskussion der technischen Experten über das vermeintlich »beste« Farbfernsehsystem für Europa kräftig erschüttern. 


\subsection{Französische »Schockdiplomatie ${ }^{124}$ : Das französisch-sowjetische Farbfernsehabkommen und die Wiener CCIR-Konferenz im März/April 1965}

Die Wirkung der Veröffentlichung des französisch-sowjetischen Kooperationsabkommens im Bereich des Farbfernsehens läßt sich anhand der Schlagzeilen messen, welche die europäische Presselandschaft Ende März 1965 prägten. In dem Leitartikel von La Nation hieß es: »Zweifellos fiel Frankreich, dem Land der Künste, die Aufgabe zu, die Farbe mit diesem großen Pinselstrich aufzutragen, der - dank der Fernsehwellen - Europa vom Atlantik bis zum Ural deckt ${ }^{125}$. Während man das Abkommen in Frankreich als »bedeutenden Sieg der französischen Technik « feierte ${ }^{126}$, trugen die Pressestimmen in den meisten anderen europäischen Ländern kritische bis zynische Züge. "De Gaulle träumt in Farben « titelte Die Welt ${ }^{127}$; »even television is now dragged into the realm of international affairs and has a role to play in the prosecution of the cold war / hieB es in einem Artikel des britischen Blattes The Guardian ${ }^{128}$. Die Frankfurter Allgemeine Zeitung sprach von einem "Farbfernseh-Affront ${ }^{129}$, der Nieuwe Rotterdamse Courant von einem $» P o l i-$ tieke triomf voor de Gaulle ${ }^{130}$, und die belgische Zeitung La Libre Belgique beklagte den französisch-sowjetischen »fait accompli«, der einen erneuten Keil zwischen Frankreich auf der einen und der Bundesrepublik und den USA auf der anderen Seite treibe ${ }^{131}$. Auch die Wochenzeitung Die Zeit stimmte am 26. März in den Kanon der kritischen Stimmen ein:

Die gaullistische Europa-Vision >vom Atlantik bis zum Urale soll zuerst auf den Bildschirmen sichtbar werden - und zwar in französisch-russischen Farben. [...] Datum und Begleitmusik der Unterzeichnung des Abkommens lassen die politische Absicht deutlich erkennen. [...] Die Moskauer Verbeugung vor der Führungsrolle de Gaulles in Westeuropa war unübersehbar. Das gaullistische Frankreich hat die Lage ausgenutzt, um auf einem kleinen Gebiet einen großen Coup zu landen ${ }^{132}$.

124 Der Begriff der »Schockdiplomatie« stammt von dem französischen Historiker und Politologen Alfred Grosser.

125 Dr. Hans Stercken, »Französische Presse zum französisch-sowjetischen Abkommen«, Bonn, 26.03.1965, in: Bundeszwischenarchiv Bonn, Signatur B 145/1356.

126 Eine Presseschau der französischen Aufmachung des Abkommens lieferte ein Bericht mit dem Titel "... und die Presse sekundiert" in: Die Welt, 24.03.1965.

127 N.N., De Gaulle träumt in Farbe, Die Welt, 24.03.1965.

128 N.N., France, Russia and la vie en rose, The Guardian, 24.03.1965.

129 N.N., Farbfernsehaffront, FAZ, 24.03. 1965.

130 N.N., Rusland aanvaardt het Franse systeem voor kleurentelevisie, Nieuwe Rotterdamse Courant, 23.04. 1965.

131 Zitiert nach einem Telegramm der französischen Botschaft in Brüssel, 26.03.1965, in: Archives du MAE, Affaires Economiques et Financières, Affaires Générales, Nr. 220a.

132 E. W.: De Gaulles Fernseh-Allianz, in: Die Zeit, 26.03.1965. 
Besonders scharfsinnig waren die Analysen der britischen Botschafter in Warschau und Paris, die die Farbfernsehfrage in den Kontext der »technological gap«-Debatte einbetteten und die Bedeutung der SECAM-Technologie in der französischen "politique de la grandeur« erkannten. Aus Warschau hieß es:

Without entering into the technological details of the SECAM system it is worth noticing that its acceptance by the Soviet Union makes it possible for France to extricate itself from the serious sscientific impasse in which it has been entangled for years. This problem is sufficiently important to direct attention to it. The French have realized for a long time that if their ambitions to play an independent political role in the world were to have any sense they had to be accompanied by scientific-technological progress ${ }^{133}$.

Nicht ohne eine gewisse Anerkennung für die "Leistung « der französischen Diplomatie stellte der britische Botschafter in Paris am 24. März in einem Telegramm an die Adresse des Foreign Office in London fest:

By a skillful operation, combining political negociation with propaganda, the French appeared to have placed themselves in a strong position to secure a number of adherents for SECAM at the Vienna meeting. It is said that General de Gaulle attaches considerable importance to this operation especially in the context of Franco-Soviet relations. [...] It would suit General de Gaulle to be able to point to something which can be regarded as the application of his pan-European policies $^{134}$.

In Paris registrierte man die Pressestimmen des Auslandes sehr aufmerksam. Aus allen europäischen Hauptstädten schickten die Botschafter ausführliche Presseanalysen, die die internationale Öffentlichkeit reflektierten. Aus London meldete man:

Il n'est pas exagéré de dire que la nouvelle a semé la panique dans les milieux compétents [...] Dans la plupart des journaux, qui publient généralement la nouvelle en première page et en caractères gras, c'est le mot >choc « qui revient le plus souvent. [...] La France et l'Union Soviétique sont accusées d'avoir machiné un mauvais coup dans l'ombre, d'avoir introduit un facteur politique décisif dans une affaire qui aurait du être maintenue sur le plan technique ${ }^{135}$.

Aus Madrid kam die Nachricht, daß die meisten spanischen Zeitungen in dem Abkommen ein Symbol der anti-amerikanischen Politik de Gaulles erkannten und befürchteten, dieser Vertrag könne den Eurovisions- und Mondovisionsbemühungen das Genick brechen ${ }^{136}$. Aus Den Haag berichtete Botschaftsmitglied Crouy, daß man in den politischen Kreisen lebhaft über das

133 Bericht vom britischen Botschafter Chancery in Warschau über einen Artikel in der Zeitung Zycie Warszawy vom 25.03.1965, in: PRO, Signatur FO 173/181314.

134 Telegramm von der britischen Botschaft Paris nach London, 24.03. 1965, in: PRO, Signatur BT 11/6433.

135 Telegramm von Courcel, französische Botschaft in London, 23.03.1965, in: Archives du MAE, Affaires Économiques et Financières, Affaires Générales, Nr. $220 \mathrm{a}$.

136 Telegramm von Boisseson, französische Botschaft in Madrid, 24.03.1965, in: ibid. 
französisch-sowjetische Abkommen diskutiere - »on en discute beaucoup et l'émotion est réelle«:

A quelques exceptions près, l'acceuil est en général mauvais et les critiques sont vives et parfois passionnées. On nous reproche, en toute mauvaise foi, de politiser l'affaire mais surtout ce qu'on appelle un sfait accomplis à la veille de la rénion de Vienne et l'intention qu'on nous prête de heurter les États-Unis. Telle est, également, la réaction de la plupart de mes collègues européens. Nous aurions interêt ces jours-ci, $\mathrm{a}$ insister sur les aspects de concurrence technique et commerciale de cette affaire ${ }^{137}$.

Leichte Kritik am französischen Vorgehen kam auch vom französischen Botschafter in Bonn, François Seydoux, auch wenn er wenige Tage später in Bonn im Sinne der französischen Regierungsinteressen für SECAM aktiv werden sollte. So telegrafierte François Seydoux am 24. März 1965 von Bonn nach Paris: "Il est sûr en tout cas que, contrairement à l'affirmation des journaux français, dont on relève ici le ton triomphant, l'accord francosoviétique n'est pas une contribution à l'unité de l'Europe. Il s'agit bien plus d'un geste unilateral qui n'a d'autre but que de servir le prestige du Gouvernement français ${ }^{138}$.

Obwohl man in Bonn zwei Tage vor der Veröffentlichung des französischsowjetischen Abkommens informiert worden war, machte dieses Abkommen die bundesdeutsche Position in Wien besonders schwierig. Die Strategie der Franzosen, über ein Abkommen mit der Sowjetunion alle Ostblockstaaten und damit auch die DDR für das SECAM-System zu gewinnen, machte die Farbfernsehfrage in Bonn ad hoc zu einem Problem gesamtdeutscher Natur. Staatssekretär von Hase faßte die schwierige Position, in der sich die bundesdeutsche Delegation in Wien nun befand, in einem Vermerk vom 24. März prägnant zusammen:

Für die Bundesrepublik verengt sich das Problem zu der Frage, ob wir zugunsten der gesamtdeutschen Farbfernseheinheit auf unseren technischen Nationalstolz und die technischen Vorteile zugunsten von SECAM verzichten sollen. Nach meiner Bewertung würde der EntschluB in der Öffentlichkeit nicht allzu gut aufgenommen werden, zumal die Industrie gegen eine solche Entscheidung polemisieren wird. Außenpolitisch betrachtet hätte eine solche Entscheidung manche Vorzüge ${ }^{139}$.

Wie sich zeigen wird, beschreibt die Feststellung von Hases genau jenen Spannungsbogen, zwischen dem sich die bundesdeutsche Position zur Farbfernsehsystemfrage bis zur Entscheidung in Oslo 1966 bewegen sollte: zwischen außenpolitischen Interessen im Sinne der deutsch-französischen Annäherung auf der einen und wirtschaftspolitischen Interessen im Sinne des Erhardschen Liberalismus auf der anderen Seite. Daß diese unterschiedlichen

137 Telegramm von Crouy, französische Botschaft in den Haag, 25.03.1965, in: ibid.

138 Telegramm von François Seydoux an das Quai d'Orsay, 25.03.1965, in: ibid.

139 Vermerk von Karl-Günther von Hase »Betr.: Farbfernsehkonferenz in Wien«, Bonn, 24.03.1965, in: Bundeszwischenarchiv Bonn, Signatur B 145/4515. 
Positionen in jeweils unterschiedlichen Ministerien bzw. Kompetenzbereichen angesiedelt waren - Bundespresse- und Informationsamt auf der einen und Bundeswirtschaftsministerium und Bundespostministerium auf der anderen Seite - machte die Aufgabe des zentralen bundespolitischen Akteurs in der Farbfernsehfrage, Karl-Günther von Hase, zu einem komplizierten Drahtseilakt innen- wie außenpolitischer Diplomatie.

Wie die Zitate aus diversen europäischen Presseorganen und internen Botschaftsberichten zeigen, war die öffentliche Meinung vor dem Beginn der CCIR-Zwischentagung am 25. März in Wien politisch aufgeladen und entsprach damit in keiner Weise jenem Verhandlungsklima, welches normalerweise bei Tagungen von Rundfunkexperten aus aller Welt herrschte. Dieses wurde von den technischen Akteuren immer wieder als offenes, vertrauenswürdiges Klima beschrieben. Die Intention der beteiligten Experten sei immer gewesen, so auch der Tenor der interviewten Ingenieure, die technisch »beste« Lösung in gemeinsamer Arbeit herauszufinden und als Standard zu empfehlen. Auch wenn viele dieser Beschreibungen ein wenig pathetisch und idealistisch klingen, weisen sie doch auf ein berufliches Selbstverständnis hin, das dem Bild des »neutralen Technikers« verpflichtet ist. Es verwundert daher nicht, daß sich diese »Bekenntnisse unpolitischer Ingenieure« während der Wiener Konferenz bei vielen Delegationsmitgliedern aus unterschiedlichsten Ländern wiederfinden. So schrieb Oberpostrat Dr. Johannes Müller rückblickend:

Im Gegensatz zu früheren Gepflogenheiten waren diese rein technischen Fragen, die frïher nur im Kreise von Fachleuten erörtert wurden, durch die Tagespresse an die Öffentlichkeit gezogen und zum Teil mit stark politischen Akzenten heftig diskutiert worden. [...] Dadurch war praktisch das Ergebnis der technischen Diskussionen durch eine politische Entscheidung vorweggenommen, und es war klar, welche Meinung insbesondere die osteuropäischen Verwaltungen und die von Frankreich beeinflußten Länder und Organisationen vertreten würden ${ }^{140}$.

Der dänische Chefdelegierte in Wien und Oslo, der Generaldirektor der dänischen Postverwaltung G. Pedersen, resümierte in einer öffentlichen Rede vor dem CCIR-Plenum:

Ich stelle fest, daß das Problem des Farbfernsehens hier im CCIR seit der Tagung in Wien nicht nur unter dem technischen Gesichtspunkt betrachtet wurde. Es gab eine starken EinfluB industrieller und politischer Interessen auf die technischen Studien. Ich hoffe sehr, daß diese Tendenz nicht zur ständigen Praxis in der CCIR-Arbeit wird. Das würde das gute Arbeitsklima, das wir in der Vergangenheit in der CCIR hatten, zugrunde richten ${ }^{141}$.

Ähnliche Formulierung ließen sich in zahlreichen Varianten auch von französischen, englischen, schweizer oder skandinavischen Ingenieuren zitieren $^{142}$.

140 MüLLER, Die internationalen Bemühungen um eine europäische Farbfernsehnorm, S. $242 \mathrm{f}$.

141 Zitiert nach PrEssLER, Farbfernseh-Erinnerungen, S. 208.

142 Sehr schön beschrieben wird die Arbeitsatmosphäre der CCIR-Arbeitsgruppen in dem »Summary Report on Interim Meetings of CCIR Study Group XI, Vienna, March 24 - April 7, 1965«. 
Susanne Strautz und Wolfgang Degenhardt sprechen daher zurecht vom Vertrauen als dem grundlegenden "sozialen Habitus« der technischen Expertengruppen der $\mathrm{EBU}^{143}$. Daß dieses Vertrauen während der Wiener Konferenz nachhaltigen Schaden erlitten hat, bestätigen auch die Interviews, die mit einigen der zentralen Akteure geführt wurden ${ }^{144}$.

Was wurde nun in Wien konkret verhandelt, wer waren die Verhandlungsteilnehmer? Wie bereits erwähnt handelte es sich um eine CCIR-Zwischentagung, an der im Gegensatz zu CCIR-Vollversammlungen immer nur bestimmte Studiengruppen der CCIR anwesend waren. In Wien waren dies die Studiengruppen X und XI, die sich mit den technischen Fragen des Hörfunks (X) und Fernsehfunks (XI) beschäftigten. Allgemeine Themen dieser Tagung waren unter anderem die Normen für den Stereo-Rundfunk, verbesserte Empfehlungen für den Austausch von Fernsehfilmen, Störabstände im Bereich des Lang- und Mittelwellenrundfunks sowie der Austausch technischer Daten für die Übertragung von Hörfunk- und Fernsehsendungen über Nach-

Dort heißt es: »Interim Meetings of CCIR Study Groups normally pass unrecorded. They are occasions when experts steeped with their subjects meet to discuss specific problems lying at the heart of international telecommunication. The business of these meetings is tedious, technical, detailed and - seen over experience of decades - cooperatively progressive. Without a free international technical forum of this sort there could be no room for technical manoeuvre; without room for technical manouvre there can be no unanimity; without unanimity on vital technical issues, international telecommunication is inhibited, if not impracticable. Thus the conduct of the work of these study groups has always been on the basis of discussion, with statement of points of agreement and disagreement, and eventual erosion of the areas of disagreement." In: PRO, Signatur HO 256/387. Zu einer ähnlichen Einschätzung kommt auch Christian Henrich-Franke in seiner Analyse der Entscheidungsfindungsprozesse im Rahmen der CCIR-Frequenzverteilungskonferenzen. Trotz des stark regulierten Verhandlungsrahmens wurde der Entscheidungsfindungsprozeß häufig durch eine informelle »Regienungskultur» beschleunigt oder gar erst ermöglicht. Internalisierte Handlungs- und Verhandlungsmuster, basierend auf einem dunch alle Mitglieder geteilten Habitus und legitimiert durch technisch-wissenschaftliche Kompetenz, haben ein spezielles "Funkregime" ermöglicht, welches sich in den meisten Fällen positiv auf die hohen Verhandlungskosten der stark formalisierten Regulierungskultur auswirkten. Siehe HENRICHFranKE, Globale Regulierungsproblematiken, S. 315-334.

143 Degenhardt, Strautz, Auf der Suche nach dem europäischen Programm. Degenhardt und Strautz analysieren in diesem Zusammenhang die sogenannte »Telstar-Krise « zwischen Frankreich und GroBbritannien, die gezeigt habe, daB die EBU sehr stark vom Verhandlungsgeschick der jeweiligen Präsidenten abhing. »Insgesamt zeigten die Telstar-Versuche, wie stark die Zusammenarbeit innerhalb der EBU von einem unbedingten Vertrauensverhältnis aller Beteiligten zueinander abhing um wie leicht Vertrauensbrüche gemeinsame Projekte gefährden konnten». (S. 87) Der Ausgleich des wechselseitigen Eigeninteresses war in der EBU schon so zur Routine geworden, daß man die Formulierung und die Beachtung genauer Spielregeln vernachlässigt hatte, was sich im Falle des politischen Prestige-Objektes Telstar als Fehler herausgestellt habe. In der Folge hätten deshalb Revanche-Kämpfe stattgefunden, um die EBU-Posten mit Leuten aus weigenen Reihe « zu besetzen! Als einen solchen politisch iberformten Revanche-Kampf sehen die beiden Autoren auch die Farbfernsehkontroverse an.

144 Siehe die Interviews mit Goussot, Fagot, Melchior, Herriger, von Hase, Einsel, Hausdörffer/ Lang, de Bresson, Dubail, Tetzner, In der Smitten, Angel. 
richtensatelliten ${ }^{145}$. Alle diese Fragen, so sind sich die diversen Chronisten der Tagung einig, traten jedoch weit zurück gegenüber den Auseinandersetzungen über die europäische Farbfernsehnorm in Studiengruppe $\mathrm{XI}^{146}$.

Aufgabe der Delegationen, die zumeist von höheren Mitarbeitern der nationalen Post- und Telekommunikationsministerien angeführt wurden, war die Diskussion der im Rahmen der EBU ad-hoc-Kommission für das Farbfernsehen erarbeiteten Untersuchungsergebnisse zu diskutieren und - wenn möglich - zu einer einheitlichen Empfehlung eines europäischen Farbfernsehstandards zu gelangen. Im Laufe des fast zweieinhalbjährigen Bestehens der ad-hoc-Kommission waren knapp zweihundert Untersuchungsberichte entstanden, die sich mit allen Einzelheiten der drei Systemalternativen beschäftigt hatten. Die sechs Länder, die an den intensiven technischen Untersuchungen im Rahmen der ad-hoc-Kommission beteiligt gewesen waren (Frankreich, Bundesrepublik Deutschland, Großbritannien, Italien, Niederlande und Schweiz), nahmen aufgrund ihrer Erfahrungen eine zentrale Stellung während der Diskussionen in Wien ein.

In der ersten Tagungswoche ging es darum, die abschließenden Untersuchungsberichte der ad-hoc-Kommission Punkt für Punkt zu diskutieren, um so zu einem Urteil über die jeweiligen technischen Stärken und Schwächen der drei Systemalternativen zu gelangen. Grundlage der Diskussion war der vorläufige Abschlußbericht der ad-hoc-Kommission, der unter dem Titel "Characteristics of the Colour Television Systems - Order of Merit and Importance « am 19. Februar vom Technischen Zentrum der EBU in Brüssel veröffentlich worden war $^{147}$. Aus diesem sowie zahlreichen früheren Berichten der ad-hoc-Kommission ging jedoch nur eine Sache wirklich eindeutig hervor, und zwar, da $B$ es kein in allen Fragen wirklich »besseres« System gab, sondern alle drei Systemalternativen in jeweils bestimmten Parametern besondere Vorteile bzw. kleinere Nachteile aufwiesen. Es war den Experten

145 Hans RindfLeisch, Tagung der Studiengruppe X und XI des CCIR in Wien in der Zeit vom 25. März bis 7. April 1965, in: Rundfunktechnische Mitteilungen 9 (1965) 3 S. $183 \mathrm{f}$.

146 Am Beginn der Tagung waren 175 Delegierte aus 25 Ländern anwesend, doch die Zahl der Teilnehmer sollte sich im Laufe der Tagung auf 230 Personen aus 45 Ländern steigern. Die ansteigende Teilnehmerzahl kam dadurch zustande, daB zahlreiche Länder, die in engem politischen Kontakt zu Frankreich standen, aufgefordert wurden, an der Tagung teilzunehmen, um so im Falle einer Abstimmung eine symbolische Mehrheit für das SECAM-System zu garantieren. Bei diesen Ländern handelte es sich zumeist um ehemalige französische Kolonialstaaten wie beispielsweise Algerien, Kamerun, Obervolta und Gabun, die allesamt durch Marokko vertreten wurden, oder Mali (vertreten durch Algerien), Marokko, Niger (vertreten durch Tunesien) und Tunesien. Siehe RINDFLEISCH, Bericht über die CCIR-Interimstagung der Studiengruppen X und $\mathrm{XI}$ in Wien vom 25. März bis 7. April 65 (nur für interne Verwendung!), in: AEG-TelefunkenArchiv, Deutsches Technikmuseum Berlin, Signatur GS 1750.

147 "Characteristics of the Colour-Television Systems - Order of Merit and Importance $«$, als EBU-Dokument mit der Bezeichnung "Com.T.(E) 194-E« in Bruissel veröffentlicht. In der CCIR-Systematik wird der Bericht als »Doc. XI/38-E« aufgeführt. 
nicht möglich, den fünfundzwanzig untersuchten Parametern eine eindeutige Wertigkeit zu geben.

Die verschiedenen Organisationen maßen den einzelnen untersuchten Systemeigenschaften wie der Kompatibilität, der Empfindlichkeit gegenüber Übertragungsverzerrungen, dem Verhalten bei magnetischer Bildaufzeichung, den Ausbreitungseffekten usw. unterschiedliche Bedeutung zu, so daß trotz der »Objektivität und der Fairneß«, mit denen die Untersuchungen durchgeführt worden waren, keine einheitliche Gesamtwertung und damit keine einheitliche technische Empfehlung zustande kam ${ }^{148}$. Bereits der erste Abschlußbericht der ad-hoc-Kommission im November 1963 war zu dem Resultat gelangt, »that with perfect equipment and in ideal conditions of reception the differences between the systems are small. It could be fairly stated that although in normal operating conditions the differences between the systems are larger than in ideal conditions, they are still relatively small ${ }^{149}$.

Damit stimmten die Abschlußberichte der EBU ad-hoc-Kommission auch mit den Ergebnissen aus den zahlreichen internationalen Publikationen überein, in denen der Vergleich der einzelnen Systemalternativen seit Jahren detailliert diskutiert worden war. Unter normalen Empfangsbedingungen, so das einmütige Fazit, lieferten alle drei Systeme zufriedenstellende Farbfernsehbilder ${ }^{150}$. Vielmehr kam es darauf an, einzelne Systemspezifika auf die je-

148 MüLLER, Die internationalen Bemühungen, S. 242f.

$149 »$ Draft Report of the EBU Adhoc Group on Colour Television* (Com.T. (E) 91-E) vom 22. November 1963, S. 29. Als Stärken des NTSC-Systems wurden die gute Kompatibilität zum s/w-Fernsehen sowie die Einfachheit (und damit kostengünstige Produktion) der Empfänger betont. Nachteile von NTSC waren die Störanfäligkeit für Phasenverschiebungen und die damit verbundenen Probleme der magnetischen Bildaufzeichnung. Als Vorteile des SECAM-Systems wurden besonders die Unanfälligkeit gegenüber Phasenstörungen und die damit verbundene einfache magnetische Bildaufzeichnung herausgestellt. Als Nachteile wurden die höheren Empfängerkosten sowie ein stärkeres Rauschen bei schlecht ausgerüsteten Empfängern benannt. Zudem stellte das SECAM-Signal in der Studiotechnik (Mischtechnik) wegen der Frequenzmodulation gewisse Probleme. Als Vorteile des PAL-Systems wurde wie beim SECAM-System die Unanfälligkeit gegenüber Phasenverschiebungen genannt. Auch mit einem einfacheren Empfänger als bei SECAM werde daher eine wesentliche Bildstabiliätssteigerung erreicht. Wegen der Ultraschall-Verzögerungsleitung, die exakter abgestimmt sein muBte als die in SECAM-Empfängern, waren PAL-Empfänger aber die teuersten.

150 Zum Beleg dieser Behauptung seien im folgenden einige Stimmen aus der internationalen Fachpresse wiedergegeben: "Zum Unglück sind die drei Verfahren, vor allem unter normalen Empfangsbedingungen so weitgehend ausgewogen in ihren Vor- und Nachteilen, daß sich keine zwingende Entscheidung ergibt«. Siehe N.N., Stand der Farbfernsehforschung, in: Frequenz 19 (1965) 9 S. 326; "Der Durchschnittsfernseher wäre daher wahrscheinlich mit jedem der drei Systeme vollauf zufrieden, zumal er ja nur Darbietungen nach einem der drei Systeme zu Gesicht bekäme und keine Vergleichsmöglichkeiten hätte. [...] Die Londoner Versuchssendungen haben in dieser Beziehung tatsächlich so gut wie keinen Unterschied zwischen den drei Systemen ergeben. [...] Käme es also ausschließlich auf die (hier unter verhältnismäßig günstigen Bedingungen 
weilige topographische Beschaffenheit eines Landes zu übertragen, um so die für das jeweilige Land »angepaßteste « Systemvariante auszuwählen ${ }^{151}$.

Diese technische Gleichwertigkeit der drei Systemalternativen war das eigentliche Dilemma, in dem die Fernsehexperten der CCIR in Wien steckten, da so im Grunde technische Kriterien zur Urteilsfindung ausschieden. Die Entscheidung dariber, welches System als europäischer Standard zu empfehlen war, konnte trotz der mahnenden Appelle seitens der »neutralen Techniker« nicht auf der Ebene wissenschaftlich-technischer Rationalität getroffen werden. Der Entscheidungsfindungsproze $B$ wurde aus diesem Grund immer stärker von außertechnischen Faktoren beeinflußt. Der verzweifelte Versuch, in immer neuen Tests Qualitätsunterschiede zwischen den Systemen zu finden, die eine qualitative Entscheidung zugunsten eines Systems erlaubt hätte, schlug fehl. Jede Entscheidung trug daher unweigerlich den Makel der politischen Begünstigung - oder, verhandlungstheoretisch gewendet: Es ging nicht mehr um die Aushandlung eines technischen Kompromisses im Sinne eines

zustandegekommene) Qualität der Bilder auf dem Schirm des Empfangsgeräts an, dann könnte die Entscheidung auch durch Los getroffen werden!« Siehe Friedrich KeLLER, Um ein technisch einheitliches Farbfernsehsystem in Europa. Die Entscheidungen sind ebenso schwierig wie dringend, in: Berichte und Informationen des österreichischen Forschungsinstituts für Wirtschaft und Politik 18 (1963) 843 S. 13 f. Auf einer Tagung von Fernsehspezialisten der Ostblockstaaten in Moskau vom 7. bis 14. Januar 1965 war man zu dem Resultat gekommen: »Bei optimalen Empfangs- und Betriebsbedingungen sichern alle drei Systeme eine fast gleichwertige Qualität des Bildes. [...] Beim Vorhandensein von Verzerrungen verhalten sich die Systeme verschieden und es gibt kein System, welches in allen Beziehungen besser ist als die anderen. [...] Die Empfänger der drei Systeme unterscheiden sich nur durch den Decoder; die Unterschiede im Preis sind aber gering, so daß diese Frage nicht entscheidend für die Auswahl eines Systems ist«. Der Bericht schloB daher mit der Empfehlung, daB man sich unbedingt um die Einführung eines einheitlichen europäischen Systems bemühen sollte! Siehe "Bericht über Beratung der zeitweiligen Arbeitsgruppe der Spezialisten zur Frage des einheitlichen Farbfernsehsystems «, Berlin, 22.1. 1965, in: Bundesarchiv, Zweigstelle Coswig, Signatur: DM 3/BRF ח/4691. Selbst Walter Bruch gab in einem Schreiben vom 17. Februar $1967 \mathrm{zu}$ : »Bei allen Untersuchungen der EBU ad-hoc-Gruppe Farbfernsehen und den anderen Expertengruppen hat sich für keine Eigenschaft des SECAM-Systems ein so großer Nachteil ergeben, daß man sagen könnte, wegen dieser Eigenschaft ist SECAM bei uns nicht anwendbar. Wohl haben sich bei unzähligen einzelnen Gesichtspunkten geringfügige Nachteile gezeigt, die summiert zu einer Einstellung gegen SECAM geführt haben. Ganz ohne Zweifel ist das SECAM-System nicht sinnvoll und logisch entwickelt worden, die Übertragungseigenschaften können daher kaum berechnet werden und seine Realisierung ist schwierig. Daher war es den Experten unsympathisch. SECAM ist bestimmt nicht so zuende entwickelt wie PAL, keiner hat Lust, sich dieses vorzunehmen«. Siehe Schreiben von Bruch »Btr. Vergleich PAL/SECAM«, Hannover, 17.2. 1967, in: AEG-Telefunken-Archiv, Deutsches Technikmuseum Berlin, Signatur GS 1648.

151 Die Qualität der empfangenen Signale hing nämlich erheblich von der Topographie der Städte oder Landschaften (Gebirge) ab. So waren beispielsweise die Vorteile des PAL-Systems gegenüber den beiden anderen Systemvarianten in flachen Gegenden »relativ gering", während sie in bergigen Gebieten oder GroBstädten mit Hochhäusern mmerklich gröBer« waren. Siehe $H$. WENDT, Farbfernseh-Empfangsbeobachtungen in GroBstädten mit den Systemen NTSC und PAL, in: Rundfunktechnische Mitteilungen 1 (1965) S. 48-50. 
»arguing «-Prozesses, sondern um den Schlagabtausch politischer oder wirtschaftlicher »Argumente im Sinne eines »bargaining «-Prozesses ${ }^{152}$.

Da die Franzosen ihre Taktik für Wien auf eben jene Verhandlungsstrategie politischer Druckausübung (»bargaining«) abgestimmt hatten, waren sie auf die im spieltheoretischen Sinne als Nullsummenspiel zu bezeichnende Verhandlungssituation wesentlich besser vorbereitet als ihre »Gegner $\ll$. Bereits die selbst von Franzosen als »coup de thêatre diplomatique ${ }^{153}$ bezeichnete Veröffentlichung des französisch-sowjetischen Farbfernsehabkommens hatte den internationalen Akteuren in Wien deutlich vorgeführt, daß die Franzosen nicht daran dachten, sich an die alten Spielregeln der CCIR-Verhandlungsriten zu halten.

Wie sich im Laufe der Wiener Konferenz zeigte, hatten diejenigen Delegationen, die nicht in das Kalkül der Franzosen eingebunden waren, dem politischen Manöver der Franzosen keine auch nur annähernd so ausgefeilten strategischen Handlungsoptionen entgegenzusetzen ${ }^{154}$. Noch nie war ein Minister Mitglied einer Länderdelegation auf einer CCIR-Zwischentagung gewesen, und noch nie waren Abstimmungsmodi über technische Parameter im Bereich der Telekommunikation zum Gegenstand diplomatischer Inszenierung geworden. Beides geschah erstmals in Wien. François Laboulaye, der SECAM-Sonderbeauftragte des französischen Staates im Range eines Ministers, war zum offiziellen Mitglied der französischen Delegation ernannt worden und wachte persönlich über Redebeiträge der französischen Delegationsmitglieder. Vor allem entfaltete Laboulaye aber eine rege Verhandlungsund Vermittlungstätigkeit außerhalb der regulären Sitzungen der CCIR-Experten, deren Ergebnisse - so der bundesdeutsche Delegationsleiter Hans Pressler in seinen »Farbfernseh-Erinnerungen « - dank der »tüchtigen Pressearbeit einiger weniger Delegationen« bereits am nächsten Tag in den Zeitungen nachgelesen werden konnten ${ }^{155}$. Es waren genau jene politischen Aktivitäten am Rande der CCIR-Zwischentagung in Wien, die ihre Wirksamkeit

$152 \mathrm{Zu}$ diesen beiden Modi der Verhandlungskommunikation im Rahmen internationaler Beziehungen siehe die anregenden Beiträge von Ursula Lehmkuhl, die in Kapitel 5 »Analyse eines Scheiterns« ausführlicher diskutiert werden. Ursula LEHMKUHL, Diplomatiegeschichte als internationale Kulturgeschichte: Theoretische Ansätze und empirische Forschung zwischen Historischer Kulturwissenschaft und Soziologischem Institutionalismus, in: Geschichte und Gesellschaft 27 (2001) 3 S. 394-423, sowie DiEs., Entscheidungsprozesse in der internationalen Geschichte: Möglichkeiten und Grenzen einer kulturwissenschaftlichen Fundierung außenpolitischer Entscheidungsmodelle, in: Loth, Osterhammel (Hg.), Internationale Geschichte, S. 187-207.

153 „Certes, en prélude à la conférence des experts du CCIR, la signature et l'accord franco-soviétique sur l'adoption du SECAM fut un véritable coup de théâtre", so der französische Chefredakteur der Fachzeitschrift Radio \& Télévision in seinem Bericht über die Wiener Konferenz. Siehe Eugène AISBERG, L'Europe polychrome, in: Radio \& Télévision 153 (1965) S. 99.

154 Aus dieser "Niederlage« sollten besonders die Briten und die Deutschen lemen, wie sich ein Jahr später in Oslo zeigte.

155 Pressler, Farbfernseh-Erinnerungen, S. 205-213. 
nicht verfehlten. In einem Bericht der britischen Delegation heißt es, daß auch die bundesdeutsche Delegation durch die französischen Aktivitäten unter Druck geriet: "During the discussions outside the formal meetings it became clear that many countries were under severe pressure from the French, at government level, to support SECAM, and there appeared to be a grave danger that Germany in particular might be persuaded to do so « ${ }^{156}$.

Selbstverständlich wußten die Franzosen, daß die bundesdeutschen Delegierten als PAL-Vertreter neben den Engländern und Niederländern als NTSC-Verfechter zu ihren mächtigsten Konkurrenten in Wien zählten. Aus diesem Grunde ließen sie nichts unversucht, um auch auf ihre bundesdeutschen "Partner" ein wenig politischen Druck auszuüben. Dieser kündigte sich in Form des Ministerialdirigenten Diehl vom Presse- und Informationsamt der Bundesregierung in Wien an. Diehl hatte am 2. April ein ausgiebiges Gespräch mit dem französischen Botschafter in Bonn, François Seydoux, in dem dieser Diehl die außerordentliche politische Dimension der Farbfernsehfrage nochmals vor Augen führte. Seydoux beklagte sich bei Diehl über die Haltung der bundesdeutschen Delegation in Wien, die »den Boden der technischen Diskussion verlasse und die französischen Auffassungen in einer polemischen Weise bekämpfe “ ${ }^{157}$ ! Seydoux bat Diehl daraufhin, sofort nach Wien zu reisen, um dort Kontakt mit dem französischen Delegationsleiter François Laboulaye aufzunehmen, da der »kritische Moment" gekommen sei. Bereits zwei Tage später war Diehl in Wien, um sich mit den bundesdeutschen Delegationsmitgliedern Ministrialrat Dr. Hans Pressler (Delegationsleiter), Dr. Hans Rindfleisch (Technischer Direktor des NDR), Prof. Richard Theile (Direktor des IRT) und Prof. Werner Nestel (Telefunken-Vorstandsmitglied) zu treffen. Diesen teilte Diehl mit: "Herr Seydoux habe darauf verwiesen, daß ein Eiserner Vorhang zwischen der SBZ und Westdeutschland entstehe, wenn Westdeutschland nicht SECAM annehme. Das Presse- und Informationsamt halte es deshalb für notwendig, in Westdeutschland SECAM zur Einführung zu bringen ${ }^{158}$.

156 „Summary Report on Interim Meetings of CCIR Study Group XI, Vienna, March 24 - April 7, 1965 «, in: PRO, Signatur HO 256/387.

157 „Vermerk über Gespräch mit Botschafter Seydoux und Botschaftsrat Delaye», Bonn, 3. April 1965, in: Bundeszwischenarchiv Bonn, Signatur B 145/4514.

158 "Niederschrift über ein Gespräch mit Herrn Min. Dirigent Diehl vom Bundespresse- und Informationsamt am 29. März 1965 in Wien aus AnlaB der CCIR-Konferenz«, 3 maschinegeschriebene Seiten, in: AEG-Telefunken-Archiv, Deutsches Technikmuseum Berlin, Signatur GS 1749. In einem Telegramm von Karl-Günther von Hase an das Auswärtige Amt in Wien bat dieser, Pressler von der Ankunft Diehls zu informieren. "Ferner bitte ich Gesandten Laboulaye zu unterrichten, daB Herr Diehl seine Einladung zum Abendessen am 4. April annimmt.« Siehe Fermschreiben von von Hase an das Auswärtige Amt in Wien, Bonn, 2.4.1965, in: Bundeszwischenarchiv Bonn, Signatur B 145/4515. 


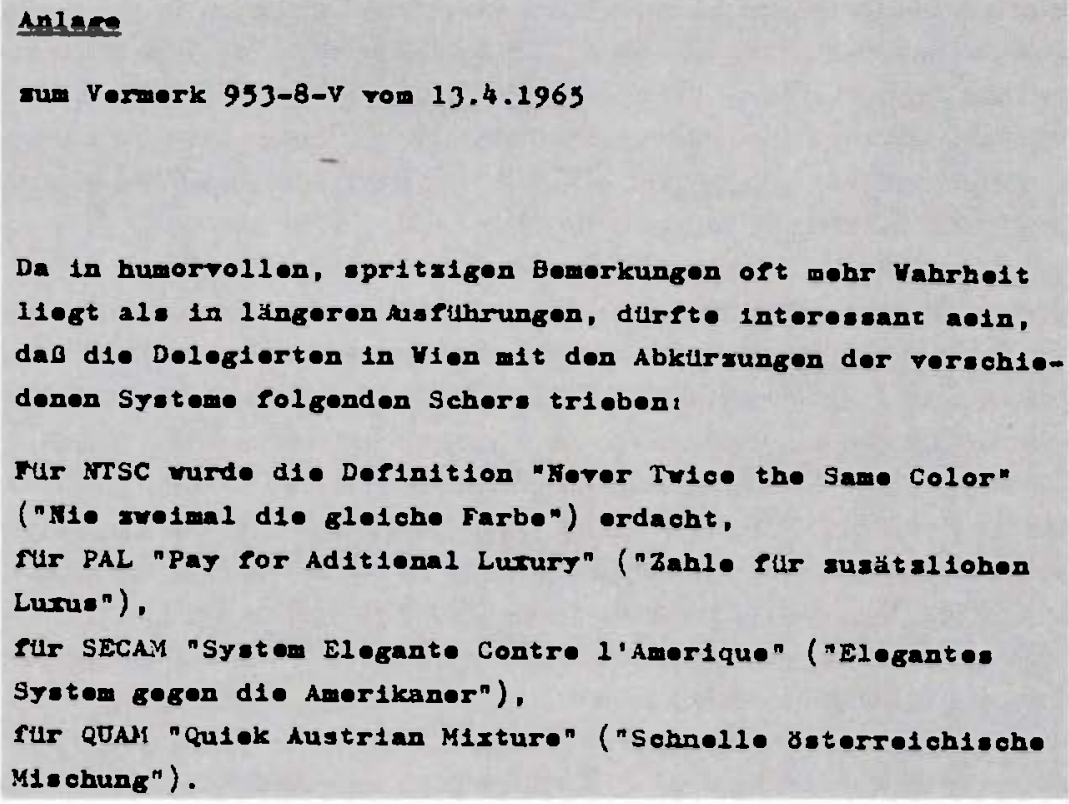

Abb. 19: Humorvolle Umdeutungen der Systemkürzel während der Wiener CCIR-Zwischentagung im März 1965, aus: Bundeszwischenarchiv Bonn, Signatur B 145/5673.

Auch wenn Diehls Auftritt in Wien für zeitweilige Nervosität innerhalb der bundesdeutschen Delegation und vor allem bei den Telefunken-Verantwortlichen sorgte, war Delegationsleiter Hans Pressler nicht an Diehls Empfehlungen gebunden, so daß es schließlich beim eindeutigen Votum der bundesdeutschen Delegation für PAL blieb ${ }^{159}$. Zudem hatte sich auch im Bundespresse- und Informationsamt die Vermutung verbreitet, daß der bundesdeutsche Delegationsleiter, der als Ministerialdirigent in Diensten des

159 Sowohl Telefunken-Vorstandsvorsitzender Felix Herriger als auch der Journalist und Funkschau-Chefredakteur Karl Tetzner bestätigen in den mit ihnen geführten Interviews, daB die Anwesenheit von Diehl von den bundesdeutschen Delegationsmitgliedern als massive politische Einmischung aus Bonn verstanden und dementsprechend miBbilligt wurde. Karl-Günther von Hase bestätigte die Aktion, räumte ihr im Interview jedoch nur die Bedeutung eines skleinen taktischen Manövers« zu. Walter Bruch berichtet in einem Vortrag auf einer Sitzung der Technischen Kommission des ZVEI am 26. April 1965 ebenfalls über diesen Vorfall: "Während unserer Tagung ist man auch in Bonn sehr aktiv gewesen. In Bonn ist man aufgewacht und es ist vor dieser letzten Abstimmung ein Vertreter vom Informationsamt aus Bonn gekommen, ein Ministerialrat Diehl [...] mit dem klaren Auftrag zu versuchen, uns noch mal [sic] von SECAM zu überzeugen. [...] Ich selbst habe an dieser Unterhaltung nicht teilgenommen, mit Absicht nicht, weil ich mich so geärgert habe, daß nun jetzt auf einmal Bonn sich einschaltet, nachdem das so weit gekommen ist «. Siehe "Vortrag des Herm Bruch auf der Sitzung der Technischen Kommission des ZVEI«, 26.04.1965, 8 seitige Transkription eines Tonbandmitschnittes, in: Archiv des Deutschen Museums München, NL 101, Nr. 202, S. 6. 
Bundespostministeriums stand, sich eher der Position des Bundespostministeriums verbunden fühlte denn der des Bundespresse- und Informationsamtes. Im Gegensatz zu der als "frankreichfreundlich « einzustufenden Haltung des Bundespresse- und Informationsamtes handelte es sich sowohl bei Bundeswirtschaftsminister Schmücker als auch bei Bundespostminister Stücklen im Hildebrandschen Sinne um "Atlantiker ${ }^{160}$. Beide Ministerien standen den Interessen der bundesdeutschen Industrie näher als denen der deutsch-französischen Annäherung im Sinne des »Freundschaftsvertrages«.

In einer späteren Analyse der Wiener Verhandlungen berichtete auch die französische Seite über die fehlgeschlagenen Bemühungen, die bundesdeutsche Seite mittels politischer Einflußnahme für SECAM gewinnen zu können: »En dépit d'un effort tenté par les séléments politiques « de la RFA pour trouver in extremis un accord avec la France, les techniciens allemands n'avaient $\mathrm{pu}$ ou voulu se laisser convaincre ${ }^{161}$. Bei anderen Delegationen dagegen blieben die Bemühungen französischer Diplomatie nicht unfruchtbar. Dies manifestierte sich auf besonders auffällige Weise gegen Ende der Konferenz, als der Vorsitzende der Studiengruppe XI, der Schwede Erik Esping, an alle 45 vertretenen Delegationen einen Fragebogen austeilte, auf dem nur eine einzige Frage stand: "What system do you choose for a public colour television service «? Ziel dieses Fragebogens war es, ein Meinungsbild über die jeweiligen Systempräferenzen der einzelnen Länder zu erhalten, nachdem schon vorher klar geworden war, daß man sich im Laufe der Konferenz wohl nicht auf eine einheitliche Empfehlung für einen europäischen Farbfernsehstandard würde einigen können. Obwohl die Statuten der CCIR klar vorgaben, daß dort beschlossene Vereinbarungen lediglich den Charakter von technischen Expertisen bzw. Empfehlungen an die jeweiligen nationalen Exekutivorgane haben konnten, unterließen die Franzosen keine Anstrengung, der Meinungsumfrage in der Presse das symbolische Gewicht einer »Abstimmung " zukommen zu lassen - sehr zum Ärger zahlreicher Delegationen ${ }^{162}$.

160 Klaus HildEBRAND, »Atlantiker« versus »Gaullisten«. Zur Außenpolitik der BRD während der 60er Jahre, in: Revue d'Allemagne et des pays de langue allemande 22 (1990) 4 S. 583-592. 161 „Note sur la Télévision en Couleur« von Philippe Olivier, Paris, 2.09. 1965, S. 10, in: Archives du MAE, Affaires Économiques et Financières, Affaires Générales, Nr. 220c.

162 Der Bericht der britischen Delegation liefert ein schönes Beispiel für die diplomatischen Bemühungen Frankreichs, die sich exemplarisch in dem Feilen an einzelnen Formulierungen zeigen. »In the final meetings the French - together with their procedural allies such as Cameroons - pressed vigorously for the replies to the questionnaires to be reproduced in summary form as a table of votes, but this was argued against by many delegates and the Chair. [...] The matter was left unresolved whilst the leaders of the French, British, Czechoslovak, U.S.A. delegations and the Chairman attempted to draft a Press Communiqué. During the long and hard discussions (France versus the rest) France first insisted on the results of the Conference beeing interpreted as an overwhelming majority in favour of SECAM. As she realized the impossiblity of securing agreement on any phrase that smacked of > voting «, she next proposed that the opinion should be expressed that $>$ but for the unsatisfactory procedures of the CCIR, it would have become evident 
Damit diese "Abstimmung « möglichst positiv für Frankreich ausfiel, wurden alle diplomatischen Hebel in Bewegung gesetzt, um möglichst viele Länder für ein SECAM-Votum zu mobilisieren. So kam es, daß die anfänglich aus 27 Länderdelegationen bestehende Tagung gegen Ende der Konferenz auf 47 Ländervertretungen angewachsen war. Walter Bruch schilderte diese verblüffende "Stimmenvermehrung « anschaulich in einem Vortrag vor den Mitgliedern der Technischen Kommission des ZVEI kurz nach seiner Rückkehr aus Wien: »Inzwischen haben die Franzosen noch Nachschub geholt. Der Vertreter von Kamerun ist aufgetreten und hat gesagt: >Ich vertrete auch Mali<; der Vertreter von Marokko ist aufgetreten und hat gesagt: >Ich vertrete Obervoltar. Ich kenne diese Länder gar nicht alle, die sich hier also um das Farbfernsehen gerauft haben, Niger und Madagaskar und ähnliche Nationen ${ }^{163}$.

Die Tatsache, daß sich zahlreiche Länder, die noch weit davon entfernt waren, einen $s / w-F e r n s e h f u n k$ aufzubauen, zu vehementen Verteidigern des SECAM-Systems aufspielten, hinterlieB bei manch einem Delegationsvertreter den bitteren Nachgeschmack einer politischen Satireveranstaltung. Bis zum letzten Tag der Konferenz, dem 6. April 1965 um 10.00 Uhr morgens, waren 44 der 45 ausgeteilten Fragebögen wieder beim Schweden Esping eingegangen. Das Resultat der Meinungsumfrage schien die französischen Anstrengungen zu belohnen: 22 Delegationen gaben an, daß sie beabsichtigten, das SECAM-System einzuführen, 12 gaben PAL an, 6 stimmten für NTSC und 3 Delegationen enthielten sich einer Meinungsabgabe.

Aber auch die SECAM-Kontrahenten hatten in letzter Minute versucht, der diplomatischen Offensive der Franzosen zumindest ein kleines Hindernis entgegenzusetzen. Zahlreiche Delegation lieferten nämlich parallel zum ausgefüllten Fragebogen eine Zusatzerklärung ab, in der sie erklärten: "The $\mathbf{x x x}$ delegation reaffirms its wish to reach agreement on a world-wide basis on the choice of a colour television system and sees in the Quadrature Amplitude Modulation (QAM) System the best possibility of achieving such a goal«. Diese "QAM «-Zauberformel war das Resultat einer deutsch-amerikanischen Absprache gewesen, die Bruch mit seinem amerikanischen Kollegen Allen erreicht hatte, um der NTSC-Familie zu einem größeren optischen Gegengewicht zum SECAM-System zu verhelfen.

Feierten die Franzosen das Resultat der Meinungsumfrage als überzeugenden Sieg ihres Systems, bemühten sich die Anhänger des PAL-oder NTSCSystems um den Nachweis, daB es sich bei den Stimmen für SECAM ledig-

that there was an overwhelming majority etc...< [...] So much for procedures and tactical ploys«. Siehe "Summary Report on Interim Meetings of CCIR Study Group XI, Vienna, March 24 April 7, 1965«, in: PRO, Signatur HO 256/387.

163 „Vortrag des Herrn Bruch auf der Sitzung der Technischen Kommission des ZVEI«, 26.04.1965, 8 seitige Transkription eines Tonbandmitschnittes, in: Archiv des Deutschen Museums München, NL 101, Nr. 202, S. 2. 
Abb. 20: Das „Orakel", aus: Archiv des Deutschen Museums München, Nachlaß Walter Bruch, Signatur NL 101, Nr. 270.

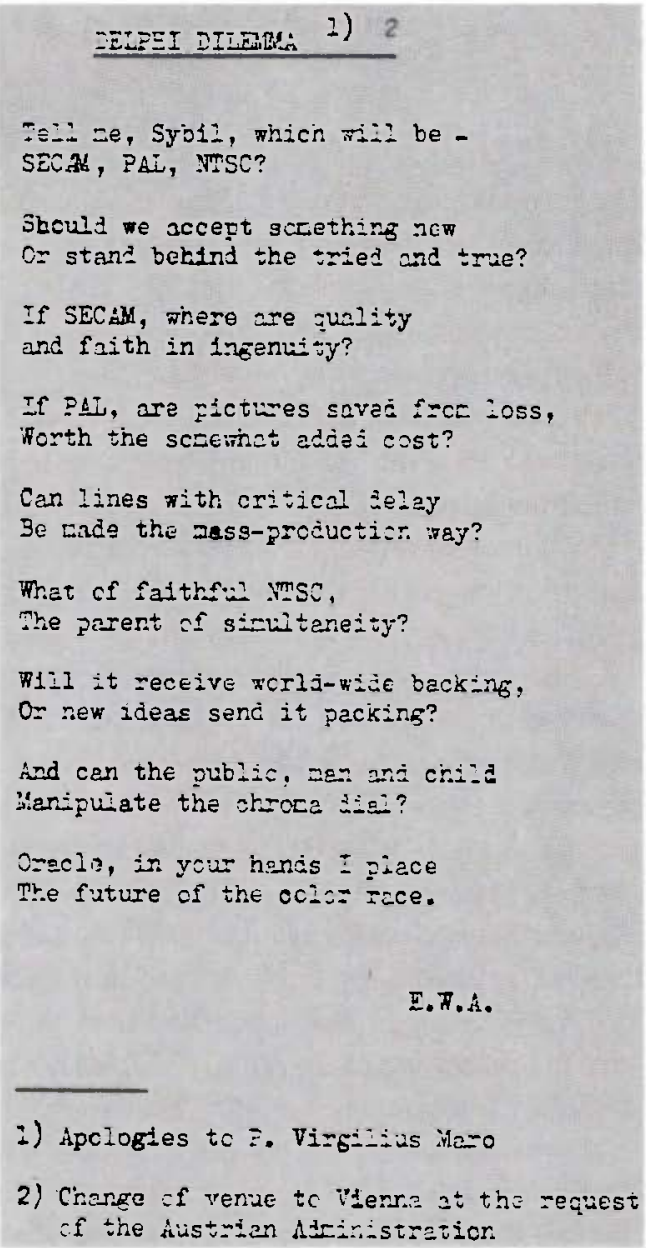

lich um eine zahlenmäßige Überlegenheit handele, die "qualitative Mehrheit« dagegen eindeutig auf Seiten des QAM-Lagers zu verorten sei. Ein weiser Unbekannter mit den Initialen E. W. A. verfaßte daraufhin ein Gedicht, welches den Urteilsspruch über »Sieger « oder »Verlierer « nach gutem alten Brauch dem Orakel überantwortete.

Da man sich auf der Wiener CCIR-Zwischentagung somit nicht auf die erhoffte Empfehlung für einen einheitlichen europäischen Farbfernsehstandard einigen konnte, wurde die Entscheidung auf die nächsste CCIR-Vollversammlung vertagt, die im Juni 1966 in Oslo stattfand. Diese Frist von einem Jahr zwischen Wien und Oslo nutzten alle beteiligten Akteure, um sich strategisch neu zu formieren und für die letzte »Entscheidungsschlacht« zu wappnen. 


\subsection{Front- und Farbwechsel zwischen Wien und Oslo}

\subsubsection{Kalte Kriegsphantasien: Der deutsch-deutsche "Farbfernsehvorhang"}

Nach der Wiener Tagung begann in den zuständigen Behörden die Analyse der Ereignisse. Herrschte im französischen Lager Zufriedenheit über die zahlenmäßige »Überlegenheit« des SECAM-Systems, klagte man auf bundesdeutscher Seite das Scheitern der versuchten europäischen Einigung und prägte die Formel vom »Farbfernsehvorhang «, der sich wie der »Eiserne Vorhang « zwischen die europäische Fernsehlandschaft zuziehen drohte. »Die Staatssekretäre von Hase und Carstens unterbreiteten die Nachricht von dem neuen televisionären Vorhang mit ernsten Gesichtern der Presse«, so lautete eine Zeitungsmeldung ${ }^{164}$. Obwohl Fachleute das Bild des »Farbfernsehvorhangs « offen als »Quatsch« bezeichneten, tauchte die Metapher in den Monaten zwischen Wien und Oslo immer wieder in der Presse auf ${ }^{165}$.

Zeigte man sich auf Seiten der bundesdeutschen Rundfunkindustrie zufrieden über das Ergebnis der Wiener Konferenz, kann die vom Bundespresseund Informationsamt häufig benutzte Vorhang-Metapher als Ausdruck ernsthafter Besorgnis über die politische Dimension der Farbfernsehfrage in bezug auf die deutsch-deutschen Beziehungen gedeutet werden. Da die DDR im Jahre 1965 kein offizielles Mitglied der CCIR war und aus diesem Grunde nur den Beobachterstatus eines OIRT-Mitgliedsstaates zugesprochen bekommen hatte, bildete die DDR die große Unbekannte im bundesdeutschen Kalkül. Aus diesem Grunde versuchte man im Bundespresse- und Informationsamt, möglichst vertrauenswürdige Einschätzungen über die Frage einzuholen, welches Farbfernsehsystem die DDR einzuführen gedenke.

Bereits am 14. April verfaßte Telefunken-Vorstandsmitglied Prof. Werner Nestel eine ausführliche Stellungnahme zu diesem Thema, in der er keinen Zweifel daran aufkommen ließ, daß sich die DDR für das PAL-System entscheiden werde. Er begründete diese Einschätzung damit, daß die $» \mathrm{SBZ}_{4-}$ im offiziellen Schriftverkehr zwischen Telefunken und Bundesministerien war nie von DDR die Rede - sich bei Standardisierungsfragen bislang immer den technischen Normen Westdeutschlands angepaßt habe. Dies sei sowohl beim UKW-Rundfunk als auch bei der Gerber-Norm der Fall gewesen. Wenn die SBZ zu ihrer westdeutschen (d.h. Gerber-Norm) s/w-Norm eine SECAM-Farbnorm hinzufügen würde, so Nestel, könnte dies weder die fran-

164 N.N.: Zwei Lager im Farbfernsehstreit, in: Zeitungs-Verlag und Zeitschriften-Verlag 16/17 (1965) S. 651.

165 "In Darmstadt, beim Fernmeldetechnischen Zentralamt (FTZ), [...] bezeichnet man die Bonner Befürchtungen über den ,Farbfernsehvorhang، allerdings schlicht und einfach als ,Quatsch Technisch, so meint man dort, ist das Problem des gegenseitigen Programmaustauschs ohne weiteres, wenngleich mit erheblichem finanziellen Aufwand, zu lösen.« In: ibid. 
Abb. 21: Karikatur des „Farbfernsehvorhangs«, aus: Archiv des Deutschen Museums München, Nachlaß Walter. Bruch, NL 101, Nr. 123.

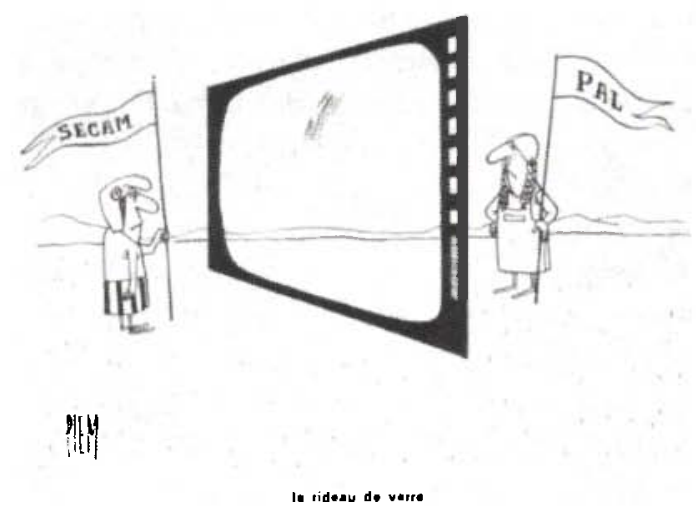

zösische noch die "Ostblock-SECAM-Norm « sein, da beide sich von der ostdeutschen (=westdeutschen) s/w-Norm unterscheiden würden. "Dies ist aber in hohem Grade unwahrscheinlich«, so Nestel ${ }^{166}$.

Wenige Tage später wurde Nestels Einschätzung auch vom TelefunkenVorstandsvorsitzenden Dr. Felix Herriger in einem mehrseitigen Schreiben an Staatssekretär von Hase wiederholt. Herrigers primäres Anliegen war es, dem Staatssekretär nochmals die Situation Telefunkens nach der Wiener Konferenz zu erläutern und ihn um politische Unterstützung für das PAL-System zu bitten, besonders bei den Bemühungen Telefunkens, die Briten und Niederländer für das PAL-System zu gewinnen ${ }^{167}$. Das Datum des Schreibens, der 22. April 1965, war ganz bewußt gewählt worden, da vier Tage später die 14. deutsch-französischen Informationsgespräche zwischen Peyrefitte und von Hase in Bonn stattfanden.

Während dieser Informationsgespräche, die auf dem Rhein-Ausflugsdampfer »Mainz« stattfanden, wurde drei Stunden intensiv über das Thema Farbfernsehen geredet ${ }^{168}$. Von Hase machte aus seiner Enttäuschung keinen Hehl,

166 Brief von Herrn Prof. Nestel an Staatssekretär von Hase, Berlin, 21.04. 1965 mit vierseitigem Anhang vom 14.04. zu den Themen "Beziehungen Frankreich/Westdeutschland « und »Westdeutschland/sowjetische Besatzungszone auf dem Gebiet von Rundfunk und Fernsehen in den letzten 20 Jahren «, in: Bundeszwischenarchiv Bonn, Signatur B 145/4515.

167 Brief von Dr. Felix Herriger an Staatssekretär von Hase, Berlin, 22.04.1965, 4 maschinegeschriebene Seiten, in: Bundeszwischenarchiv Bonn, Signatur B 145/1356.

168 Alain Peyrefitte sollte sich dieser Begegnung in seinem 1976 erschienenen Buch »Le Mal Français « - in Deutschland unter dem Titel »Was wird aus Frankreich « erschienen - in pathetischer Weise erinnern. Siehe Alain Peyrefitte, Was wird aus Frankreich?, Berlin, Frankfurt a.M. 1978, S. 28-31. In Peyrefittes Erinnerung wurde die Begegnung zu einer »Offenbarung«, die ihn veranlaBte, nach den Grüunden für die untèrschiedlichen deutsch-französischen Mentalitäten im Bereich der Forschung und Entwicklung nachzudenken. Verkirzt ließ sich Peyrefittes Reflexion auf die Stereotypen »französische Ingeniosität« versus »Deutsche Wertarbeit« reduzieren. Seine Besinnlichkeit wurde aber bald durch eine kämpferische gaullistische Rhetorik beendet: "Das SECAM-Verfahren war viel mehr als nur ein technisches Verfahren: wie die Atomwaffe 
von der französischen Seite erst so spät über das französisch-sowjetische Farbfernsehabkommen unterrichtet worden zu sein. Peyrefitte erwiderte diesen indirekten Vorwurf mit der Bemerkung, daß der französisch-sowjetische Farbfernsehvertrag »ein Ergebnis zweijähriger erfolgloser Besprechungen zwischen Frankreich und der Bundesrepublik « sei und führte für das Festhalten Frankreichs an SECAM drei Gründe an: Zum ersten sei eine technische Verschmelzung der Systeme, wie sie von Hase immer wieder einforderte, nicht machbar. Zum Zweiten hätten sich in Wien 23 Länder für das französische System ausgesprochen. Diesen Ländern fühle man sich in Frankreich »moralisch verpflichtet«. Drittens könne Frankreich rein formaljuristisch nicht mehr vom französisch-sowjetischen Vertrag zurücktreten ${ }^{169}$. Zuletzt wies Peyrefitte auf die politische Bedeutung des Abkommens mit der Sowjetunion hin, da das SECAM-System »einen Einbruch in die Länder hinter dem Eisernen Vorhang " ermögliche und forderte Deutschland auf, sich dieser Entwicklung nicht zu verschließen.

Trotz der romantischen Kulisse für dieses deutsch-französische Treffen kam es zu keiner Annäherung der Positionen. Nüchtern hieß es in der gemeinsam beschlossenen Pressemitteilung:

Staatssekretär von Hase und Staatssekretär Bornemann vom Bundesministerium für das Postund Fernmeldewesen haben dargelegt, daß sie es für wünscheswert hielten, eine Formel zu finden, die die Technik der vorhandenen Verfahren verbindet. Der französische Informationsminister, nach dessen Ansicht ein solcher Versuch den Gegebenheiten nach ohne praktisches Ergebnis bleiben würde, hat dagegen eine breite technische Zusammenarbeit zwischen den öffentlichen und privaten Organisationen der beiden Länder vorgeschlagen, um ein einheitliches europäisches System auf der Basis von SECAM und seiner technischen Eigenschaften zu entwickeln und auszuwerten $^{170}$.

Die Pressemitteilung machte klar, daß es wohl kaum zu einer politischen Lösung der Farbfernsehfrage im Rahmen der deutsch-französischen Beziehungen kommen würde. Trotzdem gab man auf seiten des Bundespresse- und Informationsamtes die Hoffnung nicht auf, zu einer technischen "Verschmelzung « der beiden Systeme gelangen zu können. Die Möglichkeit einer solchen Verschmelzung der beiden Systemalternativen PAL und SECAM wurde aber von technischen Experten aller Lager immer wieder verneint. Auf einer Besprechung im Bundespostministerium über die in Deutschland einzuführende Farbfernsehnorm am 20. Mai 1965 in Bonn versicherte auch Walter Bruch, daß er keine Möglichkeit zur Vereinigung der Systeme sehe.

oder die Concorde war es ein Beweis dafür, daß die Herausforderung angenommen werden konnte «. Ibid. S. 30.

169 „Vermerk über die 14. deutsch-französischen Informationsgespräche von Dr. Matern«, BPIA, Bonn, 27.04.1965, 3 maschinegeschriebene Seiten, in: Bundeszwischenarchiv Bonn, Signatur B 145/1356.

170 Pressekommuniqué zum 14. deutsch-französischen Informationsgespräch, Bonn, 26. 04. 1965, in: Bundeszwischenarchiv Bonn, Signatur B 145/1356. 
Abschließend hieß es, daß man auch den während des letzten deutsch-französischen Treffens auf Ebene der Informationsminister vereinbarten Gesprächen zwischen Rundfunkinstitutionen und Rundfunkindustrie keine Chancen gebe $^{171}$. Einen Tag nach der Sitzung wurde vom Bundespostministerium ein fünfseitiges Memorandum veröffentlicht, in dem das Ministerium seine Unterstiutzung des PAL-Systems kundtat. Neben den bekannten technischen Gründen wurde als zentrales Argument für PAL die Annahme vertreten, daß die SBZ das SECAM-System nicht einführen werde ${ }^{172}$. Selbst wenn es zur Einführung von SECAM in der SBZ kommen sollte, so das Memorandum, könnten die Sendungen der BRD in der SBZ immer noch in s/w empfangen werden.

Wenn diese Sendungen in der SBZ farbig empfangen werden sollen, wird die BRD in Gestalt zusätzlicher Sender nach dem SECAM-System in die Zone hineinstrahlen können, so daß der 'Farbfernsehvorhang ‘ auf diese Weise nicht zustande käme. [...] Auf jeden Fall könnten technische MaBnahmen getroffen werden, um zu vermeiden, daß die politische Teilung Deutschlands durch das technische Problem des Farbfernsehens berührt würde ${ }^{173}$.

Diese Stellungnahme des Bundespostministeriums sowie das Protokoll der vorhergegangenen Sitzung machen deutlich, daß sich die zentralen Akteure der technischen Seite des Rundfunks in der Bundesrepublik - d.h. Bundespostministerium, Fernmeldetechnisches Zentralamt, ARD, ZDF und die Rundfunkindustrie - eindeutig für das PAL-System als bundesdeutsche Farbfernsehnorm einsetzten und den baldmöglichsten Beginn von großangelegten Versuchssendungen forderten, damit man in der Bundesrepublik noch im Herbst des Jahres 1967 mit dem Farbfernsehen starten konnte. Besonders Telefunken-Vorstandsmitglied Werner Nestel wurde nicht müde, die angeblichen Nachteile des SECAM-Systems in immer neuen Stellungnahmen bei den entsprechenden Stellen im Bundespost- oder Wirtschaftsministerium zu propagieren. Dabei versäumte er es nicht, den Franzosen den »schwarzen Peter« einer möglichen europäischen Spaltung im Farbfernsehbereich zuzuschustern: Durch die Einführung der 819-Zeilennorm sowie einer von der Gerber-

171 Vermerk von Dr. Freibüter »Betr.: Besprechung im Bundespostministerium über die Einführung einer Farbfernsehnorm in der Bundesrepublik«, Bonn, 20.05. 1965, 4 maschinegeschriebene Seiten, in: Bundeszwischenarchiv Bonn, Signatur B 145/2864.

172 Als Begründung dieser Annahme wurden folgende Punkte genannt: 1. die SBZ sei daran interessiert, ihre Sendungen im Bundesgebiet zu verbreiten; 2. die SBZ habe auch im s/w-Fernsehen eine andere Norm als die anderen Ostblockländer. Ein "Fernsehvorhang " bestehe also bereits; 3. daB im Falle der SECAM-Einführung eine eigene, dritte SECAM-Norm speziell für die SBZ eingeführt werden müsse; 4 . daß erfahrungsgemäB ein fait accompli, d.h. die zeitlich frühere Einführung von PAL in der BRD, zur Anwendung des gleichen Systems in anderen Ländern führe. Siehe "Memorandum über die Einfuihrung einer Farbfernsehnorm für die Bundesrepublik Deutschland «, Bundesminister für Post- und Fernmeldewesen, Bonn, 21.05.1965, 5 maschinegeschriebene Seiten, in: Bundeszwischenarchiv Bonn, Signatur B 145/2864.

173 Ibid. S. 4. 
norm abweichenden 625-Zeilennorm habe Frankreich bereits »zweimal aus eigenem Willen einen >Vorhang ' zwischen Frankreich und Deutschland gelegt ${ }^{174}$.

Ende Mai 1965 stand das Bundespresse- und Informationsamt in seinen Bemühungen, auf eine deutsch-französische Einigung im Bereich des Farbfernsehens hinzuarbeiten, somit ziemlich isoliert da. Nachdem Frankreich zudem nicht auf die bundesdeutsche Offerte reagierte, die während der deutschfranzösischen Konsultationen vereinbarten Gespräche zwischen Industriellen und Verantwortlichen der Rundfunkinstitutionen beider Länder in die Tat umzusetzen, wurde während der Kabinettssitzung vom 21. Juli 1965 beschlossen, mit ausgedehnten PAL-Versuchssendungen in der Bundesrepublik zu beginnen, damit die Rundfunkindustrie entsprechende Erfahrungen bei der Einstellung der Empfänger sammeln konnte. Staatssekretär von Hase schlug folgenden Kabinettsbeschluß vor, der anschließend einstimmig angenommen wurde:

Die Bundesregierung nimmt davon Kenntnis, daß für das im Herbst 1967 in der Bundesrepublik Deutschland einzuführende Farbfernsehen schon jetzt mit Versuchssendungen begonnen werden muB. Da es bislang nicht gelungen ist, sich auf eine einheitliche europäische Farbfernsehnorm zu einigen, stimmt die Bundesregierung zu, daß in der Bundesrepublik Deutschland mit dem PALVerfahren gearbeitet wird, solange es nicht zu einer Einigung über eine einheitliche europäische Farbfernsehnorm kommt ${ }^{175}$.

Diese Formulierung hatte den Vorteil, daß sie vom Bundespresse- und Informationsamt als offen genug für eine mögliche europäische Einigung ausgelegt werden konnte, von den Befürwortern des PAL-Systems jedoch als Weichenstellung in Richtung definitiver Übernahme von PAL in der Bundesrepublik verkauft werden konnte ${ }^{176}$. Wie sich zeigen sollte, waren die offizielle Verlautbarung des Beginns von Versuchssendungen mit einem bestimmten System sowie der geplante Einführungstermin gewichtige Argumente in den Verhandlungen mit Drittstaaten, da sie als Ausdruck politischer Entschlossenheit ausgelegt werden konnten. Wie das britische Beispiel zei-

174 „Einige Angaben zur Frage der europäischen Farbfernsehnorm«, 3 maschinegeschriebene Seiten, Anhang eines Briefes von Dr. Herriger an Staatssekretär von Hase, 25.05. 1965, in: Bundeszwischenarchiv Bonn, Signatur B 145/2864.

175 Mitteilung des Rechtsreferats, Bonn, 12.08.1965, in: Bundeszwischenarchiv Bonn, Signatur B $145 / 2864$.

176 Genau in diesem Sinne wurde das frühere Pressekommuniqué des BPIA vom 22.07.1965, in dem der Beginn von PAL-Versuchssendungen angekündigt wurde, auch von seiten der britischen Diplomatie gedeutet. In einem Brief des britischen Botschafters in Bonn (Roberts) an O'Neill (Foreign Office) vom 22. Juli 1965 heiBt es: »As so often, von Hase's remarks can be interpreted in more than one way. They may be no more than soft words to conceal, for the sake of French susceptibilities, a firm German decision to go ahead with PAL. But they may equally well be taken as a sign that the Germans'attachment to their own system is not as firm as it might appear and that they do not wholly exclude the possibility of a switch themselves $\ll$. In: PRO, FO 173/181314, General Department, Akte GT 41/79. 
gen wird, war die Verlautbarung des Postmaster General, mit entsprechenden Farbfernsehversuchsendungen auf PAL-Basis zu beginnen, das entscheidende Signal für die britische Rundfunkindustrie, sich nun ernsthaft mit dem PALSystem zu beschäftigen. Ohne ein solches Signal waren die aufwendigen Investitionen aus Sicht der Rundfunkindustrie nicht zu rechtfertigen.

\subsection{2. „Our major European partner«: Der deutsch-britische Schulterschluß}

Obviously our own policy must be based on an agreed technical verdict, but you may feel as I do that there is a risk here of our missing. While the technical argument runs on, a very promising political opportunity of functional co-operation and alignment with what is now I suppose our major European partner ${ }^{177}$.

Dieses Zitat aus einem Brief des britischen Botschafters in Bonn, Sir Frank Roberts, deutet auf eine entscheidende Wende der politischen Allianzen in der Farbfernsehkontroverse Mitte des Jahres 1965 hin, deren Ursache im folgenden Abschnitt näher erläutert wird. Die britische Delegation war in Wien mit der klaren Anweisung des Postmaster General angereist, "to press strongly for NTSC « und $»$ strongly oppose the adoption of SECAM ${ }^{178}$. Von diesem Kurs war man in Wien auch nicht abgewichen, dennoch traf man sich gegen Ende der Konferenz mit Vertretern der bundesdeutschen Delegation und vereinbarte ein baldiges Treffen zwischen Vertretern der Postministerien, Rundfunkanstalten und der Rundfunkindustrie beider Länder ${ }^{179}$. Im Foreign Office war man sich der neuen Dimension der Farbfernsehkontroverse seit dem französisch-sowjetischen Abkommen bewußt ${ }^{180}$ und durchaus bereit, sich der politischen Auseinandersetzung mit den Franzosen auch auf diesem

177 Brief des britischen Botschafters in Bonn, Sir F. Roberts, an das Foreign Office vom 21.07.1965, in: PRO, FO 173/181314, General Department, Akte GT 41/79.

178 Brief von Willis (Chairman des Technical Advisory Committee) an Benn (Her Majesty's General Postmaster) vom 26.02.1965, in: PRO, Signatur HO 256/387.

179 "Recognizing, therefore, the particular positions of the U.K. and the Federal Republic of Germany at this stage, arrangements are being made for an informal and early exchange of views between experts of the Post Office, Broadcasting Authorities and Industry of the two countries with the objective of reviewing the problems that would rise in practice if we had to consider the coexistence of two or three colour systems «. Siehe "Summary Report on Interim Meetings of CCIR Study Group XI, Vienna, March 24 - April 7, 1965«, in: PRO, Signatur HO 256/387.

180 In einem Telegramm von Sir Patrick Reilly (britische Botschaft Paris) an das Foreign Office vom 25.03.1965 heißt es: »I know the technical reasons why we prefer the American NTSC system, and indeed we here have been giving them as much publicity as possible in attempt to counter the formidable French effort in favour of SECAM. I submit, however, that the conclusion of the French-Soviet agreement makes it impossible for us to continue to regard this question as a purely technical one and I feel bound to urge that in deciding whether to persist in our support of the American system we should take full account of the political aspects. \& In: PRO, Signatur FO 371/181313. 
Gebiet zu stellen. Noch während der Wiener Tagung verlautete es kämpferisch aus dem Foreign Office:

Thus the struggle is by no means over, and if it is a mark of a bad European to refuse to switch to SECAM, we are still in pretty good company. [...] If the General has luck with his present campaign, he may perhaps be able to manœuvre everyone into position where the UK attitude to SECAM becomes a test of our European spirit. But he has not yet achieved his result, so that, whatever may happen in the future, we see no need for us to submit such a test this week ${ }^{\mathbf{1 8 1}}$.

Wie dieses Zitat deutlich zeigt, entwickelte sich die Farbfernsehfrage nun auch in Großbritannien zu einem Politikum ersten Ranges. Vor dem Hintergrund der europapolitischen Realitäten wurde die PAL-SECAM-Kontroverse für die Briten zu einem weiteren Prüfstein der integrationspolitischen Kompromißbereitschaft.

Wenige Tage nach dem Ende der Wiener Konferenz kam es im britischen Postministerium zu einer Lagebesprechung des Television Advisory Committee (TAC), an der alle zentralen Akteure des britischen Rundfunks (Postministerium, Rundfunkanstalten, Industrie) beteiligt waren. Nach einem ausführlichen Bericht der Wiener Tagung seitens des britischen Delegationsleiters Merriman wurde diskutiert, welche Konsequenzen aus der Wiener Konferenz zu ziehen seien. Der allgemeine Tenor der Diskussion war, daß wohl wenig Aussichten darauf bestünden, daß sich in Europa eine größere Anzahl von NTSC-Anhängern finden würde. Besonders die Schweiz und die skandinavischen Länder hätten ihre Vorliebe für das PAL-System in Wien deutlich zum Ausdruck gebracht. Sir Hugh Green, Generaldirektor der BBC, berichtete zudem über die Entschlossenheit, mit der die zuständigen Rundfunkbehörden in der Bundesrepublik seiner Ansicht nach das PAL-System verteidigten. Sowohl der Vertreter der privaten Fernsehanstalt ITA, Sir Robert Fraser, als auch einige Vertreter der britischen Rundfunkindustrie teilten daraufhin mit, "that they would be prepared to accept PAL « - vorausgesetzt, daß weitere technische Studien durchgeführt würden ${ }^{182}$. Zusammenfassend hielt Sitzungsleiter Prof. Willis Jackson fest: "Although there was nothing in the technical discussions in Vienna which invalidated the United Kingdom view that NTSC was on technical grounds the best of the three systems for adoption in this country, nevertheless in the present situation there were good reasons why we should take a closer look at PAL with a view to assessing what penalties we should incur by adopting it ${ }^{183}$.

181 Brief von Sir G. Johnston (Foreign Office) an Sir P. Reilly (britische Botschaft Paris) vom 31.03. 1965, in: PRO, Signatur: FO 371/181313.

182 »Minutes of a meeting [des Television Advisory Committee, A.d.V.] held at 10 a.m. on Thursday 15 th April, 1965, at GPO Headquarters«, London, 5 maschinegeschriebene Seiten, in: PRO, Signatur HF 10/3.

183 Ibid. S. 4. 
Bereits Anfang Mai kam es daraufhin zu dem in Wien vereinbarten Besuch einer Gruppe bundesdeutscher Fernsehexperten in London ${ }^{184}$. Wie aus den Gesprächsprotokollen hervorgeht, sorgten die PAL-Vorführungen dafür, da $B$ sich die technische Einschätzung der beiden diskutierten Verfahren (NTSC und PAL) in den Augen der britischen Fernsehexperten eindeutig zugunsten des PAL-Systems verschoben ${ }^{185}$. Der AbschluBbericht des »Technical Sub-Committee « des TAC brachte dies deutliche zur Sprache: »The TSC therefore considers that there are no technical or operational reasons why the U.K. should not abandon its strong support for NTSC and instead be prepared to adopt the PAL system ${ }^{186}$.

Begründet wurde diese Stellungnahme neben der technischen Gleichwertigkeit beider Systeme vor allen mit den strategischen Optionen, welche ein solcher Richtungswechsel eröffnen konnte. Wichtigstes Argument war, daß die Übernahme des PAL-Systems in GroBbritannien auch die Niederlande zur Wahl von PAL bewegen könnte. Dies bedeutete konkret, daß die Zahl der in Europa diskutierten Systemvarianten auf zwei reduziert wurde. Auch bislang unentschiedene Länder wie Belgien oder Jugoslawien könnten, so die Meinung des TSC, durch diese Entscheidung auf die Seite des PAL-Lagers gezogen werden. Nicht zuletzt würden vielleicht einige osteuropäische Länder angeregt, über ihre bisherige pro-SECAM-Haltung nachzudenken. Das Kalkül des TSC schien sich zu bestätigen, als im Juni von der britischen Botschaft in Den Haag die Meldung kam, daß die Niederländer bei ihrer Untersuchung des PAL-Systems zur gleichen Einschätzung wie die Briten gekommen waren. Allerdings hatte man auch in Den Haag noch keine politische Entscheidung getroffen ${ }^{187}$.

Obwohl sich also das »technische Gewissen « des Television Advisory Committee, dessen Aufgabe die Empfehlung rundfunktechnischer Entschei-

184 Auf deutscher Seite waren Dr. Kronjäger und Dr. Müller vom FTZ, Prof. Theile vom IRT, Dr. Schwarz vom ZDF, Herr Boom vom ZVEI und Walter Bruch als Telefunken-Vertreter beteiligt. Auf britischer Seite waren Kilvington und Clinch (GPO), Dr. Maurice und Watson (BBC), Howe (ITA), Steele (Independant Television Contractors Association (ITCA), Jones und Rogers (BREMA) und Dr. Broadway (Electronic Engineering Association EEA) vertreten.

185 In dem Abschlußbericht des Treffens heiBt es: »While NTSC remains the first choice of the U.K. on technical grounds, a new appraisement of the situation in the light of recent developments in PAL suggests that the balance of advantage on technical grounds for NTSC is much less than it was thought to be. On operational grounds there are strong arguments for adopting PAL in the U.K. if, as now appears probable, a large proportion of Westem Europe does likewise.«. Siehe »Television Advisory Committee, Technical Sub-Committee, Committee Paper No. 360, Report of informal discussion on the PAL television system, London 4./5. Mai 1965«, in: PRO, Signatur HO 256/387.

186 »Colour Television/Report by the T.S.C.«, London, Mai 1954, in: PRO, Signatur: HO $256 / 387$.

187 Brief von P. Garran, britische Botschaft Den Haag, an Sir O'Neill, Foreign Office in London, Den Haag, 11.06.1965, in: FO 371/181314. 
dungen an den Postmaster General war, im Prinzip für einen Wechsel der britischen Position zugunsten des PAL-Systems entschieden hatte, gab es nach Bekanntwerden des TSC-Reports Widerstände gegen diese Entscheidung. Die kritischen Stimmen kamen aus den Reihen der BBC, allen voran von BBC-Chefingenieur Francis McLean. Dieser erläuterte die Gründe für seinen Widerstand in einem Brief an Chefingenieur Barron vom britischen Postministerium. McLean plädierte dafür, in der ganzen Diskussion vier Punkte zu unterscheiden: 1. die technischen Charakteristika der einzelnen Systeme; 2. die operationalen Faktoren beim Programmaustausch; 3. die eingebundenen politischen Interessen; 4. die Exportfrage von Studio-, Sender- und Empfängeranlagen. Während McLean die technischen Charakteristika beider Systeme ähnlich wie seine Kollegen vom TSC durchaus ausgewogen beurteilte, warnte er vor einer allzu schnellen Beurteilung der politischen Dimension der Farbfernsehfrage. Für ihn war es keineswegs sicher, daß sich alle Ostblockstaaten und die Sowjetunion definitiv für SECAM entscheiden würden:

It has been suggested that, without our support of PAL, the whole of Continental Europe might adopt SECAM but I would rate this as highly unlikely. There seems to be no doubt anywhere that if the whole of Europe including the Eastern Bloc were to adopt the NTSC system this would be the happiest solution for Europe and the World and give the best outlook for the future $^{188}$.

Für die BBC war das Thema des Programmaustausches mit den USA von entscheidender Bedeutung. Der britische Postminister Anthony Wedgwood Benn brachte die komplizierte Lage Großbritanniens in einem Brief an den Leiter des Television Advisory Committee vom 7. Mai 1965 auf die einfache aber prägnante Formel: "Failing agreement on a worldwide standard will make the choice of a system for this country particularly difficult because we are linked to America by a common language and to Europe by geographical proxymity ${ }^{189}$. Da die BBC ihren Widerstand gegen das TSC-Urteil in der Folgezeit nicht aufgab - McLean beklagte sich u.a. darüber, an der Abfassung des Berichtes nicht beteiligt gewesen zu sein, obwohl er offizielles Mitglied des TSC war ${ }^{190}$ - spitzte sich die Farbfernsehdiskussion in Großbritannien zunehmend auf einen Konflikt zwischen dem Foreign Office und der BBC zu. Während im britischen Außenministerium die politische Dimension der Farbfernsehfrage im Vordergrund des Interesses stand, überwog im taktischen Kalkül der BBC die Hoffnung, in Europa doch noch einen ein-

188 Brief von McLean (Chief Engineer BBC) an Barron (Engineer-in-Chief GPO), London, 31.05. 1965, in: PRO, Signatur HO 256/387.

189 Brief von Benn (MGP) an Willis (Chairman TAC), Mitte Mai 1965, in: PRO, Signatur HO $256 / 387$.

190 Siehe Brief von McLean (Chief Engineer BBC) an Barron (Engineer-in-Chief GPO), London, 31.05.1965, in: PRO, Signatur HO 256/387. 
heitlichen Farbfernsehstandard auf die Beine stellen zu können. Politischer Handlungsdruck ergab sich aus Sicht des Außenministeriums vor allem wegen des am 11. Juni anstehenden de Gaulle-Besuches in Bonn. In London befürchtete man, de Gaulle könne bei diesem Anlaß erneut versuchen, massiven politischen Druck auf die Bundesrepublik auszuüben, um die Westdeutschen zur Übernahme des SECAM-Systems zu bewegen ${ }^{191}$.

Obwohl das Thema Farbfernsehen bei den Gesprächen zwischen de Gaulle und Erhard unangesprochen blieb, zeigte man sich im Foreign Office zunehmend ungehalten über die »Verweigerungshaltung « der BBC, die es Großbritannien nicht erlaube, eine aktivere Rolle in der europäischen Farbfernsehkontroverse einzunehmen. Foreign-Office Mitarbeiter D. D. Brown nahm in einem Brief vom 4. August 1965 kein Blatt vor dem Mund als er schrieb:

I understand that the main difficulty is the reluctance of the Chief Engineer of the BBC, Mr. McLean, to abandon his support for the NTSC system. The result is that U.K. policy is paralysed, while the French continue their efforts to win support for SECAM, which our experts are unanimous in regarding as inferior to either of the alternatives. I recommend that the Secretary of State should send a minute to the Postmaster General in attempt to break this deadlock and get things moving ${ }^{192}$.

Als Ende Oktober noch immer keine Entscheidung seitens des TAC getroffen worden war, schien die Geduld im Foreign Office zu Ende zu sein. In einem vertraulichen Schreiben hieß es, wenn die Techniker nun nicht zu einem endgültigen Urteil kommen würden, werde die Entscheidung auf einer höheren politischen Ebene getroffen - und dies sowohl aus politischer wie ökonomischer Notwendigkeit ${ }^{193}$. Die politische Notwendigkeit wurde im Foreign Of-

191 In einer Notiz von Brown (Foreign Office) vom 2.06. 1965 heißt es: »There is a risk that General de Gaulle, in the course of his visit to Bonn on June 11, will try to push the Germans into some commitment on SECAM. It is therefore to our interest to encourage the Germans to stand firm on PAL, particularly as we ourselves are unlikely to be able to accept SECAM on technical grounds. I accordingly submit a draft letter to Mr. Tomkins, who will be in charge in Bonn from tomorrow, for Sir C. O'Neill's signature, suggesting that he should let the Germans know that there is a good chance of Ministers here deciding to support PAL. If the draft is approved, Sir P. Garran would be authorised to speak similarly to the Dutch«. In: PRO, Signatur FO 173/181314, General Department, Akte GT 41/74.

192 Brief von Brown (FO) an O'Neill (FO) vom 4.08.1965, in: PRO, Signatur: FO 173/181315, General Department, Akte GT 41/86. In die gleiche Kerbe schlug auch sein Kollege O'Neill in einem Telegramm an den britischen Botschafter Sir Roberts in Bonn wenige Tage später: »I entirely agree with what you say about the importance of seizing this opportunity for functional cooperation and alignment with the Federal Republic.[...] Unfortunately the Postmaster General's Television Advisory Committee is still deadlocked, apparently because of the continuing reluctance of the BBC to abondon NTSC, on which they, unlike the independent television people, have done a lot of work«. Siehe Telegramm von O'Neill (FO) an Roberts (britische Botschaft Bonn), London, 14.08. 1965, in: ibid.

$193 »[\ldots .$.$] the technicians in the United Kingdom have now been discussing this question for a$ good six months. If they are still unable to reach agreement among themselves surely the time must come when a decision has to be taken by a higher authority, in the light not only of tech- 
fice vor allem damit begründet, daß man dem massiven politischen Druck der Franzosen etwas entgegensetzen müsse, der sich zunehmend auch auf den außereuropäischen Bereich, etwa den Mittleren Osten und Afrika, ausdehne ${ }^{194}$. Allerdings war man sich im Foreign Office ebenfalls darüber im klaren, daß vieles von dem, was die Franzosen an diplomatischer Aktivität in Sachen SECAM entfalteten, nicht viel mehr als heiße Luft war. So urteilte Brown ein wenig süffisant über die vergeblichen Versuche von Laboulaye, den Briten das SECAM-System »schmackhaft « zu machen:

In general I do not think that we ought to make too heavy weather of the various French arguments. Surely the fact is that most of these arguments are simply ex post facto rationalisations of the General's determination to stymie the Americans and find something - anything - on which he can initiate technical cooperation with the Russians. The more closey one looks at de Laboulaye's cloud capped towers and gorgeous pinnacles, the more one gets the impression that they are all done with mirrors ${ }^{195}$.

Trotz dieser Abgeklärtheit war man im Foreign Office unzufrieden darüber, $\mathrm{da} B$ man den Franzosen kein eigenes außenpolitisches Gewicht entgegensetzen konnte, solange der Postmaster General keine offizielle Empfehlung zugunsten von PAL abgegeben hatte. Erst Ende November war es schlieBlich soweit. Brown teilte der britischen Botschaft in Bonn am 30. November mit, daB der Postmaster General nun endlich eine Stellungnahme zugunsten von PAL abgeben werde. Zwar werde die offizielle Veröffentlichung erst nach Zustimmung der Regierung erfolgen können, aber, so Brown an den Botschafter Roberts gewandt, »you have discretion to let the Federal German authorities know of this recommendation ${ }^{196}$. Am 2. Dezember informierte daraufhin Botschaftsrat Gorham Wirtschaftsminister Schmücker sowie Regierungssprecher Karl-Günther von Hase über die Entscheidung des TAC. Beide seien hocherfreut über diese Entscheidung gewesen, so Gorham, und würden natürlich verstehen, daß eine offizielle Verlautbarung noch nicht erfolgen könne ${ }^{197}$.

nical advice but of political and economic considerations. « Siehe das vertrauliche Schreiben von Brown (FO), London, 27. Oktober 1965, in: PRO, Signatur: FO 173/181315.

194 Der britische Botschafter in Paris, Ramsbotham. berichtete diesbezüglich über ein Gespräch mit dem französischen »SECAM-Botschafter« Laboulaye, das er am 26. Juli mit diesem in Paris gefuhrt habe.mThe French also, of course, are thinking of the political dividends they would derive from extending the SECAM-system to the Middel East or even Africa. [...] All this may sound a little unreal but the French undoubtebly have big ideas for exploiting their invention. Certainly SECAM is an important element in General de Gaulle's policy towards the Eastern European countries. Brief von Ramsbotham an Brown, Paris, 26.07.1965, in: PRO, Signatur FO 173/181315, General Department, Akte GT 41/86.

195 Brief von Brown (FO) an Logan (Brit. Botschaft in Paris), 6. 10. 1965, in: PRO, Signatur FO 173/181315, General Department, Akte GT 41/120.

196 Brief von Brown an Britische Botschaft in Bonn, 30.11.1965, in: PRO, Signatur: FO 173/181315, General Department, Akte GT 41/132.

197 Brief von Gorham (Britische Botschaft Bonn) an Miss Evans (FO), Bonn, 2.12. 1965, in: PRO, Signatur FO 371/181315, General Department, Akte GT 41/138. 
Schien mit dieser Entscheidung eine machtvolle deutsch-britische PAL-Allianz geschmiedet, die sich wenige Monate später auf der CCIR-Vollversammlung in Oslo durchaus bewähren sollte, so bleibt doch die Frage zu klären, weshalb es von seiten der BBC zu solch massivem Widerstand gegen das PAL-System gekommen war? Diese Haltung schien um so unverständlicher, da sich sowohl die technischen Experten des Postministeriums, des privaten Fernsehsenders ITV als auch die der britischen Rundfunkindustrie eindeutig für das PAL-System ausgesprochen hatten. Die Antwort auf diese Frage liefern einige versteckte Hinweise in der Korrespondenz zwischen BBC Chefingenieur Francis McLean und dem Scientific Attaché der britischen Botschaft in Moskau, Garrett, vom 9. Juni 1965. In einem Schreiben vom 9. Juni 1965 berichtet McLean von Gerüchten, daß die französisch-sowjetische Kooperation nicht so reibungslos verlaufe, wie die Franzosen sich das vorgestellt hätten:

A rumour is going round in Western Europe that all is not well with the Franco-Russian agreement. It is said that the French are not able to live up to the expectations of the Russian authorities in the supply of manufacturing information, particularly on colour tubes; and that the USSR has developed another system using quadrature modulation and is showing less interest in SE$\mathrm{CAM}^{198}$.

Wie sich zeigen sollte, hatten die von McLean als Gerüchte bezeichneten Informationen über die Probleme der französisch-sowjetischen Farbfernsehbeziehungen durchaus einen wahren Kern.

\subsection{3. $» A$ rumour is going round ...« Die sowjetische Systemvariante NIR}

»Je sais qu'ils sont en train de le faire « - so lautete eine Bemerkung des SECAM-Sonderbeauftragten François de Laboulaye am 5. März auf dem Höhepunkt seiner Verhandlungen mit den sowjetischen Fernsehexperten in Moskau im März $1965^{199}$. Das zähe Ringen um die Vertragsformulierung »basé sur le procédé SECAM et de son standard" hatte Laboulaye, wie sich im Juni 1965 herausstellen sollte, richtigerweise als Hinweis darauf gedeutet, $\mathrm{da} B$ die sowjetischen Techniker an einer eigenen Systemvariante arbeiteten, die sie - falls sie es für taktisch notwendig hielten - als Faustpfand der sowjetischen Mitgift in die französisch-sowjetische Farbfernsehliaison aus dem Hut zaubern konnten. $\mathrm{DaB}$ dieses Faustpfand jedoch bereits kurz nach der Gründung der im Farbfernsehvertrag vereinbarten "Commission mixte franco-soviétique sur la télévision en couleurs « vom 10. bis 12. Mai 1965 in Moskau zum bestimmenden Thema der französisch-sowjetischen Beziehun-

198 Brief von McLean (BBC) an Garrett (britische Botschaft Moskau), London, 9. 06. 1965, in: PRO, Signatur HF 10/3.

199 Telegramm von Laboulaye an Peyrefitte, Moskau, 5. März 1965, in: Archiv du MAE, Affaires Économiques et Financières, Affaires Générales, Nr. 219a. 
gen in dieser Frage werden sollte, kam für die Franzosen äußerst überraschend. Dabei war die französische Delegation voller Zuversicht von der Wiener CCIR-Zwischentagung nach Paris zurïckgekehrt. Sogar im Quai d'Orsay, wo man den ehrgeizigen außenpolitischen Plänen de Gaulles - zumindest im Fall der SECAM-Frage - mit deutlicher Reserviertheit begegnet war, zeigte man sich erfreut über den gelungenen französisch-sowjetischen Schulterschluß in Wien:

Si les négociateurs français pouvaient, lors de la signature de l'Accord du 22 mars, s'interroger sur la volonté des Russes de s'engager de façon irréversible en faveur du procédé SECAM, la Conférence de Vienne devait contribuer à dissiper leurs appréhensions. En effet, dans l'atmosphère de crise qui a entouré les débats de la Conférence, les délégations française et soviétique ont étroitement concerté leur action, et le front uni présenté par les partisans du SECAM a contrasté avec l'improvisation des alliances dans le camp de ses adversaires. Ce premier test de la coopération entre les deux pays est donc satisfaisant et Moscou, tout comme nous, s'en félicite ${ }^{200}$.

Bereits am 29. April 1965 reiste François Laboulaye in Begleitung des ORTF-Chefingenieurs Louis Goussot nach Moskau, um dort mit den Genossen Gwischiani und Roudniev alle nötigen Vorbereitungen für die erste $\mathrm{Zu}-$ sammenkunft der Commission Mixte zu treffen. Beide Seiten benannten ihre Delegationsmitglieder, stellten einen provisorischen Arbeitsplan auf, werteten die Ergebnisse der Wiener Konferenz in einem offenen Meinungsaustausch aus und diskutierten anschließend über die weiteren Schritte, die in gemeinsamem Interesse zur Förderung des SECAM-Systems unternommen werden müBten. Besondere Aufmerksamkeit wurde dabei der »deutschen Frage« gewidmet. Was die DDR angehe, so Gwischiani, werde die sowjetische Regierung alle notwendigen Schritte unternehmen, "pour que les autorités de Bonn n'aient plus aucun doute sur la détermination de celles de Berlin ${ }^{201}$ ! Eine ähnliche Aktivität, so der Vizepräsident des Komitees für Koordinierung der Wissenschaft und Technik in der Sowjetunion, erwarte man auch von den französischen Behörden ${ }^{202}$.

Bereits vierzehn Tage später (10.-12. Mai) trat die Commission mixte in Moskau zum ersten Mal zusammen. Nachdem sich die Kommission offiziell

200 „Note sur la Coopération franco-soviétique dans le domaine de la télévision en couleurs«, verfaßt von der Abteilung "Direction des Affaires Économiques et Financières« des Quai d'Orsay, Paris, 22.04.1965, 5 maschinegeschriebene Seiten, S. 4, in: Archives du MAE, Affaires Économiques et Financières, Affaires Générales, Nr. 219 a.

201 »ote des conversations MM. de Laboulaye et Goussot avec MM. Roudniev et Gvishiani, les Jeudi 29 et Vendredi 30 avril 1965«, Paris, 3.05.1965, 6 maschinegeschriebene Seiten, hier S. 4, in: Archives du MAE, Affaires Économiques et Financières, Affaires Générales, Nr. 219a.

202 Laboulaye schlug daraufhin vor, eine Delegation von Fernsehtechnikern aus der DDR nach Paris einzuladen, damit diese zusammen mit Fachleuten der ORTF das SECAM-System studieren könnten. Außerdem werde die CFT in Kürze eine industrielle Mission in die DDR unternehmen. »M. Gvishiani a déclaré que ces deux mesures lui paraissaient judicieuses et suffisantes«. wNote des conversations MM. de Laboulaye et Goussot avec MM. Roudniev et Gvishiani«, S. 5, in: ibid. 
konstitutiert und man sich auf alle Formalitäten der Arbeitsweise geeinigt hatte, fand noch am Abend des 10. Mai eine erste Arbeitssitzung statt. Waren die ersten Tagesordnungspunkte rein technischer Natur, kam es am Nachmittag des 11. Mai zur Analyse des Wiener Konferenzergebnisses und zur Festlegung des weiteren strategischen Vorgehens.

Der französische Delegationsleiter Laboulaye definierte ein 4 Punkte-Programm, das folgendermaßen aussah: 1. Da das SECAM-System in Wien eine deutliche Stimmenmehrheit erhalten habe, sei es nicht notwendig, die CCIRVollversammlung in Oslo abzuwarten, da sich an der technischen Ausgangslage sowieso nichts ändern werde. »De ce point de vue« so Laboulaye, »Oslo ne changera rien à ce qui a été dit à Vienne. Nous sommes donc justifiés à ne pas attendre une nouvelle délibération du CCIR. Seul le SECAM peut faire l'unanimité « ${ }^{203}$. 2. Eine Analyse dieser SECAM-Mehrheit ergebe, daß sich in dieser Gruppe Länder mit unterschiedlichem technisch-industriellen Entwicklungsstand befänden. Aus diesem Grunde müsse daran gearbeitet werden, enge industrielle und informelle Kontakte zwischen allen SECAMBefürwortern herzustellen. 3. Die vorhandene SECAM-Mehrheit müsse weiter ausgebaut werden. Dies bedeute: „Rallier les hésitants; convertir les partisans des autres systèmes ${ }^{204}$ ! $\mathrm{Zu}$ den "Zögernden « zählte Laboulaye Belgien, Finnland, Jugoslawien und die Türkei. Jedes dieser Länder müsse man einzeln für SECAM gewinnen, indem man politischen oder industriellen Druck ausübe - »ou les deux simultanément «! 4. Schließlich müsse man versuchen, auch außerhalb Europas Verbündete für SECAM zu gewinnen. Laboulaye dachte hier vor allem an den Mittleren Osten sowie afrikanische und südamerikanische Länder. Zusammenfassend erklärte Laboulaye: „En d'autres termes, il faut prouver le mouvement en marchant ${ }^{205}$. Mit diesem kämpferischen Pathos endete die erste Sitzung der Commission Mixte, und beide Seiten gratulierten sich gegenseitig für diesen gelungenen Auftakt einer ohne Zweifel zukunftsreichen Zusammenarbeit.

Nur einen Tag später wurden zwei Ingenieure der ORTF und der Generalsekretär der FNIE in Moskau zu ihrer großen Überraschung zu einer Demonstration eingeladen, bei der sowjetische Fernsehtechniker ein Farbfernsehsystem namens NIR präsentierten, benannt nach dem sowjetischen Komitee für Koordinierung der Wissenschaft und Technik (KNIR) ${ }^{206}$. Zwar hatten die

203 „Commission Mixte Franco-Soviétique sur la télévision en couleurs. Compte rendu de la première réunion«, 14 maschinegeschriebene Seiten, hier S. 11, in: Archives du CHTV/INA, Nachlaß Michel Dubail.

204 lbid. S. 12.

205 Ibid.

206 Das NIR-System verwendete die selben Modulationsprinzipien wie das NTSC- oder PALSystem, nämlich das Prinzip der Quadratur-Amplituden-Modulation. Während aber beim NTSCSystem in jeder Zeile der Farbvektor (F) übertragen wird, dieser beim PAL-System zeilenweise abwechselnd mit dem spiegelsymmetrischen Farbvektor F' übertragen wird, wird beim NIR-Sy- 
französischen Ingenieure keine Gelegenheit, Näheres über das sowjetische System zu erfahren, doch konnten sie selbst bei flüchtigem Blick feststellen, daß dieses System deutliche Unterschiede zum SECAM-System der CFT aufwies. Doch soviel stand fest: Die Aufgabe der im SECAM benutzten Frequenzmodulation des Farbhilfsträgers zugunsten der beim NTSC oder PAL benutzten Amplitudenmodulation machte es mehr als fraglich, ob man noch von einem System »basé sur le procédé SECAM et de son standard « sprechen konnte.

Auch wenn der wissenschaftliche Berater der sowjetischen Botschaft in Paris, Nederoub, sich Anfang Juli alle Mühe gab, den Präsidenten der FRANTECO davon zu überzeugen, daß es sich beim NIR-System durchaus um eine SECAMVariante im Sinne des französisch-sowjetischen Abkommens handele, war die Verwirrung in den politischen Kreisen gro $B^{207}$. Zum einen fühlte sich die französische Seite in gewisser Weise »übers Ohr gehauen« und empfand die NIR-Initiative als Vertrauensbruch, auch wenn - wie eine kritische Lektüre des Textes des französisch-sowjetischen Abkommens eindeutig ergab - die Formulierungen des Abkommens sprachlich so vage waren, daß eine juristische Vertragsverletzung sehr schwer nachzuweisen war. Zum anderen war man vor allem im politischen Lager erstaunt, daß die bislang von den Technikern immer als unmöglich bezeichnete »Fusion« zwischen dem PAL- und dem SECAM-System nun in Form des NIR-Systems doch Realität geworden zu sein schien.

Leider kann über die Motivation der sowjetischen Seite nur spekuliert werden, da keine direkten Überlieferungen aus sowjetischen Archiven eingesehen werden konnten. Allerdings lassen sich Grundzüge der sowjetischen Strategie indirekt über Bestände aus den Archiven der DDR rekonstruieren. Glaubt man der Darstellungen des Stellvertreters des Ministers für Post- und Fernmeldewesen der DDR, Genosse Probst, der in einem Schreiben seinen Minister (Schulze) über eine Aussprache mit Gwishiani vom 3. Juni 1965 über Fragen der sowjetisch-ostdeutschen Zusammenarbeit auf dem Gebiet des Farbfernsehens berichtete, so war Gwishiani selbst von der NIR-Initiative

stem zeilenweise abwechselnd der Farbvektor F und ein Farbvektor F"' gesendet, der mit der (B-Y)-Richtung zusammenfällt und als Vektor für die Referenzphase Null dient. Er überträgt damit im Unterschied zum NTSC- oder PAL-System nicht den Farbton, sondern nur die Farbsättigung. Auf der Empfängerseite wird mit Hilfe einer Verzögerungsleitung die Gleichzeitigkeit der beiden Farbartinformationen wieder hergestellt. Gegenüber den nichtlinearen Phasenfehlern hatte das NIR-System demnach die gleichen Vorteile wie das PAL-Verfahren. Bei Reflexionserscheinungen sowie sinusförmigen Störungen war das NIR-System jedoch störanfälliger und führte zum Phänomen der so genannten »farbigen Ränder«. Auch musste die verwendete Verzögerungsleitung zwei- bis dreimal so genau sein wie beim PAL-System.

207 »Note sur la télévision en couleurs« de Philippe Olivier, Ministère de l'Information, Paris, 2. September 1965, 21 Seiten, hier S. 7 f., in: Archives du MAE, Affaires Economiques et Financières, Affaires Générales, Nr. 220c. 
der sowjetischen Fernsehtechniker überrascht worden. Probst berichtet: »Genosse Gwishiani äußerte dazu, daß die Franzosen objektiv im Recht seien [daß es sich beim NIR nicht um eine Weiterentwicklung von SECAM in Sinne des französisch-sowjetischen Farbfernsehvertrages handele, A.d.V.] [...] Die entstandene komplizierte Situation beruhe auf dem unklugen und untaktischen Vorgehen einiger sowjetischer Wissenschaftler. [...] Genosse Gwishiani erklärte weiter, daß er möglichst bald mit den französischen Vertretern Kontakt aufnehmen würde, um die entstandenen Komplikationen zu bereinigen $\aleph^{208}$.

Schon Ende Mai war eine DDR-Delegation bestehend aus Fernsehtechnikern und Beamten des Ministeriums für Post- und Fernmeldewesens in Moskau gewesen, um eine gemeinsame ostdeutsch-sowjetische Strategie für die anstehenden Verhandlungen der DDR mit der CFT über eine mögliche Übernahme des SECAM-Systems auszuarbeiten ${ }^{209}$. Nachdem man in Moskau beschlossen hatte, das Thema Farbfernsehen in den »Vertrag zwischen den Regierungen der UdSSR und der DDR über die Erweiterung und Vertiefung der wissenschaftlich-technischen Zusammenarbeit zwischen beiden Ländern auf einigen wichtigen Zweigen der Wissenschaft und Technik « aufzunehmen, war zwei Mitarbeitern des Rundfunk- und Fernsehtechnischen Zentralamtes auch das NIR-System vorgeführt worden ${ }^{210}$.

Wie sich später zeigen sollte, funktionierte auch die sowjetisch-ostdeutsche Kooperation auf dem Gebiet des Farbfernsehens auf dem Papier wesentlich reibungsloser als in der Realität. Der Probst-Bericht über das Treffen mit Gwishiani ist aber aus einem anderen Grund von Interesse, da er auf eine Tatsache hinweist, die in der kommenden Schilderung der »NIR-Debatte« immer

208 »Information über eine Aussprache zwischen dem Stellvertreter des Ministers für Post- und Fernmeldewesen, Genosse Probst, und dem Stellvertreter des Vorsitzenden des Staatlichen Komitees für die Koordinierung der Forschungsarbeiten der UdSSR, Genosse Gwishiani, am 3.6.1965 von 18:30 bis 20:30«, Berlin, 4.6.1965, in: Bundesarchiv Coswig, Signatur DM $3 / 8290$.

209 Bezüglich dieser Abstimmung heißt es im Bericht des Leiters der Abteilung Planung und Technik im Ministerium für Post- und Fernmeldewesen, Lipfert: "Bezüglich des taktischen Vorgehens wurde empfohlen, daß beide Seiten nach gemeinsam abgestimmten Richtlinien die Verhandlungen mit Frankreich führen. Dadurch soll erreicht werden, daB einerseits die UdSSR im Rahmen der Interessen der DDR auf Frankreich Einfluß nehmen kann, andererseits aber verhindert wird, daB Frankreich mit beiden Staaten Abkommen zu unterschiedlichen Bedingungen abschlieBt«. Bericht von Lipfert, Leiter der Abteilung Planung und Technik im Ministerium für Post- und Fernmeldewesen, über Reise nach Moskau bez. Zusammenarbeit auf dem Gebiet des Farbfernsehens, Berlin, 2.6. 1965, 12 maschinegeschriebene Seiten, in: Bundesarchiv Coswig, Signatur DM 3/8290.

210 Bericht von Probst an Schulze, Berlin, 25.6.1965, über die Beratungen vom 26.-31.05.1965 in Moskau zur »Prüfung der Möglichkeiten der wissenschaftlich-technischen Zusammenarbeit auf dem Gebiet des Farbfernsehens zwischen der DDR und der UdSSR «, in: Bundesarchiv Coswig, Signatur DM 3/8290. 
wieder auftauchen wird: die unterschiedlichen Interessen von politischen und technisch-wissenschaftlichen Entscheidungsträgern in der Endphase der europäischen Farbfernsehdiskussion. Je näher das Datum der CCIR-Vollversammlung von Oslo im Juli 1966 rückte - der letzten Gelegenheit zur Realisierung eines einheitlichen europäischen Farbfernsehstandards -, desto intensiver wurden die Bemühungen derjenigen Akteure und Institutionen, die diese Einigung unter allen Umständen erreichen wollten. Zu dieser Gruppe zählten vor allen Dingen die Techniker und Ingenieure der nationalen Rundfunkanstalten, da genau ihre Institutionen waren, die am unmittelbarsten mit dem technischen Mehraufwand und den finanziellen Belastungen konfrontiert wurden, die die Einführung unterschiedlicher Farbnormen bedeutete.

Obschon man auf französischer Seite alle Anstrengungen unternahm, ein Bekanntwerden der sowjetischen Entwicklung zu verhindern, sprach sich das NIR-System wie ein Lauffeuer in den europäischen Technikerkreisen herum. Wie das bereits wiedergegebene Zitat des BBC-Chefingenieurs McLean - »a rumour is going round ${ }^{211}$ - beweist, kursierten die Gerüchte über das neue System bereits Anfang Juni in den Farbfernsehgremien der EBU und CCIR. McLean selber entfaltete in den folgenden Monaten eine ungeheure Aktivität, um das als potentielle europäische Kompromißlösung im Raum schwebende NIR-System systematisch zu untersuchen und es so für die anstehende CCIRDiskussion als europäische Alternative »hoffähig " zu machen. McLeans öffentlich bekundetes Interesse am NIR-System während der Tagung der EBU ad-hoc-Kommission in Hannover am 2. und 3. Juni brachten ihm sogar eine Rüge vom General Post Office ein, das ihn höflich aber bestimmt darauf hinwies, da $\beta$ er auf den EBU-Tagungen die Interessen der britischen Regierung, nicht die der BBC zu vertreten habe! Der Direktor des Radio Services im General Post Office, Lillicrap, hoffte zumindest, daß seine Intervention bei McLean nicht ohne Folgen bleiben werde: »Perhaps my comments will not be without effect for the future ${ }^{212}$. Allerdings machte sich McLean wenig aus diesen politischen Einmischungen und entwickelte sich bis zur Osloer Konferenz zum zentralen Akteur der Informations- und Werbearbeit für das NIR-System. Bevor diese Aktivitäten aber näher beschrieben werden, muß zuerst ein Blick auf die Reaktionen der Franzosen geworfen werden, deren Strategie durch das Erscheinen des NIR-Systems ernsthaft gefährdet zu sein schien.

211 Am 2. und 3. Juni tagte die EBU ad-hoc-Kommission in Hannover. Hier hatte BBC Chefingenieur Francis McLean die Gerüchte eines sowjetischen Systems aufgeschnappt und sich daraufhin an die britische Botschaft in Moskau gewandt, um nähere Informationen zu diesem System erhalten zu können. Siehe Brief von McLean (BBC) an Garrett (britische Botschaft Moskau), London, 9.06.1965, in: PRO, Signatur HF 10/3.

212 Brief von Lillicrap (GPO) an Merriman, Deputy Engineer-in-Chief, London, 5.07.1965, in: PRO, Signatur HO 256/387. 
Während der Monate Juni, Juli und August versuchte man im Informationsministerium einzuschätzen, welches die politischen und technisch-industriellen Konsequenzen waren, die mit dem Erscheinen des NIR-Systems verbunden waren. Dabei waren die Meinungen und Ratschläge, die sich Informationsminister Alain Peyrefitte von seiten des Außenministeriums und der ORTF einholte, durchaus wenig ermunternd. Sowohl das Quai d'Orsay als auch das "Office " machten aus ihrer Zuneigung für das NIR-System als potentieller europäischer Einheitslösung keinen Hehl. So scheute sich Olivier Wormser in seiner Eigenschaft als Direktor der Finanzabteilung des Quai d'Orsay in einem Brief an Peyrefitte nicht davor, vor den Folgen einer erneuten europäischen Isolation Frankreichs zu warnen: »Au point où en sont les choses, la question me paraît être la suivante: le Gouvernement Français veut-il adopter, en matière de télévision en couleurs, un procédé technique que les autres pays de l'Europe occidentale n'adopteront très vraisemblablement pas? Veut-il, dans ce domaine, répéter l'expérience déjà faite en matière de télévision en blanc et noir ${ }^{213}$ ? Die französische Regierung, so Wormser weiter, müsse in seinen Augen eine definitive Wahl treffen. Entweder müsse sie die Durchsetzung des SECAM-Systems mit allen politischen und wirtschaftlichen Mitteln und entsprechenden Konsequenzen vorantreiben, oder die Herbeiführung eines einheitlichen europäischen Standards unterstützen, was für Wormser gleichbedeutend mit der Aufgabe des SECAM-Systems zugunsten der PAL- oder NIR-Variante war.

Auch die Ingenieure der ORTF zeigten ein lebhaftes Interesse an der sowjetischen Systemvariante, auch wenn sie dieses Interesse gegenüber dem Informationsministerium offiziell nicht zum Ausdruck bringen durften! Hinter verschlossenen Türen, so bezeugen zahlreiche ORTF-Ingenieure in Interviews, wurde fleißig mit dem NIR-System experimentiert ${ }^{214}$. Trotz dieser versteckten Aktivitäten setzte sich letztlich der ursprünglich anvisierte politische Kurs durch. Nicht zuletzt deshalb, weil sich de Gaulle im Juli massiv für eine aktivere Rolle der französischen Politik in der SECAM-Frage stark machte. In einer Gesprächsnotiz vom 21. Juli notierte Alain Peyrefitte: "Le Général de Gaulle a déclaré: >Ne vous laissez pas endormir pour la télévision en couleur. Rien ne s'est fait depuis plusieurs mois. On ne marque pas le progrès que l'on devrait marquer. Il faudra que vous en parliez au Conseil le moment venuc. Et il a ajouté: >Ne vous laissez pas faire par les Allemands « ${ }^{215}$.

213 Brief von Olivier Wormser an Alain Peyrefitte, Paris, 18.08.1965, 4 maschinegeschriebene Seiten, in: Archives du MAE, Affaires Économiques et Financières, Affaires Générales, Nr. $220 \mathrm{c}$. 214 Siehe Interviews mit Claude Mercier, Jean-Jacques Matras, Jacques Fagot, in: Archives du CHTV/INA sowie die Interviews des Autors mit Jacques Fagot, Gérard Melchior, Yves Angel und Louis Goussot.

215 Note von Alain Peyrefitte an Jean-Jacques de Bresson, Paris, 21.07.1965, in: Archives du MAE, Affaires Économiques et Financières, Affaires Générales, Nr. 220c. 
Am 3. September beschloß die französische Regierung in einer Kabinettssitzung, daß man gemäß dem französisch-sowjetischen Farbfernsehabkommen alles daran setzen solle, das französische SECAM-System mit Hilfe der Sowjetunion bei einer gröBtmöglichen Zahl von Ländern als Farbfernsehwahl durchzusetzen. Zudem beschloB die Regierung, der CSF einen Kredit von 70 Millionen französischen Franken zu gewähren, damit sie entsprechende Entwicklungs- und Werbeaktivitäten entfalten konnte ${ }^{216}$. Um den französischsowjetischen Farbfernsehvertrag gemäß seiner Bestimmungen zu erfuillen, so schrieb Alain Peyrefitte an François Laboulaye, müsse man die wahren Hintergründe der sowjetischen NIR-Initiative ergründen, um so entsprechenden politischen Druck auf die Sowjetunion ausüben zu können ${ }^{217}$.

Obwohl sich de Gaulle zufrieden über den Kabinettsbeschluß vom 3. September zeigte, vermutete er, daß man im Quai d'Orsay die SECAM-Angelegenheit nicht mit dem politischen Elan verfolgte, der in seinen Augen angemessen gewesen wäre ${ }^{218}$. Am 7. September unterrichtete Peyrefitte seinen Kabinettschef Jean-Jacques de Bresson über ein Gespräch, in dem er den General über den Kabinettsbeschluß informiert habe: »Il [de Gaulle, A.d.V.] approuve qu'on ait écarté l'idée de s'entendre avec le PAL. Il se méfie d'une tentation qu'éprouveraient, selon lui, M. de Laboulaye et les Services de l'ORTF, de se mettre d'accord avec les Allemands pour assurer une fallacieuse unité occidentale, à laquelle, pour sa part, il ne croit pas et où il voit

216 Brief von Alain Peyrefitte an Jacques Bernard Dupont, Generaldirektor der ORTF, Paris, 8.09.1965, in: ibid. In diesem Brief unterrichtet Peyrefitte Dupont von der Entscheidung der Regierung und empfiehlt diesem im Anschrieben, »de vous inspirer des indications contenues dans ce document«. Dies könnte, so die Vermutung des Autors, als Anspielung auf die in den Augen des Informationsministers zu zaghafte Unterstitzung des SECAM-Systems seitens der ORTF interpretiert werden.

217 Brief von Alain Peyrefitte an François Laboulaye: »Instructions reiatives à des missions à accomplir en URSS et en Italie«, Paris, ohne Datum (wahrscheinlich 8.09.1965), 5 maschinegeschriebene Seiten, in: ibid.

218 De Gaulle klagte in einem Gespräch mit Peyrefitte am 23.09.1965 darüber, daß man nun endlich die Widerstände in eigenen Lager überwinden müsse, um die SECAM-Angelegenheit zu einem erfolgreichen Ende zu führen: "Dans tout ça, on ne s'est pas débarrassé des arrière-pensées. Il y a celles des électroniciens. Du fait que la CSF, Ponte et de France ont un procédé, les concurrents sont contre, automatiquement, d'instinct. [...] Et puis, il y a les arrière-pensées du Quai d'Orsay, qui cherche toujours l'arrangement, par définition. Il n'a jamais fait que ça de sa vie. L'intérêt national, pour lui, est toujours secondaire. [...] Il y a même des arrière-pensées dans l'ORTF. Car, pour lui, le plus facile [le plus important?, A.d.V.], c'est l'échange des programmes. [...] Tout ça fait que cette affaire importante au point de vue national, faire triompher un procédé français et le faire adopter par l'Europe, ou tout au moins par une large partie de l'Europe, de préférence à un autre, se dilue dans l'esprit de beaucoup. On n'y va pas carrément«. Zitiert nach Peyrefitte: C'était de Gaulle, Bd. 2, S. 541. 
surtout le moyen pour l'Amérique de nous dominer. Il estime indispensable d'aller de l'avant avec les Russes ${ }^{219}$.

Verantwortlich für die schleppenden Fortschritte machte de Gaulle vor allem den Ministre plénipotentiaire und FRANTECO-Chef François de Laboulaye. Bevor dieser von Peyrefitte als SECAM-Minister eingesetzt wurde, war Laboulaye als »Chargé d'Affaires « in Diensten des Quai d'Orsay in Moskau tätig gewesen. In den Augen de Gaulles fühlte sich Laboulaye aus diesem Grunde noch immer dem "falschen « Denken des Quai d'Orsay verpflichtet, das darin bestand, eine Kompromißlösung zu finden. De Gaulle setzte sich aus diesem Grund Mitte September 1965 energisch dafür ein, daß Laboulaye augenblicklich von seinen Funktionen entlassen werde ${ }^{220}$. In einem Telegramm an Außenminister Couve de Murville, der gerade an der Generalversammlung der UNO in New York teilnahm, berichtete Peyrefitte diesem von der Entschlossenheit de Gaulles, die SECAM-Angelegenheit mit neuem Schwung und neuem Personal anzugehen:

Comme vous le savez, le Général de Gaulle avait, voici quelques jours, très nettement indiqué au Premier Ministre qu'il était opposé à l'envoi en mission a Moscou de François Laboulaye. [...] Le Chef de l'État est visiblement convaincu que toutes les administrations intéressées au problème de la télévision en couleur souhaitent au fond d'elles-mêmes qu'une fusion, sous une forme ou sous une autre, intervienne entre les procédés SECAM et PAL $[\ldots]^{221}$.

Allerdings, so Peyrefitte weiter, habe er Laboulaye noch nichts von dieser Entscheidung de Gaulles mitgeteilt. Vielleicht könne der Außenminister diese Frage nach seiner Rückkehr in die Hand nehmen - »il reste à trouver la formule qui permettra de dégager notre collègue de ses obligations sans le blesser ou le vexer inutilement ${ }^{222}$ ! Als mögliche Nachfolger für Laboulaye hatte Peyrefitte unter anderem Olivier Wormser, den Polytechniker Chesson sowie seinen technischen Berater im Kabinett, Jacques Thibau, ins Auge gefaßt. Da Wormser - wie gesehen - aus seiner Reserviertheit gegenüber der SECAM-Politik des Generals kein Geheimnis machte, kam dieser für Peyrefitte nicht mehr für diesen Posten in Frage. Dagegen waren sich Couve de Murville und Peyrefitte darin einig, daß sich der Polytechniker Chesson wegen seiner doppelten Ausbildung als Diplomat und Ingenieur auf besondere Weise für diesen Posten eigne, da ihm weder die Ingenieure der ORTF noch

219 Note von Alain Peyrefitte an de Bresson, Paris, 7.09.1965, in: Archives du MAE, Affaires Économiques et Financières, Affaires Générales, Nr. 220c.

220 Seinem Informationsminister machte de Gaulle in deutlichen Worten klar, daß er wünsche, »que François Laboulaye fôt immédiatement et totalement déchargé des responsabilités qui lui avaient été confiées en la matière. " Dieses berichtete Informationsminister Peyrefitte dem AuBenminister Couve de Murville in einem Telegramm. In: Archives du MAE, Affaires Économiques et Financières, Affaires Générales, Nr. 220c.

221 Ibid.

222 Ibid. 
die der CFT etwas vormachen könnten ${ }^{223}$ ! Aus welchen Gründen letztlich Jacques Thibau als Nachfolger von François Laboulaye bestimmt wurde, konnte aus den Quellen nicht rekonstruiert werden ${ }^{224}$.

Die von de Gaulle angesprochene Mission nach Moskau zielte darauf, daß sich einige Ingenieure der ORTF ein detaillierteres Bild vom NIR-System machen sollten. Damit ein von politischen Beziehungen unabhängiges Urteil möglich wurde, schickte CSF-Generaldirektor Maurice Ponte seinen Technischen Direktor, Jacques Fagot, wenige Tage vor der ORTF-Mission ebenfalls nach Moskau. Vom 23. bis 29. September hatte Fagot die Gelegenheit, die technischen Details des NIR-Systems in Moskau zu studieren ${ }^{225}$. Fagots Bericht blieb jedoch nicht lange geheim. Bereits einen Tag nach seiner Rückkehr besuchte er die Ingenieure der ORTF, die wenige Tage später zu ihrer Mission aufbrechen sollten. Aus technischer Sicht lautete Fagots vorsichtiges Urteil, daß das NIR-System in einigen Bereichen durchaus Verbesserungen gegenüber dem SECAM-System vorweisen konnte, Fragen wie magnetische Aufzeichungsmöglichkeiten oder die Definition der geforderten Exaktheit der benötigten Verzögerungsleitung hingegen noch völlig im Dunkeln geblieben waren. Insgesamt schätzte Fagot, und dies war von zentralem Interesse für Maurice Ponte und die politischen Stellen, daß die Sowjets durchaus ernsthafte Ambitionen mit dem NIR-System verfolgten. War die Entwicklung des NIR-Systems bislang als reine Ambition einer kleinen Technikergruppe angesehen worden, zeigten - so Fagot - nun auch die politischen Funktionäre des KNIR mehr und mehr Interesse am NIR-System ${ }^{226}$.

${ }^{223}$ In einem Bericht über ein Gespräch zwischen Peyrefitte und Couve de Murville heißt es: »[...] Je [Peyrefitte] lui [Couve] indique que, polytechnicien, et admis à Normale Sciences, Chesson est en mesure de ne pas s'en laisser conter par les techniciens, soit de l'ORTF, soit de la CSF. Il [Couve] vérifie aussitôt cette origine dans l'annuaire et admet que de pareils titres, uniques dans la carrière diplomatique depuis la mort de Paris, font de lui un candidat tout désigné à la succession de Laboulaye«. Dieses Zitat verdeutlicht auf prägnante Weise das Elitedenken in der französischen Personalpolitik, so wie es von Pierre Bourdieu in seiner Studie "La noblesse d'État« untersucht worden ist. Siehe »Note pour M. de Bresson sur la conversation avec M. Couve de Murville le mardi 19 octobre 1965« von Alain Peyrefitte, Paris, 22.10.1965, in: Archives du MAE, Affaires Économiques et Financières, Affaires Générales, Nr. 220c.

224 In einer Gesprächsnotiz heiBt es über Thibau: »J'explique à Couve l'intérêt qui s'attache au maintien de la cellule FRANTECO et, tout en chargeant Thibau de s'occuper de plus en plus de la télévision en couleur, je ne crois pas possible de ne pas donner de successeur à Laboulaye.« Siehe "Note pour M. de Bresson sur la conversation avec M. Couve de Murville le mardi 19 octobre 1965 « von Alain Peyrefitte, Paris, 22.10.1965, in: Ibid.

225 Ein ausführlicher, 12 seitiger Reisebericht von Fagot findet sich in: Archives du CHTV/NA, Nachlaße Michel Dubail.

226 "M. Fagot est convaincu que les Russes tiennent plus que jamais au NIR. Il s'est rendu compte que les fontionnaires du KNIR, neutres jusque là, ont maintenant tourné casaque et pris position en faveur du NIR." So der Bericht des ORTF-Ingenieurs Jean-Jacques Matras an Jacques Thibau, Paris, 30.09. 1965, in: Archives du MAE, Affaires Économiques et Financières, Affaires Générales, Nr. 220c. 
Genau diese Einschätzung beunruhigte CSF-Chef Maurice Ponte, der davor warnte, die Russen nun politisch unter Druck zu setzen, indem man sie vor die Wahl stelle: entweder SECAM (CSF) oder NIR. Der Grund für Pontes Beunruhigung war selbstverständlich, daß er um die erfolgreiche Abwicklung der im Anhang zum französisch-sowjetischen Farbfernsehvertrag vereinbarten Geschäfte mit den Russen fürchtete ${ }^{227}$. Am 2. Oktober fand auch im Informationsministerium eine Auswertung der Fagot-Reise statt. CFT-Generaldirektor Henri Peyroles berichtete Kabinettschef Jean-Jacques de Bresson in einem langen Gespräch über die Eindrücke, die Fagot in Moskau hatte sammeln können. Peyroles wies erneut auf die aus Sicht der CSF sehr kritische Situation hin und brachte den Wunsch zum Ausdruck, "qu'on lui [Maurice Ponte, A.d.V.] laisse le temps d'achever la négociation de ses contrats industriels avant que la discussion ne soit, sur le plan français, portée sur un plan politico-industriel «228. Damit man die sowjetische Seite aber nicht vor den Kopf stoße, so Peyroles, müsse man ihnen ersthaftes Interesse am NIRSystem vorspielen und sowjetische Techniker zu diesem Zweck nach Paris einladen:

La position de M. Ponte est au fond la suivante: Il faut accepter d'examiner le NIR pour ne pas braquer les Russes et risquer de faire échouer les négociations industrielles CSF/KNIR; cet examen doit viser à démolir le NIR, c'est-à-dire à prouver aux soviétiques que le NIR sc'est un PAL qui n'ose avouer son nom،. Mais il faut le démolir 'gentiment،, de façon à aider les milieux soviétiques qui, dans cette affaire, sont pour le SECAM, par exemple M. Gvichiani; [...] plus on gagne du temps, moins les soviétiques seront en mesure de tenir la date de l'automne 1967 pour faire démarrer la télévision en couleur ${ }^{229}$.

Diese Ausführungen machen klar, daß sich die strategischen Interessen der Industrie bzw. der CSF/CFT deutlich von denen der politischen Institutionen, allen voran von denen des Informationsministeriums und de Gaulles, unterschieden. Während der Kabinettsbeschluß vom 3. September die Weisung zu einer verstärkten politischen Offensive zur Durchsetzung des SECAM-Systems erteilt hatte, plädierte Ponte zu politischer Zurückhaltung, um seine industriellen Vertragsabschlüsse nicht zu gefährden. Pontes Situation wurde dadurch erschwert, daß die CSF insgesamt in einer kritischen finanziellen Lage war, die es dem Unternehmen unmöglich machte, weitere finanzielle Risiken

227 »M. Ponte observe que les Russes exercent sur lui un chantage: >si vous n'acceptez pas le NIR, vous n'aurez pas vos accords industriels $\varsigma$. M. Ponte n'a pas caché à M. Matras que la conclusion de ces accords industriels >le préoccupait plus que tout $\diamond »$. Siehe $»$ Note pour le Ministre a.s. communication de $\mathbf{M}$. Matras sur son entretien du 30 . septembre avec M. Fagot «, angefertigt von Philippe Olivier, Paris, 30. September 1965, in: Ibid.

228 Bericht über das Gespräch zwischen Jean-Jacques de Bresson und Henri Peryroles vom 2.10. 1965, Paris, 13. Oktober, 5 maschinegeschriebene Seiten, in: ibid, hier S. 2.

229 Ibid. S. 3. 
bezüglich SECAM auf sich zu nehmen ${ }^{230}$. Bereits im August 1965 wurden daher Gespräche zwischen Ponte und dem französischen Selfmade-Millionär Floirat aufgenommen ${ }^{231}$, der sich an einem Einstieg in das Farbfernsehgeschäft interessiert gezeigt hatte ${ }^{232}$. Erschwerend kam hinzu, daß die ORTF-Ingenieure nach ihrem Besuch in Moskau die Chance witterten, das NIR-System wegen seiner Zwitterstellung - ein bißchen PAL (Amplitudenmodulation), ein bißchen SECAM (Verzögerungsleitung) - als europäische Kompromißlösung hoffähig machen zu können.

Während ihrer Moskau-Reise Anfang Oktober 1965 hatten die ORTF-Ingenieure ohne Abstimmung mit dem Informationsministerium den »Erfinder" des sowjetischen NIR-Systems, Prof. Tesler, nach Paris eingeladen, um dort eine ausführliche Demonstration des Systems zu machen. Dieser Besuch soll-

230 Die hohen Verluste, die die CSF in den Jahren 1965 und 1966 einfahren sollte, führten 1967 sogar dazu, daß Ponte seinen Posten als Generaldirektor der CSF aufgrund des Druckes einer jüngeren Gruppe innerhalb des Managements von CSF und unter Führung der Banque de Paris et des Pays Bas (die mit $30 \%$ an der CSF beteiligt war) aufgeben mußte. Siehe Aktennotiz von Dr. Felix Herriger über eine Besprechung mit Botschafter a.D. Freiherr von Welck, Ulm, 16.08. 1967, in: AEG-Telefunken-Archiv, Deutsches Technikmuseum Berlin, Signatur GS 7954. Von Welck vertrat seit April 1967 die Interessen der CSF in Deutschland und war aus diesem Grunde an den CSF/Telefunken-Verhandlungen über das "Nichtangriffs-Abkommen « beteiligt, das im Februar 1968 die Patentstreitigkeiten zwischen beiden Unternehmen friedlich regelte.

${ }^{231}$ Zur Charakterisierung der Person Floirats heiBt es in einer Notiz über eine Besprechung zwischen Dr. Eckert (Telefunken Frankreich) und M. Gruson (CSF) vom 4.3.1966 in Paris: »Der (baldige) dritte Gesellschafter der CFT, M. Floirat, scheint ein ausgesprochener Selfmademan zu sein. Er hat zuerst mit einer kleinen Karosseriefabrik angefangen, später eine Reihe von Transportunternehmen aufgekauft und mit dem daraus verdienten Geld aus Heeresbeständen in Indochina spottbillig Flugzeuge aufgekauft. Aus deren späterer Rückvermietung an die französische Regierung sind ihm Millioneneinnahmen zugeflossen, deren Transfer aus Indochina nach Frankreich ihm jedoch nur unter der Bedingung zugestanden wurde, daB er die damals illiquide RadioFrance mit einem Teil des Geldes übernehme und stütze. Dies hat er getan, und eine der Tochtergesellschaften der Radio-France ist Europe 1. Die Vermutung, daB M. Floirat, dem auch die Flugzeugfabrik Breguet gehört, seine vitale Persönlichkeit in den Dienst der von de Gaulle geförderten SECAM-Sache stelle, um damit vermehrt Aufträge der französischen Regierung bei Breguet zu erreichen, wurde von $M$. Gruson für durchaus nicht abwegig gehalten.« In: AEG-Telefunken-Archiv, Deutsches Technikmuseum Berlin, Signatur GS 7954.

232 Alain Peyrefitte berichtete seinem Kabinettschef am 28.09.1965 über Gespräche, die er mit Floirat gefuihrt habe. Floirat sage, daB Ponte das bisher von der CSF und Saint-Gobain in die CFT investierte Kapital auf 3 Milliarden alte Francs schätze. Ponte und Vogue (Chef Saint-Gobain) seien einverstanden, daB Floirat ein Drittel des Kapitals sowie den Vorsitz der CFT übernehme. Floirat sei bereit, neben der einen Milliarde $(=1 / 3$ des bisher investierten Kapitals) weitere hundert Millionen alte Francs »Eintrittsgeld « zu bezahlen. Außerdem verlangte Floirat von Peyrefitte (bzw. vom französischen Staat) Kredite in Höhe von 2 Milliarden alte Francs, um die SECAM-Aktivitäten entsprechend ausbauen zu können. Peyrefitte berichtet an dieser Stelle auch darüber, daB der französische Staat Ponte einen weiteren Kredit in Höhe von 3,5 Milliarden alte Francs gewähren werde, um die von der CSF erfundene neue Farbfernsehbildröhre produktionsreif zu machen. Siehe »Note pour M. Bresson«, Paris, 28.09. 1965, in: Archives du MAE, Affaires Économiques et Financières, Affaires Générales, Nr. $220 \mathrm{c}$. 
te noch vor der nächsten Sitzung der Commission mixte stattfinden, die für den 22. November angesetzt worden war. Diese in den Augen des Informationsministeriums äußerst ungünstige Konstellation veranlaßte Alain Peyrefitte dazu, seinen sowjetischen Kollegen Gwishiani während seines Besuches in Paris am 20. November um eine Vertagung des zweiten Zusammentreffens der Commission mixte zu bitten, "notamment au fait que les techniciens soviétiques n'aient pu, jusqu'à présent, participer aux essais de la variante NIR du SECAM effectués dans les laboratoires de l'ORTF « ${ }^{233}$. Gwishiani war mit der Vertagung einverstanden und schlug vor, daß sich die Kommission Ende Dezember treffen sollte. Doch auch dieser Termin konnte nicht eingehalten werden, da ein anderes Ereignis die französische Lage erneut erschweren sollte.

Wie bereits erwähnt, verbreitete sich die Kunde eines neuen sowjetischen Farbfernsehsystems trotz der französischen Geheimhaltungsbemühungen in den entsprechenden Expertenkreisen sehr schnell. Als sich die Teilnehmer der EBU ad-hoc-Kommission vom 7. bis 9. Dezember 1965 in Rom trafen, um über die weiteren Fortschritte im Bereich der Farbfernsehtechnik zu beraten, war das sowjetische NIR-System zum inoffiziellen Haupttagungspunkt geworden. Besonders die Italiener und die BBC zeigten großes Interesse am NIR-System, doch gab die französische Delegation zu verstehen, daß man noch keine detaillierten Informationen preisgeben könne, da die Untersuchungen des NIR-Systems auch in Frankreich noch in vollem Gange seien. Im Tagungsbericht des BBC-Chefingenieurs McLean hieB es diesbezüglich:

There was a very brief résumé to the meeting of the principles of the system, but the French would not in open meeting give any more particulars because they had not yet officially accepted it. In private however particulars give. [...] There is clearly a struggle going on in France. The CFT people are fighting for the conventional SECAM, but we were told that ORTF has made an official request to the French govermment that they should switch their support to the Russian proposal. [...] the RAI man said to me, did not this new Russian system represent the compromise for which we had all been looking ${ }^{234}$ ?

Ein Beobachter des britischen Postministeriums während der Tagung in Rom berichtete sogar, daß ihn der schwedische Delegationsleiter und Vorsitzende der Studiengruppe XI (Fernsehen), Erik Esping, darum gebeten habe, sich beim britischen Postminister dafür einzusetzen, die britische Entscheidung für das PAL-System noch herauszuzögern, da sich mit dem NIR-System eine

233 Telegramm von A. Jordan, Quai d'Orsay, an die französische Botschaft in Moskau, Paris, 23.11.1965, in: Archives du MAE, Affaires Économiques et Financières, Affaires Générales, Nr. 220d.

234 Siehe den von Mclean verfassten "Report of the EBU ad hoc meeting in Rome«, in: PRO, Signatur: HO 256/387. 
echte Chance für das Zustandebringen eines einheitlichen europäischen Standards eröffne ${ }^{235}$.

Auf bundesdeutscher Seite, besonders bei Telefunken, wurde die französische Zurückhaltung als Scheitern der französisch-sowjetischen Beziehungen gedeutet. Gleichzeitig stand aber für Telefunken fest, daß das NIR-System wegen mangelhafter Möglichkeiten zur internationalen Untersuchung der technischen Parameter als ernsthafte Alternative in Oslo nicht auftauchen könne $^{236}$. In Paris sorgte dieses internationale Interesse am NIR-System für Unbehagen, aber man war sich der Tatsache bewußt, daß eine Abweisung dieser Interessen nach den Gepflogenheiten internationaler Zusammenarbeit auf dem Gebiet der Rundfunktechnik kaum möglich sein würde ${ }^{237}$. Während die ORTF-Ingenieure dem NIR-System durch die Umbenennung in SECAM IV politisch den Rücken zu stärken versuchten, wurden im Informationsministerium die strategischen Konsequenzen durchgespielt, die ein offizielles Eintreten Frankreichs für das NIR-System haben könnte.

Während Außenminister Couve de Murville und der noch immer im Amt befindliche FRANTECO-Chef Laboulaye den Bericht der ORTF-Delegation aus Rom dahingehend deuteten, daß man in bilateralen Gesprächen mit Ländern wie der Bundesrepublik, der Schweiz, Italien und sogar Großbritannien versuchen sollte, dem NIR-System zum Durchbruch als neuem europäischen Standard zu verhelfen ${ }^{238}$, fiel die Analyse des Ministerkollegen Peyrefitte an-

235 Brief von Clinch, General Post Office-observer at the EBU-Conference in Rome, 8.12.1965, in: PRO, Signatur: FO 371/181315, General Department, Akte GT 41/142.

236 In einem Vermerk von Dr. Freibüter vom Fernsehreferat des BPIA vom 1. Februar heiBt es: "Trotz Befragens innerhalb der UER sind die Franzosen bislang nicht bereit gewesen, den zuständigen AusschuB der UER über die russische SECAM-Variante zu informieren. Der Vorsitzende des zuständigen technischen Ausschusses, der auch in Wien bei der Tagung des CCIR die entsprechende Leitung hatte, der Schwede Esping, steht auf dem Standpunkt, daB in Oslo, wo die Entscheidung gefällt werden muB, nur über drei Systeme diskutiert werden kann (NTSC, SECAM, PAL), da ein viertes Verfahren dem AusschuB bislang nicht zur Kenntnis gebracht worden ist. Würde das noch geschehen, so müBte dieses Verfahren erst geprüft werden. Eine Prüfung würde einige Jahre in Anspruch nehmen. So lange könnte die Entscheidung nicht hinausgeschoben werden. Die Entscheidung muB in diesem Sommer in Oslo fallen. Man ist sicher, daB die Entscheidung mit großer Mehrheit für PAL fallen wird $\kappa$. In: Bundeszwischenarchiv Bonn, Signatur B 145/2864.

237 "Il me parait de plus en plus difficile de ne pas satisfaire la curiosité que manifestent les membres de l'UER à l'endroit des essais dont ils savent parfaitement qu'ils se déroulent à l'ORTF sur le procédé NIR-SECAM IV. Une telle attitude serait contraire aux usages, les ingénieurs des instituts de radio-télévision européens ayant depuis longtemps adopté le plus grand libéralisme quant aux échanges entre eux de renseignements techniques. « Siehe Note "Intérêt manifesté par les pays d’Europe occidentale pour le SECAM IV «, Paris, 6.01.1966, in: Archives du MAE, Affaires Économiques et Financières, Affaires Générales, Nr. 220d.

238 „Note pour M. de Bresson/a.s. télévision en couleurs«, Paris, 11.12.1965, in: ibid. Der ORTF-Ingenieur Jean-Jacques Matras erinnerte sich in einem Interview aus dem Jahre 1985 daran, daB Laboulaye dieses Eintreten nicht gut bekommen sei: "Il [Laboulaye] s'est révélé un par- 
ders aus. Im Informationsministerium kam man zu dem Schluß, daß ein "Wechseln des Pferdes inmitten des Rennens ${ }^{239}$ aus industrieller wie aus politischer Sicht nur Nachteile mit sich bringen würde. In einer zehnseitigen Stellungnahme teilte man François Laboulaye und dem Quai d'Orsay mit, daß die ORTF-Ingenieure zwar festgestellt hätten, daß es sich beim NIR-System um eine SECAM-Variante handeln würde, es sich in Wirklichkeit jedoch um ein System »à mi-chemin entre le SECAM-CSF et le PAL « handele. Die Aufnahme von bilateralen Gesprächen würde daher mit Sicherheit als Schwächung der französischen Position aufgenommen werden. Außerdem bestünde die Gefahr, so die Einschätzung von Jean-Jacques de Bresson, daß es auf Seiten der SECAM-Gegner zu folgendem Kalkül kommen könnte: Wenn man in sich Frankreich für das NIR-System entschieden habe, das daran ließen die Techniker keinen Zweifel - im Grunde mehr Verwandtschaft zum PAL-als zum SECAM-System aufweise, werde der nächste Schritt der PAL-Anhänger aus der Forderung bestehen, aus diesem Grunde doch gleich das NIR-System zugunsten des PAL-Systems aufzugeben ${ }^{240}$ !

Ohne weiter auf die taktisch-strategischen Überlegungen eingehen zu können, stand die Handlungsanweisung für den neuen Leiter ${ }^{241}$ der französischen Delegation bei der zweiten Sitzung der Commission mixte, Kabinettschef Jean-Jacques de Bresson, Mitte Januar 1965 fest: Weitere Untersuchung des NIR-Systems durch die technischen Experten beider Länder sollten stattfinden, aber keinenfalls sollte das französisch-sowjetischen Farbfernsehvertrag festgelegte Ziel aufgegeben werden, ein französisch-sowjetisches System „basé sur le procédé SECAM et de son standard» in beiden Ländern zur Ein-

tisan du SECAM IV [...] il avait une fonction importante au Quai d'Orsay, il a été aussitôt limogé«. Siehe Interview von Hélène Eck mit J.-J. Matras, September 1985, fünfseitige Transkription, in: Archives du CHTV/INA.

239 Im französischen Original heißt es »changer de cheval au milieu du gué«. Die komplizierte Abwägung der einzelnen Perspektiven (Vor- und Nachteile aus industrieller und politischer Perspektive) ist ausgiebig dokumentiert in der »Note a.s. de la Télévision en couleur« von Philippe Olivier für J.-J. de Bresson, Paris, 7.12.1965, 11 maschinegeschriebene Seiten, in: Archives du MAE, Affaires Économiques et Financières, Affaires Générales, Nr. 220d.

240 »Remarques sur la note du 10 décembre 1965 remise à M. le Ministre des Affaires Etrangères par le President de FRANTECO «, verfaßt von Jean-Jacques de Bresson, Paris, 22.12. 1965, 10 maschinegeschriebene Seiten, in: ibid.

241 Im Zuge der Kabinettsumstellung der Regierung Pompidou am 8. Januar 1966 wechselte Alain Peyrefitte auf den Posten des Wissenschaftsministers. Sein Nachfolger im Amt des Informationsministers wurde Yvon Bourges. Auf besonderen Wunsch von de Gaulle wurde Peyrefitte jedoch weiterhin mit allen Fragen des Farbfernsehens betraut. Peyrefittes Kabinettschef, JeanJacques de Bresson, wechselte auf den Posten des Directeur du Service Juridique im Außenministerium, blieb auf Wunsch von Peyrefitte jedoch ebenfalls mit den Farbfernsehfragen betraut. Nach den Unruhen im Mai 1968 und der damit verbundenen Krise der ORTF wurde de Bresson im Juli 1968 als enger Vertrauter von de Gaulle mit dem Posten des Generaldirektors der ORTF betraut, den er bis 1974 innehatte. Zu den politischen Einflissen auf die Personalpolitik der RTF/ ORTF unter de Gaulle siehe Bourdon, Histoire de la télévision sous de Gaulle. 
führung zu bringen und - wenn möglich - als europäischen Standard durchzusetzen.

Mit genau diesen Empfehlungen gingen die beiden Delegationen nach der zweiten Sitzung der Commission mixte am 29. Januar 1966 auseinander. Es wurde eine Arbeitsgruppe gebildet, deren Aufgabe eine vertiefende Vergleichsuntersuchung der beiden Systemvarianten SECAM III und NIR - aus "political correctness« offiziell SECAM IV getauft - $\mathrm{war}^{242}$, so daß auf der nächsten Sitzung der Kommission eine definitive Entscheidung getroffen werden konnte ${ }^{243}$. Vor allem die Ingenieure der ORTF bemühten sich in der Folgezeit das NIR-System experimentell so weit zu erforschen, daß es kritischen Nachfragen bezüglich seiner technischen Brauchbarkeit von seiten interessierter CCIR-Länder standhalten würde. $\mathrm{DaB}$ die ORTF-Aktivitäten gar nicht im Sinne der CSF waren, geht aus folgendem Zitat des ehemaligen Technischen Direktors der CSF, Jacques Fagot, hervor: "Les gens de l'ORTF ont travaillé le système russe énormément, parce qu'ils étaient persuadés qu'on pouvait arriver à une solution européenne sur cette variante russe. [...] $\mathrm{La}$ CSF a eu une peur bleue que si l'on préconise la variante russe on arrive au PAL ${ }^{244}$.

In der Zeit zwischen der zweiten und dritten Sitzung der Commission mixte (29. Januar bis 13. April 1966) sollte aber nicht nur in Frankreich und der Sowjetunion an der NIR-Variante geforscht werden. Besonders in den Laboratorien der BBC wurde das NIR-System eifrig studiert. McLean selbst war Anfang Februar 1966 nach Moskau gereist, um sich in persönlichen Gesprächen u. a. mit Gwishiani ein Bild von der Haltung der Sowjetunion zum NIRSystem zu machen ${ }^{245}$. In den Gesprächen, die McLean während seines Moskauer Aufenthaltes mit den Beamten der britischen Botschaft hatte, machte

242 Jean-Jacques Matras erinnert sich bezuiglich der Namensgebung: »Au cours d'un voyage à Moscou, on nous a fait part du NIR, qui nous est apparut comme un bon compromis entre PAL et SECAM - sur le plan politique. [...] Ce système plus ou moins proposé par les soviétiques [...] et mis au point par nous, nous nous sommes mis dans la tête un peu bêtement que ce système pourrait faire l'unité. Comme nous savions que le Gouvernement, le Général de Gaulle en particulier, était très attaché au mot SECAM, nous avions reussi à convaincre tout le monde du nom SECAM IV ${ }_{\ll}$. Siehe Transkription des Interviews von Hélène Eck mit Jean-Jacques Matras, September 1985, in: Archives du CHTV/NA.

243 "Protocole de la $2^{\text {ème }}$ session de la Commission mixte franco-soviétique sur la télévision en couleur«, Paris, 29.01.1966, 11 maschinegeschriebene Seiten, in: Archives du CHTV/NA, Nachlaß Michel Dubail.

244 Siehe die Transkription des Interviews von Hélène Eck mit Jacques Fagot, 25.05. 1984, in: Archives du CHTV/INA. Dieses Urteil wurde dem Autor auch von den Interviewpartnern Louis Goussot, Gérard Melchior, Jacques Fagot und Yves Angel bestätigt.

245 Über dieses Treffen berichtet Baudet (frz. Botschafter in Moskau) in einem Telegramm an das Quai d'Orsay, Moskau, 24.2.1966, in: Archives du MAE, Affaires Économiques et Financières, Affaires Générales, Nr. 220d. McLean soll bei dieser Gelegenheit auch eine sowjetische Delegation zu Demonstrationszwecken nach London eingeladen haben. 
sich dieser für die neue sowjetische Variante stark. Botschaftsmitglied A. J. Williams berichtete dem Foreign Office am 4. März über McLeans Einstellung: »McLean told us that the performance of SECAM IV is very close to that of PAL, and that the BBC might well seriously consider lending their support to SECAM IV at the international meeting to be held at Oslo in June, if there seemed to be the likelihood of a European agreement on the basis of this system ${ }^{246}$.

Interessanterweise wurde das Interesse der BBC am NIR-System in Frankreich ganz anders gedeutet. Aus der französischen Botschaft in Moskau interpretierte man den Besuch McLeans dahingehend, daß man an ein Täuschungsmanöver der Briten glaubte: Die Briten wollten das NIR-System lediglich deshalb untersuchen, um in Oslo seine Schwächen aufzeigen zu können und es somit als mögliche europäische Alternative auszuschließen ${ }^{247}$ ! In England machte sich McLean mit seiner offenen Sympathie für SECAM IV jedoch nicht nur Freunde. Besonders im britischen Außenministerium war man über McLeans »Alleingänge « verärgert. Der Direktor der Radio Services im General Post Office, Lillicrap, der sich bereits im Juni 1965 über McLeans PAL-feindliche Haltung beschwert hatte, wandte sich am 24. März 1966 an dessen Vorgesetzten, den BBC-Generaldirektor Hugh Carleton Greene, um diesen von der Besorgnis der britischen Rundfunkgerätehersteller-Vereinigung (British Radio and Electronic Manufacturer Association, BREMA) zu unterrichten:

What chiefly bothers us is that the BBC have put in a lot of work on the NIR system and given a series of demonstrations to visitors from other European countries. It is fair to say that they have been careful to avoid press publicity for the demonstrations in this country. But it will clearly not help us to secure support for PAL if the BBC plays a prominent part in the development and demonstration of a rival system ${ }^{248}$.

246 Telegramm von Williams (Britische Botschaft Moskau) an Brown (Foreign Office), Moskau, 4.03.1966, in: PRO, Signatur FO 173/187373.

247 Telegramm von Baudet, französische Botschaft Moskau, an das Quai d'Orsay, Moskau, 24.02.1966, in: Archives du MAE, Affaires Économiques et Financières, Affaires Générales, Nr. 220d.

248 Brief von Lillicrap (GPO) an Greene, London, 24.03.1966, in: PRO, Signatur: HO 256/387. Lillicraps Kollege Stanesby, der eine Kopie des Briefes an Greene erhalten hatte, zeigte sich aber wenig zuversichtlich, daß man McLean »ruhigstellen « könnte: »I hope that your letter to Sir Hugh Greene will help to bring McLean in line. But I must confess my concern about the damage that has already been done and the possibility, indeed my belief, that McLean will continue to draw attention to the BBC's work on NIR «. Note von Stanesby an Lillicrap, London, 29.03.1966, in: PRO, Signatur: HO 256/387. Wie die folgende Geschichte beweist, sollte Stanesby in seiner Einschätzung recht behalten. Aus einer Notiz von Merriman (FO) vom 2.06. 1966 geht hervor, daB der Präsident der belgischen PTT kurz vor Beginn der CCIR-Tagung in Oslo um eine NIR-Demonstration der BBC bat. Da man im Postministerium Angst davor hatte, daß die BBC-Aktivitäten eine zu große Aufmerksamkeit erregen könnten, plante man nur den Chef der belgischen Postverwaltung Claeys und einem Assistenten unauffallig zu Vorführungen des NIR-Systems einzuladen. Daraus machte die BBC jedoch eine Aktion, an der Kollegen aus 
Greene war sich der zwiespältigen Lage durchaus bewußt und wies Lillicraps Bedenken zurück. Die BBC stehe weiterhin zu der Empfehlung des Television Advisory Committee, in Großbritannien das PAL-System einzuführen. Allerdings bestehe, so Greene in einem Schreiben an das Postministerium, weiterhin großes Interesse seitens der BBC an einem europaweiten Standard, beziehungsweise herrsche Sorge vor einer Spaltung Europas und damit auch Afrikas und Asiens. Wenn das NIR-System in Oslo nicht diskutiert würde, so Greene, wäre eine Spaltung sicher. Aber: »If NIR is put forward I think it is still very doubtful as to whether it would be accepted by all countries, but it is a possibility $\ll^{249}$.

Auch in der Bundesrepublik erkannte man die strategische Bedeutung des NIR-Systems. Der Technische Direktor des NDR, Dr. Hans Rindfleisch, berichtete auf mehreren Sitzungen der Technischen Direktoren der ARD von den Diskussionen über das NIR-System im Rahmen der EBU ad-hoc-Kommission und machte darauf aufmerksam, daß vor allem die »ärmeren « Länder in Oslo mit großer Wahrscheinlichkeit darauf drängen würden, das technisch noch unausgereifte NIR-System weiteren Studien zu unterziehen ${ }^{250}$. Dies weniger, weil sie von dessen technischer Überlegenheit überzeugt waren, sondern aus dem einfachen Grunde, weitere Zeit bis zur Einführung des Farbfernsehens zu gewinnen. Damit dieser Fall nicht eintrete, so berichtete Werner Nestel in einer Telefonnotiz, habe Rindfleisch ihn darum gebeten, von seiten der Rundfunkindustrie entsprechenden Druck zu machen ${ }^{251}$.

Genau dies tat man bei Telefunken seit Ende des Jahres 1965 in immer offensiverer Art und Weise. Besonders vor Auslandsreisen höherer Politiker, beispielsweise der Paris-Reise Erhards im Januar 1966, der Madrid- und Lissabon-Visite des Außenministers Schröder im März 1966 oder der Südamerikareise des Wirtschaftsministers Schmücker im Mai 1966, richteten sich die Vorstandskollegen Herriger und Nestel meist gemeinsam in einem Schreiben an die Herren Minister, um diesen entsprechende "Anregungen«

Holland, Irland, Spanien und Portugal beteiligt wurden. Im GPO war man darüber sehr erregt, schrieb McLean einen bösen Brief und brach die Aktion unmittelbar ab! In: PRO, Signatur HO 256/387.

249 Brief von Greene (BBC) an German (GPO), London, 25.03.1965, in: PRO, Signatur: HO $256 / 387$.

250 Belgien zählte sicherlich nicht zu den »ärmeren« Ländern im Sinne von Rindfleisch und war dennoch sehr an der sowjetischen NIR-Variante interessiert. Neben dem Grund der Verschiebung des Einführungstermins war bei vielen kleinen und vor allen Dingen mehrsprachigen Ländern, die im Falle einer SECAM-PAL-Spaltung mit erheblichen Mehrkosten auf Sender- und Empfängerseite konfrontiert werden würden, das Interesse am NIR-System als potentiellem Einheitssystem besonders groB.

251 Telefonnotiz von Nestel über vier Telefongespräche am 1.3.1966 mit Intendant Hess (ARD), Dr. Rindfleisch (NDR), Oberpostdirektor Müller (FTZ) und Dr. Broadway (EMI, London), in: AEG-Telefunken-Archiv, Deutsches Technikmuseum Berlin, Signatur GS 1646. 
über die politischen und wirtschaftlichen Interessen Deutschlands am PALSystem mit auf den Weg zu geben ${ }^{252}$. Auch verfaßte man bei Telefunken einen Entwurf zu einem Runderlaß des Auswärtigen Amtes, der allen diplomatischen Vertretungen der Bundesrepublik im Ausland zugeschickt werden sollte, um diese entsprechend zu instruieren. Der Wortlaut des Rundschreibens, das am 28. Februar verschickt wurde, läßt keinen Zweifel über die »Schuldfrage« zu, das heißt darüber, wem die zu diesem Zeitpunkt unklare techno-politische Lage zu verdanken sei. »Die französische Regierung hat von Anfang an die Ausbreitung des französischen Systems mit politischen Mitteln gefördert und diesbezüglich Vereinbarungen mit den Ostblockstaaten getroffen «, so der Wortlaut des Rundschreibens. Das Schreiben endete mit folgender Empfehlung des Ministerialdirigenten Diehl: »Für den Fall, daß von deutscher industrieller Seite in Ihrem Gastland Bemühungen unternommen werden, das deutsche PAL-System einzuführen, so bitte ich Sie - ohne Verwendung politischer Argumente - solche Bemühungen in geeigneter Weise zu fördern ${ }^{253}$.

Nachdem im Dezember 1965 auch die Bemühungen auf oberster industrieller Ebene gescheitert waren ${ }^{254}$, ein deutsch-französisches bzw. CFT/Te-

252 Dem Schreiben vor der Reise des Bundesaußenministers Schröder wurde zudem die sechsseitige »Information über die Probleme, die sich bei der Auswahl eines Farbfernsehsystems in den europäischen Ländern ergeben« beigefügt, in der Werner Nestel seine sehr persönliche Deutung der bisherigen Farbfernsehkontroverse zum besten gab. Oberflächlich um technische Objektivität bemüht, ist das Schreiben im Grunde eine subtile Verdrehung der Lage zugunsten Deutschlands und des PAL-Systems, in: Bundeszwischenarchiv Bonn, Signatur B 145/2864.

253 Runderlaß des Auswärtigen Amtes, Bonn, 14.01.1966, in: Bundeszwischenarchiv Bonn, Signatur B 145/2864.

254 Bereits im Juli 1965 waren der Telefunken-Vorstandsvorsitzende Dr. Felix Herriger und der AEG- und Telefunken-Aufsichtsratsvorsitzende Dr. Heyne auf Einladung von CSF-Chef Maurice Ponte nach Paris gereist, um die Frage eines Zusammengehens von Telefunken und CSF zu diskutieren. Im Gedächtnisvermerk des Treffens heißt es diesbezüglich: „Die Möglichkeiten, das PAL- und das SECAM-System technisch zu verschmelzen, werden wegen der grundsätzlichen Unterschiede beider Systeme als sehr gering angesehen. Herrn Dr. Heynes Vorschlag, durch eine geeignete Namensgebung für ein einheitliches System einen KompromiB zu ermöglichen, fand keine Resonanz«. Im Interview mit dem Autor (Ulm, 7.08. 1997) berichtete Dr. Herriger darüber, daß Ponte sich alle Mühe gegeben habe, ein guter Gastgeber zu sein (»das Diner war hervorragend« ... »danach gab es sehr guten Cognac«), doch hätten Dr. Heyne und er beschlossen, die Sache zu überdenken. Beim Gegenbesuch von Ponte in Berlin im Dezember 1965 habe man diesem dann definitiv mitgeteilt, daß man keine Chancen für eine Einigung sehe. Allerdings standen zu diesem Zeitpunkt schon die Fragen einer möglichen Patentabhängigkeit PALs von SECAM im Vordergrund der Gespräche. In einem Brief von Herriger an Ponte vom 23.12.1965 stellte Herriger fest: »Wir stehen - wie wir es ja auch in der Besprechung gemeinsam festgestellt haben - heute vor einer in den letzten Jahren entstandenen Situation, die uns im Interesse der beiden Unternehmen nur mehr wenig Spielraum läßt. Bitte seien Sie überzeugt, daß wir unsererseits nach wie vor zu allen Überlegungen und Gesprächen bereit sind, die auch die von uns vertretene Geschäftspolitik in ausreichendem Maße berücksichtigen«, in: AEG-Telefunken-Archiv, Deutsches Technikmuseum Berlin, Signatur GS 7954. 
lefunken-System auf die Beine zu stellen, betrieb man auf Seiten Telefunkens eine gezielte Anti-SECAM bzw. Anti-Frankreich Politik, die sich vor allem in zahlreichen Gesprächen und Briefen des Telefunken-Vorstandsmitgliedes Werner Nestel widerspiegelt. In einer Besprechung mit dem Botschafter der Bundesrepublik in Paris, Dr. Klaiber, wies Nestel eindeutig Frankreich den »schwarzen Peter« für die entstandene »Farbfernsehspaltung« zu:

Dies ist nun schon die dritte Selbstisolierung Frankreichs, nachdem es sich bei der Einführung des Fernsehens zunächst für eine eigene 819-Zeilennorm entschieden hatte und später, als es bemerkte, daB dadurch der Programmaustausch für die Eurovision zu sehr erschwert wurde, eine 625-Zeilennorm festlegte, bei der es einige Daten anders wählte als bei der 625-Zeilennorm des übrigen Europa, angeblich um die eigene Industrie zu schützen ${ }^{255}$.

Neben der negativen Darstellung der französischen Positionen richtete Telefunken seine PAL-Politik darauf aus, von seiten der Briten eine offizielle Erklärung des Postmaster General über den Eröffnungstermin des Farbfernsehens in Großbritannien zu erwirken. Allerdings äußerte sich der Direktor der britischen Telefunken-Partnergesellschaft EMI, Dr. Broadway, skeptisch zu der Möglichkeit einer öffentlichen Regierungserklärung zum Einführungstermin, da die Regierung gerade ihren Rücktritt erklärt habe und am 31. März Neuwahlen seien. Broadway sollte sich irren, da der Postmaster General zwei Tage nach dem Telefonat mit Nestel, am 3. März 1965, vor dem britischen Unterhaus bekanntgab, daß man das Farbfernsehen im Herbst 1967 einführen werde. Die britische Pro-PAL-Haltung in Großbritannien war somit offiziell. Lediglich Mc Lean, »den man zu PAL gezwungen habe«, so Broadway, übe nun aus persönlichen Gründen »Rache« durch sein Eintreten für $\mathrm{NIR}^{256}$.

Mit der öffentlichen Bekanntgabe des Einführungstermins des Farbfernsehens in Großbritannien ging die Farbfernsehkontroverse in ihre entscheidende Phase. Drei Monate vor Beginn der CCIR-Vollversammlung in Oslo nahmen alle Beteiligten strategische Positionierungen vor. Das PAL-Lager wurde am 17. Juni - also wenige Tage vor Beginn der Vollversammlung - durch das offizielle Statement des niederländischen Postministeriums zugunsten des PAL-Systems weiter gestärkt ${ }^{257}$. Zwar hätten die niederländischen Rundfunk-

255 Besprechung mit Botschafter Dr. Klaiber, Paris, 28.01.1966 (PAL/SECAM), 5 maschinegeschriebene Seiten, hier S. 2, in: Bundeszwischenarchiv Bonn, Signatur B 145/2864.

256 Wie Nestel berichtete, glaubte Dr. Broadway aber nicht, daß McLeans Aktionen von Belang seien. Ibid.

257 In der Ankündigung heißt es: "Aangezien de tijd, noodig voor de beproeving van andere, eventueel nog te ontwikkelen systemen [...] ontbreekt, is het noodzakelijk dat thans gekozen wordt uit de drie nu volledig bekende systemen, t.w. NTSC, PAL en SECAM.« Mit dieser Stellungnahme verwehrte sich das niederländische Postministerium indirekt auch gegen die Diskussion des NIR-Systems als potentielle »vierte Lösung « und rückte wie in Großbritannien und der Bundesrepublik das Kriterium »Einführungstermin« in den Vordergrund der Argumentation. Das 
anstalten die Entscheidung über die Einführung des Farbfernsehens aus finanziellen Gründen gerne weiter aufgeschoben, doch war letztlich die Entscheidung des Postministeriums ausschlaggebend ${ }^{258}$. Das offizielle Bekenntnis der Niederlande zu PAL war ein wichtiger Baustein der symbolischen Verstärkung des PAL-Lagers, doch war man bei Telefunken seit dem Farbbildröhren-Abkommen mit Philips davon überzeugt, daß sich das Heimatland von Frits Philips für PAL entscheiden werde. Auch die Briten waren seit Ende 1965 davon überzeugt, daß die Niederländer sich für PAL entscheiden würden - »since Philips decides the Dutch government's policy in such matters $\aleph^{259}$.

Mit der britischen und niederländischen Entscheidung für PAL, die im britischen Fall zudem mit der konkreten Festlegung des Einführungstermins im Herbst 1967 verbunden war, hatten sich die drei Länder mit den mächtigsten Rundfunkindustrien in Europa für die Telefunken-Farbfernsehvariante entschieden. Sowohl für die bundesdeutsche, niederländische als auch englische Industrie stand dabei die baldige Einführung des Farbfernsehens aus verkaufstechnischen und absatzstrategischen Gründen im Vordergrund. $\mathrm{Ob}$ es nun das PAL- oder NTSC-System war, welches eingeführt werden würde, trat - mit Ausnahme Telefunkens - dabei in den Hintergrund. Waren es die großen Rundfunkgerätehersteller gewesen, die Anfang der sechziger Jahre aus Sorge vor einem Absatzrückgang im s/w-Geschäft vor einer verfrühten öffentlichen Diskussion über das Farbfernsehen gewarnt hatten, machten sie sich 1966 aufgrund der ersten Sättigungserscheinungen des s/w-Marktes zu vehementen Fürsprechern des baldigen Beginns farbiger Fernsehsendun-

Kommuniqué findet sich im Anhang eines Briefes von Frits Philips an Werner Nestel vom 17.06.1966, in: AEG-Telefunken-Archiv, Deutsches Technikmuseum Berlin, Signatur GS 1649.

258 Am 14. Juni berichtet Werner Nestel über zwei Telefongespräche mit den Herren Wijns, Philips Hamburg, und le Clercq, Philips Eindhoven. Nestel bat beide um die Möglichkeit einer offiziellen pro-PAL-Stellungnahme der niederländischen Regierung. Auch bat er darum, da $B$ man in Oslo keine Verzögenungstaktik anwende. Le Clercq habe ihm geantwortet: „Die Rundfunkanstalten in Holland haben Geldschwierigkeiten. Sie haben sich in Dubrownik der Gruppe der kleinen Länder angeschlossen, die die Einführung des Farbfernsehens verschieben wollen«. Bei der PTT (Post- und Telekommunikationsbehörde) bestehe aber keine Gefahr der Verzögerung, da der niederländische Delegationschef von der PTT gestellt werde. Siehe Telefonnotiz Nestel, 14.06. 1966, in: AEG-Telefunken-Archiv, Deutsches Technikmuseum Berlin, Signatur GS 1649.

259 In einem Brief von Eland (Britische Botschaft Stockholm) an Hillier-Fry (FO) vom 12.10.1965 findet sich folgende interessante Bemerkung über die Situation in Holland: »Mr. von Utfall (Head of the technical branch of the Swedish Radio/Television, adviser of the Swedish government on technical questions about radio and television, member of the Swedish delegation at Vienna) told me that the director of the Swedish Philips Company (which controls 50\% of the Swedish radio and television industry) had told him that he believed that the Dutch Government were now moving in the direction of PAL and away from NTSC. Mr. von Utfall thought that there was probably a lot of truth in this, since $>$ Philips decides the Dutch government's policy in such matters $\varsigma$. [...] It seems that Philips has noted which way the wind is blowing «, in: PRO, Signatur BT 11/6433. 
gen $^{260}$. Bereits 1964 war abgeschätzt worden, daß der Einführungstermin Herbst 1967 günstig sei, um einen möglichst reibungslosen Produktionsfluß beim Übergang zur Farbe gewährleisten zu können ${ }^{261}$.

Auch den Franzosen war klar, daß der anvisierte Einführungstermin des Farbfernsehens von zentraler Bedeutung für die Diskussion in Oslo werden würde. Auf der dritten Sitzung der Commission mixte setzten sie aus diesem Grunde alles daran, zu einer französisch-sowjetischen Systemdefinition zu gelangen, die der des SECAM III-Systems (CSF) entsprach ${ }^{262}$. Als die beiden Delegationen sich am 13. und 14. April in Moskau trafen, konnte das Arbeitsziel des Treffens aus französischer Perspektive daher nur lauten, die sowjetische Seite auf den »alten« SECAM-Kurs zu verpflichten. Bereits am 29. März hatte die während der zweiten Sitzung der Commission mixte zum Vergleich des SECAM- und NIR-Systems gegründete Arbeitsgruppe ihren Abschlußbericht vorgelegt, der als Arbeitsgrundlage der dritten Sitzung dien$\mathrm{te}^{263}$. Die vergleichenden Untersuchungen, die zum größten Teil in den Laboratorien der ORTF in Paris gemacht worden waren, kamen zu dem Schluß, $\mathrm{da} ß$ es sich beim NIR-System um ein im Prinzip gleichwertiges Farbfernsehsystem handele, viele wichtige Parameter aber noch nicht im Detail untersucht werden konnten. Vor allem fehle jegliche Erfahrung im Bereich der Empfängerproduktion, die für die baldige Einführung des Farbfernsehens

260 In einem Gespräch zwischen ZVEI, ZDF, ARD, IRT und Bundespost in Köln am 3.07.1964 hatte der Vorsitzende der Fachabteilung 14 (Fernsehen) des ZVEI, Herr Meyer, erklärt, daß die Industrie in der Fernsehproduktion eine Durststrecke bekomme und unbedingt 1967 Farbfernsehen brauche. Der Intendant des WDR, Klaus von Bismarck, wollte als Einfühnungstermin aber lieber 1968, weil für den Rundfunk die Saison erst um die Weihnachtszeit beginne; dies wurde vom ZVEI strikt abgelehnt, da die Saison mit der Funkausstellung im Herbst beginnen müsse. Abschließend bat Herr Meyer die anwesenden Intendanten noch um Unterstützung durch »Knüller « im s/w-Programm, die den schwächer werdenden s/w-Markt unterstützen könnten! Gesprächsnotiz von W. Bruch, Hannover, 3.07. 1964, in: Archiv des Deutschen Museums München, Signatur NL 101, Nr. 202.

261 Stellungnahme des ZVEI auf der 65. Tagung der Technischen Direktoren der ARD vom 3. bis 4.09.1964 in Frankfurt a.M., in: Historisches Archiv des WDR/Protokolle der Technischen Direktion 1961-1964.

${ }^{262}$ In einer Besprechungsnotiz von Dr. Eckart (Telefunken Frankreich) mit M. Gruson (CSF) vom 4.03.1966 heiBt es: »Auch die CSF sieht daher die Frage, ob es beim Einfuihrungstermin 1967 bleibt oder nicht als das wesentlichste Element für die kommende Entscheidung an. M. Gruson unterstellt, daß auf jeden Fall die englische und die deutsche Industrie, aber aus den beschriebenen Gründen auch die französische Industrie 1967 beginnen wollen, und somit die Chance für SECAM IV mangels rechtzeitiger Testergebnisse und Erfahrungswerte nicht groB sind. M. Gruson deutete sogar die Möglichkeit an, daB sich Rußland allein für SECAM IV entscheiden könnte, was nach dem franco-sowjetischen Vertrag möglich ist, da die Russen sich nur verpflichtet haben, ein System ^auf der Basis von SECAM « zu wählen«, in: AEG-Telefunken-Archiv, Deutsches Technikmuseum Berlin, Signatur GS 7954. Wie sich zeigen sollte, lag Gruson mit seiner Einschätzung richtig.

${ }^{263}$ Siehe den 13 seitigen "Rapport technique du groupe spécial mixte franco-soviétique pour la télévision en couleur«, Paris, 29.03. 1966, in: Archives du CHTV/INA, Nachlaß Michel Dubail. 
von zentraler Bedeutung sei. Aus diesem Grunde sei - im Falle der Wahl des SECAM IV-Systems - mit einer sechzehnmonatigen Verzögerung des Beginns des Farbfernsehens zu rechnen. Der Wortlaut des Berichtes läßt aber darauf schließen, daß man von seiten der Techniker darum bemüht war, klare pro- oder contra-Positionen zu vermeiden. Deutliches Zeichen dieser Zurückhaltung war, daß eine abschließende Bewertung der vergleichenden Untersuchungen vollkommen fehlte. Die Bewertung der Testergebnisse, so der Eindruck, sollte den politischen Entscheidungsträgern beider Delegationen im Rahmen der Commission mixte überlassen werden.

Genau dies geschah am 13. April in Moskau. Nachdem in offiziöser Diplomatensemantik die prinzipielle Überlegenheit sowohl des NIR-als auch des SECAM-Systems gegenüber den Varianten NTSC und PAL festgestellt worden war, gelangte man zu folgender Feststellung:

Compte tenu de ce que la variante SECAM III est la seule qui soit prête à être produite industriellement, qu'elle a été présentée avec succès sur le plan international lors d'émissions transmises par faisceaux hertziens et par le satellite soviétique Molnya I, que cette variante a déjà obtenu à la conférence du CCIR à Vienne, en 1965 l'approbation d'une majorité de pays, compte tenu de ce que la variante SECAM IV tout en étant également à un niveau technique élevé, n'a pas d'avantage décisif par rapport au SECAM III et se trouve encore au stade de l'élaboration, la Commission recommande l'adoption du SECAM III comme le système commun franco-soviétique de télévision en couleur prévu par l'Accord du 22. Mars $1965^{264}$.

Aus diesem Wortlaut geht eindeutig hervor, daß sich die französische Position durchgesetzt hatte ${ }^{265}$. Als jedoch die Taktik für ein gemeinsames französisch-sowjetisches Vorgehen während der Olsoer Konferenz bestimmt wurde, ließ man dem NIR-System zumindest theoretisch eine Hintertür offen. Falls vor oder während der Osloer Tagung der Eindruck entstehen sollte, daß das NIR-System eine reale Chance hätte, sich als europäischer Standard durchzusetzen, würden sich weder Frankreich noch die Sowjetunion dieser Lösung widersetzen ${ }^{266}$. $\mathrm{Zu}$ diesem Zweck wurde vereinbart, daß man allen am NIR-

264 »Protocole de la $3^{\text {ème }}$ session de la Commission mixte franco-soviétique sur la télévision en couleur«, Moskau, 14. 04.1966, 6 maschinegeschriebene Seiten, hier S. 3 f., in: Archives du CHTV/INA, Nachlaß Michel Dubail.

265 Allerdings hatte sich die französische Linie nicht aus den Gründen durchgesetzt, die Walter Bruch in der ihm eigenen, zur Übertreibung neigenden Weise formulierte: "Sie haben sicher gehört«, so schrieb Bruch in einem Brief an Werner Nestel, »daß sich die Russen für SECAM III entschieden haben. Ein Sieg für Herrn Ponte!! Ich darf hier feststellen, daß meine unermüdliche Arbeit, die Nachteile von NIR hinauszuexperimentieren [!] und wissenschaftlich zu untermauern und meine Demonstrationen sowie Interventionen in England mit zu dieser Entscheidung beigetragen haben«, in: AEG-Telefunken-Archiv, Deutsches Technikmuseum Berlin, Signatur: GS 1646.

266 „Si d'ici la réunion de l'Assemblée plénière du CCIR à Oslo ou au cours de l'Assemblée elle-même, il apparaissait que le SECAM IV est susceptible de recevoir réellement l'adhésion des pays dont le ralliement serait décisif pour l'adoption d'un système européen unique [= Bundesrepublik und Großbritannien, A.d.V.], la France et l'URSS seraient prêtes à choisir également 
oder SECAM IV interessierten Ländern die von der gemeinsamen Expertenkommission erarbeiteten vergleichenden Untersuchungsergebnisse auf Anfrage zukommen lassen würde. Damit aber keine Mißverständnisse über die grundsätzliche Entscheidung der französischen und sowjetischen Position aufkommen könnten, müsse die Herausgabe dieser Dokumentation immer von einem schriftlichen Kommentar begleitet werden, der die Gründe der Entscheidung beider Länder für das SECAM III-System wiedergebe. $\mathrm{Zu}$ diesem Zweck wurde bereits zum Abschluß des Treffens ein gemeinsames Kommuniqué verfaßt, das entsprechende Verbreitung in der Presse finden sollte (siehe S. 313).

Vor der CCIR-Vollversammlung in Oslo waren damit die politischen und industriellen Weichen der zentralen Akteure der Farbfernsehkontroverse gestellt worden. Bevor die Verhandlungen in Oslo detailliert beschrieben werden, macht es Sinn, die wichtigsten Entwicklungen in der Farbfernsehkontroverse zwischen der CCIR-Zwischentagung in Wien im Frühjahr 1965 und dem Beginn der CCIR-Vollversammlung in Oslo Ende Juni 1966 noch einmal in vier Punkten zusammenzufassen.

1. Frankreich und die Sowjetunion vereinbarten in ihrem Farbfernsehabkommen vom 22. März 1965 eine Kooperation auf dem Gebiet des Farbfernsehens, die sich u.a. in der Einführung eines gemeinsamen Farbfernsehsystems auf der Basis des SECAM-Systems und seines Standards niederschlagen sollte. Politisch bedeutete dieses Abkommen den ersten Schritt zu einer vertraglich festgelegten Annäherung beider Staaten. Für Staatspräsident Charles de Gaulle wurde das Farbfernsehen so zum Medium und Katalysator seines neuen außenpolitischen Kurses, der Frankreichs Souveränität in dem Dreierschritt »détente - entente - coopération « zu verstärkter nationaler Souveränität führen und Frankreichs Rolle im Konzert der europäischen und internationalen Mächte stärken sollte. Dieser hohe Symbolwert des SECAMSystems war letztlich ausschlaggebend dafür, daß es trotz der eher zurückhaltenden Unterstützung von seiten des Quai d'Orsay und der ORTF zur offiziellen Erklärung im Rahmen der Commission mixte kam, das französische SECAM III-System als gemeinsames französisch-sowjetisches System in Oslo zu vertreten. Die sowjetische NIR-Variante konnte sich trotz ihrer technischen Attraktivität als potentielle Kompromißlösung zwischen PAL und SECAM nicht durchsetzen. Hauptgrund dafür war ihre technische Unausgereiftheit. Die Entscheidung für das NIR-System wäre gleichbedeutend mit einem Aufschub des anvisierten Einführungstermins des Farbfernsehens (Herbst 1967) um mindestens anderthalb Jahre gewesen.

cette variante et à la présenter en commun «. Protocole de la $3^{\mathrm{e}}$ session de la Commission mixte franco-soviétique sur la télévision en couleur, Moskau, 14.04.1966, 6 maschinegeschriebene Seiten, hier S. 4, in: ibid. 


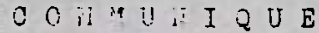

Le Connission lixto fronco-soviśtique sur la télévicion en couleur institúe coniormémert à 1 'accord sur 1 coopération ding le doaine ì la tólévision an couleur conclu entre l'U.Z.5.3., et la Frnnce a tenu à iloscou va sene session, les 13 et 14 avril 1966.

Les traviux de cette sesłion ge sont deroulás daiı une .tmosprère de totule compenension et de fructueuse collabcration. La Counission wixte a pris note avec satiof action des resultats positifs de la coopération atieints au cours de l'annee qui s'est ścollée dopuis le conclusion de l'accord.

La Contisision a fait le point des esiais comparatifo cies variantes SECAN-III et SECAM-IV du système comuun de télévision en couleur et a note le nivaau technicue élévé de ces cieux variantes.

Tenant cnncte du fait que la variante SBCAli-III est prete pour la prociuction industrieile, terant compie par ailleurs don avantajes inciscutabies de cette viricnte par rapport aux autres systeises cie tolívision en couleur en prósence, de eno que du fait que le SACAi-III a fnjt l'objet de demonstrations intemationales curonnós de succ is jucice à des ómissions transmises par faisceaur hertriens et pur le satellite soviétique "folnya-I" et qu'il a regu à Vienne l'appui d'une majorité de p.ys, le Comission a recon ardé l'adoption du SECHA-III come sjateje conoun fronco-soviótique de bisévision en couzeur.

Ia Comrision a ejalement ex.mine un certiin nombre de questions ayant trait iu developperent, entre les organismos frarçais et soviétiques conpitents, de la coopération relutire ל. la mise au poini industrielle du système commun de télévigion en couleur.

icscul, le I4 Avril I966

Abb. 22: "Communique der französisch-sowjetischen Farbfernsehkommission vom 14. April 1966, aus: Archives du CHTVINA, Nachlaß Michel Dubail.

2. Die neue Ostpolitik de Gaulles war u.a. ein Resultat der französischen Unzufriedenheit über die Entwicklung der deutsch-französischen Beziehungen. Der französisch-sowjetische Farbfernsehvertrag stellte Bonn vor vollendete Tatsachen. Die nachfolgenden Bemühungen des französischen Informationsministers und seines bundesdeutschen Gegenübers doch noch zu einer deutsch-französischen Einigung zu gelangen, scheiterten nicht zuletzt an 
den politischen Weisungen de Gaulles sowie am Desinteresse des bundesdeutschen Wirtschafts- und Postministeriums und der deutschen Rundfunkindustrie. War damit die französische Strategie gescheitert, die Bundesrepublik über den politischen Hebel DDR zur Übernahme des SECAM-Systems zu bewegen, kam es statt dessen zu einer deutsch-britischen Annäherung, die von bundesdeutscher Seite sogar als »Kompensation « der französischen Ablehnung des britischen Beitrittsgesuchs zur EWG verstanden wurde ${ }^{267}$. Auch von seiten des britischen Außenministeriums wurde die Übernahme des PAL-Systems als politische Annäherung an die Bundesrepublik verstanden. Lediglich die BBC hielt bis Ende 1965 eisern an der Bevorzugung des amerikanischen NTSC fest, während die britische Rundfunkindustrie mit der Entscheidung für PAL die Chance einer gewissen Emanzipation von der amerikanischen Konkurrenz erkannte. Die offiziellen Bekanntmachungen der Übernahme des PAL-Systems in Großbritannien und den Niederlanden im März bzw. Juni 1966 waren eine wichtige symbolische Rückendeckung für das PAL-Lager in Oslo.

3. Aus industrieller Perspektive bedeuteten die oben genannten Stellungnahmen der britischen und niederländischen Regierungen, daß das PAL-System die drei mächtigsten europäischen Rundfunkindustrienationen hinter sich versammelt hatte. In allen drei Ländern wurde aber nicht die Entscheidung der Wahl eines der drei Systemalternativen zum zentralen Anliegen ihrer industriepolitischen Aktivitäten, sondern die Herbeiführung eines konkreten Einführungstermins des Farbfernsehens. Absatzschwierigkeiten im Fernsehgeschäft, zum Teil bedingt durch eine erste Sättigungskurve des s/w-Marktes, machten die Einführung des Farbfernsehens im Herbst 1967 zur geschäftspolitischen Priorität. Eine Aufnahme des NIR-Systems in das Konzert der europäischen Farbfernsehsystemalternativen hätte unweigerlich bedeutet, daß der Einführungstermin wegen zusätzlicher technischer Untersuchungen um schätzungsweise eineinhalb Jahre verzögert worden wäre. Aus diesem Grund setzten die Rundfunkunternehmen der Bundesrepublik, der Niederlande und Großbritanniens alles daran, daß die NIR-Variante in Oslo keine Rolle spielen würde.

4. Für viele nationale Rundfunkanstalten entwickelte sich gerade das NIRSystem zum letzten Hoffnungsträger eines möglichen Kompromisses als europäischer Farbfernsehstandard. Zu den zentralen Akteuren einer systematischen Untersuchung und damit der Einbeziehung des NIR-Systems in die europäische Diskussion zählten die Ingenieure der britischen BBC und der französischen ORTF. Unterstützt von vielen kleineren Ländern, die sich von der Untersuchung des NIR-Systems eine weitere Aufschiebung des Einführungstermins des Farbfernsehens erhofften, sowie der mehrsprachigen Län- 
der, die unter allen Umständen einen einheitlichen europäischen Farbfernsehstandard durchsetzen wollten, investierten beide Anstalten in die technische Entwicklung und Werbung für das System auf der EBU- und CCIR-Ebene.

Mit diesen politischen und industriellen Hintergründen vor Augen werden die Ereignisse verständlich, die sich im Rahmen der CCIR-Vollversammlung vom 22. Juni bis 22. Juli 1966 in Oslo abspielten. 


\section{5. »De coloribus disputandum est $\aleph^{268}$ Oslo, 22. Juni bis 22. Juli 1966}

Als am 22. Juni 1966 die CCIR-Mitgliedsstaaten zu ihrer elften Vollversammlung in Oslo zusammenkamen, handelte es sich um die bislang teilnehmerreichste Zusammenkunft in der Geschichte der CCIR. Wie der bundesdeutsche Delegationsleiter, Ministerialdirigent Hans Pressler, in seinen „Farbfernseh-Erinnerungen« schrieb, war der Konferenzsaal so gro $\beta$, daß der Vorsitzende Wortmeldungen mit dem Fernglas identifizieren mußte ${ }^{269}$ ! Allerdings fanden nur die Eröffnungs- und Abschlußsitzungen in dieser großen Runde statt, ansonsten kamen die technischen Experten der verschiedenen Delegationen in den elf Studienkommissionen der CCIR zusammen, die sich - wie im Falle der Studienkommission XI (Fernsehen) - wiederum in verschiedene Untergruppen mit speziellen Arbeitsthemen unterteilten ${ }^{270}$. Der große Andrang in Oslo erklärt sich unter anderem wegen der bedeutenden Aktivitäten, die seit der letzten Vollversammlung im Jahre 1963 von den Studienkommissionen im Bereich der Farbfernsehtechnik oder im Bereich der Satellitentechnik (Studienkommission IV) geleistet worden waren. Dementsprechend hoch waren die Erwartungen, die man von seiten der nationalen Post- und Telekommunikationsbehörden, der Rundfunkindustrie und der Rundfunkorganisationen an diese Vollversammlung hatte, da die im Rahmen der CCIR erarbeiteten Empfehlungen meist mit der internationalen Standardisierung wichtiger technischer Parameter im Telekommunikationsbereich verbunden waren.

Der Chefredakteur der französischen Fachzeitschrift »Radio \& Télévision«, Eugène Aisberg, der schon die Wiener Tagung mit einem leidenschaftli-

268 Eugène AISBERg, Heures décisives pour la télévision en couleurs, in: Radio \& Télévision 141 (1964) S. 34. Dort heißt es: »On devine sans peine quel écheveau de considérations techniques préoccupe ceux sur qui pèse la lourde responsabilité d'opérer le choix. [...] Il est, cependant, difficile de présumer la décision finale. Aux considérations purement techniques voudraient se mêler des questions de politique, d'une certaine forme de nationalisme et aussi l'influence d'énormes intérêts financiers. Mais nous sommes persuadés que la sagesse prévaudra et que le choix sera opéré en toute indépendance et avec une totale objectivité au terme d'une discussion qui ne manquera pas d'être animée. Car, contrairement à ce qu'affirment les anciens, de coloribus disputandum est...«. Die Entscheidungsträger in Oslo ließen sich aber nicht von Aisbergs weisen Worten inspirieren...

269 Hans Pressler, Farbfernseh-Erinnerungen, S. 212.

270 Die Studiengruppe XI teilte sich in drei Untergruppen auf: Arbeitsgruppe A unter der Leitung des Schweden Erik Esping; Arbeitsgruppe B unter der Leitung des Italieners Cappucini und Arbeitsgruppe C unter der Leitung von Dr. Johannes Müller vom FTZ Darmstadt. Die Arbeitsgruppe A war wiederum in zwei Untergruppen geteilt. Untergruppe A 1 unter der Leitung des Tschechoslowaken Swoboda beschäftigte sich mit Normfragen im Bereich des s/w-Fernsehens. Lediglich die Arbeitsgruppe A 2 beschäftigte sich in Oslo mit den Problemen des Farbfernsehens. 
chen Plädoyer für eine entpolitisierte Diskussion der Farbfernsehfrage kommentiert hatte ${ }^{271}$, stimmte seine Leser in einem pathetischen Leitartikel mit dem Titel »Unité avant tout!« auf die anstehende Entscheidung in Oslo ein:

Ce qui n'a pas pu être fait pour le noir et blanc, doit l'être pour la couleur. Nous n'avons pas le droit de laisser échapper cette chance unique qui s'offre à nous: un seul système de TV couleurs pour toute l'Europe. [...] Et que le meilleur gagne! [...] La politique n'a rien à faire dans cette question, pas plus que de ridicules considérations d'amour-propre national ou de cupides calculs financiers ${ }^{272}$.

Mit Sicherheit spiegeln die Worte Aisbergs die Hoffnungen vieler Delegierter, in Oslo doch noch zu einem einheitlichen europäischen Farbfernsehstandard zu finden. Nüchterner kommentierte dagegen der im Fernmeldetechnischen Zentralamt der Bundespost in Darmstadt für Farbfernsehuntersuchungen zuständige Ingenieur Fritz Jaeschke die Situtation vor Oslo. In seinem Artikel "Europa vor der Einführung des Farbfernsehens« in der Zeitschrift "Umschau in Wissenschaft und Technik « schrieb Jaeschke kurz vor Beginn der Vollversammlung in Olso: "Drei Systeme stehen also zur Wahl, und es ist schon jetzt zu sagen, daß ein einheitliches Farbfernsehsystem in Europa in den nächsten Jahren jedenfalls nicht durchzusetzen sein wird, denn sowohl die SECAM- als auch die PAL-Anhänger sind - zum Teil aus technisch-wirtschaftlichen, zum Teil aus politischen Motiven - überzeugt, an ihrer Konzeption festhalten zu müssen ${ }^{273}$.

Beide sollten letztlich recht behalten - zum einen kam es zu der von Aisberg befürchteten Politisierung der Diskussionen, zum anderen hatte Jaeschke das Ergebnis dieser Diskussionen korrekt vorausgesagt. Doch gilt es zunächst, sich die einmonatigen Verhandlungen in Oslo sowie die diplomatischen und industriepolitischen Aktivitäten, die sich im Rücken der Osloer Delegationen abspielten, näher anzuschauen.

Wie bereits beschrieben, waren wichtige außen- und industriepolitische Rahmenbedingungen bereits vor Beginn der Verhandlungen geklärt worden. Entsprechend instruiert reisten die jeweiligen Delegationsleiter nach Oslo. Im Bundespostministerium hatte am 10. Juni 1966 nochmals eine vorbereitende Besprechung zwischen Bundespost, ARD, ZDF und ZVEI für die CCIRVollversammlung stattgefunden, auf der beschlossen worden war, daß die deutsche Delegation in Oslo für das PAL-System eintreten sollte. Man hielt

271 "Quel que soit le système adopté, il faudrait faire taire tous les sentiments d'amour-propre national pour, dans un ésprit d'unité européenne, l'adopter à l'exemple de tous les autres pays. Bien entendu, nous n'avons jamais caché nos préférences personelles qui vont au système SECAM. Et cette préférence n'est nullement fondée sur un stupide chauvinisme, mais sur une étude approfondie des qualités et des défauts comparés des trois systèmes en présence». Eugène AIsBERG, Le suspense, in: Radio \& Télévision 152 (1965) S. 65.

272 Eugène AIsBerg, Unité avant tout, in: Radio \& Télévision 163 (1966) S. 105.

273 Fritz JAESCHKE, Europa vor der Einfuihrung des Farbfernsehens, in: Umschau in Wissenschaft und Technik 66 (1966) 8 S. 257-261, hier S. 257. 
demnach an der Entscheidung fest, die bereits im März 1966 getroffen worden war $^{274}$. Da man in Bonn sehr wohl um die feste Haltung der Franzosen wußte, hatte man sich mehr oder weniger mit der Tatsache abgefunden, daß es in Oslo wohl nicht zu einer einheitlichen Empfehlung kommen werde.

Auch dem britischen Delegationsleiter Stanesby waren entsprechende Weisungen des Postmaster General Wedgwood Benn mit auf die Reise nach Oslo gegeben worden. Diese faßte der Vorsitzende des Technical Sub-Committee des Television Advisory Committee, Lord Barron, knapp und präzise zusammen: "press strongly for PAL - strongly oppose SECAM III - not initiate any discussion about NIR ${ }^{275}$. Im Gegensatz zur Bundesrepublik hatte es Postminister Anthony Wedgwood Benn auch nicht für notwendig gehalten, die britischen Botschaften in Europa in Form eines »Runderlasses « über die Position der britischen Regierung in der Farbfernsehfrage zu informieren. Vielmehr sah er die Sache recht pragmatisch. Falls konkreter Handlungsbedarf entstehe, werde man entsprechend agieren: $\gg$ A considerable amount of lobbying would go on at Oslo, and if it was felt that during the conference it would be helpful, in the case of a country which was wavering, if we were to put political pressure on the country in the European capital concerned then the U.K. delegation will transmit their request through our Ambassy in Oslo ${ }^{276}$.

Generell ging man auch in Großbritannien davon aus, da $B$ viele der kleineren Länder, die den Programmaustausch mit größeren Fernsehnationen dringend brauchten, versuchen würden, eine Entscheidung über ein einheitliches System möglichst zu verschieben, "in the hope of beeing able to persuade France to abandon SECAM III for SECAM IV «. Da die britische Regierung die Einführung des Farbfernsehens für Ende des Jahres 1967 beschlossen hatte, war man jedoch weder im Postministerium noch im Außenministerium an einer Verschiebung des Einführungstermins interessiert ${ }^{277}$.

274 Auf der 72. Tagung der Technischen Kommission der ARD in Trier vom 4.-5.04.1966 berichtete Dr. Hans Rindfleisch über die Sitzung vom 2.03.1966 im Bundespostministerium, bei der die bundesdeutsche Strategie für Oslo definiert worden war: „Bei dieser Besprechung kam man zu der Überzeugung, daB voraussichtlich in Oslo 3 Farbfernsehverfahren zur Debatte stehen werden. Beim derzeitigen Sachstand wird vermutlich keine CCIR-Empfehlung, sondern nur ein Bericht, der die drei Farbfernsehverfahren festhält und beschreibt, verabschiedet werden. Bei der Besprechung in Bonn wurde verabredet, eine offiziöse Fühlungnahme mit den Engländern einzuleiten, um ein abgestimmtes Vorgehen in Oslo zu besprechen. Herr Ministerialdirigent Pressler hat dem Vorsitzenden der Technischen Kommission diese Fühlungnahme erneut zugesagt«. Siehe Bericht über die 72. Tagung der Technischen Kommission der ARD in Trier, in: Historisches Archiv des WDR, Protokolle der Technischen Kommission/ARD/1956-1968.

275 Brief von Barron (Chairman of the Technical Sub-Committee of the TAC) an Willis (Chairman of the TAC), London, 2.06.1966, in: PRO, Signatur HO 256/387.

276 Handschriftliche Notiz von Brown (FO) über Gespräch mit Birchall (GPO), London, 17.06. 1966, in: PRO, Signatur: FO 371/181315, General Department, Akte GT 41/26.

277 Brief von Dunrossil (FO) an K. A. East (Britische Botschaft Oslo), London, 14.06. 1966. Entgegen der Beteuerungen von Wedgwood Benn hatte man im Außenministerium dennoch ver- 
Wie diese Beispiele demonstrieren, reisten die Delegationen der zentralen Akteure allesamt mit klaren Weisungen und strategischen Absprachen nach Oslo. Damit widersetzten sie sich eindeutig dem Beschluß, welcher der UERVerwaltungsrat auf seiner letzten Sitzung vor Oslo Anfang Juni 1966 in Dubrovnik gefaßt hatte, nämlich seinen Mitgliedern zu empfehlen, alles dafür zu tun, um bei der Tagung in Oslo zu einer einheitlichen Empfehlung für einen europäischen Farbfernsehstandard zu kommen. Außerdem wurde auf der Sitzung festgestellt, daß PAL und SECAM III schlecht konvertierbar seien, SECAM IV aber relativ einfach mit PAL konvertiert werden könne. Da für SECAM IV aber noch nicht genügend Erprobungszeit vorgelegen habe, sollte auf der Konferenz in Oslo angestrebt werden, die für SECAM IV erforderliche Erprobungszeit durch Vertagung zu ermöglichen ${ }^{278}$.

Mit entsprechend unterschiedlichen Erwartungshaltungen trafen sich die in Oslo anwesenden Delegationen der Studiengruppe XI am 24. Juni zur ersten Arbeitssitzung. Wie in Wien war dem Schweden Erik Esping die Leitung der Arbeitsgruppe Farbfernsehen übertragen worden, und wie in Wien begann die Tagung mit der Erstellung eines »Meinungsbildes « anhand eines Fragebogens, der alle Delegationen aufforderte, ihre Systempräferenz und den anvisierten Einführungstermin des Farbfernsehens in ihrem Land anzugeben $^{279}$. Als das Resultat dieser Fragebogenaktion am 1. Juli in einem 15 seitigen Bericht publiziert wurde, konnte man das Ergebnis als eine deutliche Polarisierung der anwesenden Delegationen in ein PAL- und ein SECAM-Lager sowie einer kleinen Fraktion von NIR- oder SECAM IV-Anhängern (v.a. Belgien, Luxemburg, Portugal, Tunesien) deuten. Auch die Angaben über den geplanten Einführungstermin variierten zwischen exakten Jahresangaben $^{280}$ und so unbestimmten Formulierungen wie »not yet fixed " (Saudi-Arabien), »not in the near future (Australien) oder »probablement en 1970«

sucht, der britischen Delegation politische Weisungen mit auf den Weg zu geben. In dem oben zitierten Brief sagt Dunrossil, daß er East einen Umschlag mit den politischen Anweisungen für die britische Delegation in Oslo zuschicken werde. Am 25.06. schrieb East an Lord Dunrossil, daß die Anweisungen zum politischen Verhalten der Delegation in Oslo diese nicht erreicht hätte, da der Koffer, in dem die Anweisungen enthalten waren, wegen Übergewichtes nicht mit nach Oslo geflogen sei. Dunrossils Bemerkung zu dieser merkwürdigen Geschichte: "I really think someone must be taken to task about this«. Es kann vermutet werden, daB Dunrossil mit diesem »jemand " BBC Chefingenieur McLean meinte. In: PRO, Signatur FO 371/181315, General Department, Akte GT 41/25.

278 Auf der Tagung berichtet Dr. Rindfleisch über die Beschlüsse des EBU-Verwaltungsrates in Dubrovnik. »Niederschrift der 73. Tagung der Technischen Kommission der ARD vom 14.-15.6.1966 in Hamburg«, in: Historisches Archiv des WDR, Protokolle der Technischen Kommission/ARD/1956-1968.

279 Documents on CCIR Study Groups Period 1963-1966, Doc.Temp./138, 1.7.1966.

28012 Länder gaben an, 1967 mit Farbfernsehen beginnen zu wollen, 4 im Jahre 1968, 6 ein Jahr später, 16 Länder planten, 1970 mit Farbfernsehen zu beginnen. 
(Liechtenstein). Einige Delegationen gaben sogar an, gar nicht zu wissen, ob und wann sie Farbfernsehen einzuführen gedachten ${ }^{281}$ !

Angesichts dieser unterschiedlichen Meinungsäußerungen, die - wie unschwer zu erkennen - den technisch-industriellen Entwicklungsstand der Länder spiegelten, wurde am 4. Juli aus arbeitstechnischen Gründen beschlossen, eine Untergruppe der Studiengruppe XI (XI A 2 getauft) zu bilden, in der nur die Delegationen folgender Länder vertreten waren: Frankreich, Bundesrepublik Deutschland, Großbritannien, Yugoslawien, Tschechoslowakei, Italien, Sowjetunion, Niederlande und Schweiz.

Als diese am 7. Juli ihre Arbeit aufnahm, kam es zu einer überraschenden Initiative der französischen Delegation, die - wie in Wien - durch hochrangige diplomatische Vertreter »verstärkt« worden war $^{282}$. Zur zentralen Figur dieser Inszenierung wurde Philippe Olivier, der als technischer Berater im Kabinett von Alain Peyrefitte bereits als Nachfolger für François Laboulaye gehandelt worden war $^{283}$. Was die Mitglieder der französisch-sowjetischen Commission mixte während ihrer dritten Sitzung im April 1966 als eher unwahrscheinliche Annahme ins Protokoll aufgenommen hatten, nämlich den Verzicht auf die Durchsetzung von SECAM III zugunsten der SECAM IVVariante im Falle der berechtigten Hoffnung, da $\beta$ diese Systemalternative echte Chancen als einheitliches europäisches Farbfernsehsystem haben wer$\mathrm{de}^{284}$, wurde den Mitgliedern der Untergruppe XI A 2 von französischer Seite am 7. Juli tatsächlich als »großzügiges Angebot« offeriert. Sowohl die französische als auch die sowjetische Delegation erklärte, zugunsten von SECAM IV auf SECAM III zu verzichten, falls sich die Anhänger des PAL-Systems dazu bereit erklärten, sich ebenfalls dieser Systemvariante anzuschlieBen. Die Übernahme des NIR- oder SECAM IV-Systems, so betonten die Franzosen, würde aber einen Aufschub des Einführungstermins des Farbfernsehens um mindestens sechs Monate bedeuten. Zudem sollten sich alle anwesenden Länder dazu verpflichten, in diesen sechs bis maximal zwölf Monaten

281 Die Kenyanische Delegation gab beispielsweise folgende Erklärung ab: »There are no plans at the present time for the introduction of colour television $\ll$. Siehe Documents on CCIR Study Groups Period 1963-1966, Doc.Temp./138, 1.7.1966, S. 8.

282 Louis Goussot als Vertreter der ORTF und Jacques Fagot als Vertreter der CSF in der französischen Delegation gaben im Interview an, daß den technischen Experten (also ihnen) von den anwesenden politischen Vertretern sogar offiziell der Mund verboten worden sei. Die anwesenden Vertreter des Quai d'Orsay bzw. des Informationsministeriums hätten das alleinige Recht beansprucht, offizielle Verlautbarungen im Namen der französischen Delegation zu machen. Als einer dieser politischen Vertreter bestätigte auch Jean-Jacques de Bresson dies im Gespräch.

${ }^{283}$ Neben Olivier waren mit M. Rodocanachi und Louis Amigues auch zwei Vertreter aus der Verwaltung des Quai d'Orsay Mitglieder der französischen Delegation.

284 „Protocole de la $3^{\text {eme }}$ session de la Commission mixte franco-soviétique sur la télévision en couleur«, Moskau, 14.04.1966, 6 maschinegeschriebene Seiten, S. 4, in: Archives du CHTV/ INA, Nachlaß Michel Dubail. 
ihre Forschungen auf dem Gebiet des Farbfernsehens auf die SECAM IVVariante zu beschränken.

Mit diesem überraschenden Angebot reagierten die Franzosen auf eine Initiative der dänischen Delegation, die der Untergruppe bei ihrem ersten Zusammentreffen am 4. Juli ein Dokument zum Studium zukommen lieB, das ein System namens »SEQAM « als europäischen Farbfernsehstandard vorschlug ${ }^{285}$. Tatsächlich handelte es sich bei dem von der dänischen Delegation vorgeschlagenen System - das von der britischen und bundesdeutschen Delegation unterstützt wurde ${ }^{286}$ - lediglich um ein neu getauftes PAL. Alleine diese begriffliche Annäherung an das SECAM-System stellte in den Augen des Leiters der britischen Delegation, H. Stanesby, ein "großes Opfer " für die PAL-Anhänger dar ${ }^{287}$. Die französische Offerte sorgte dagegen im bundesdeutschen und britischen Lager für Aufregung. Mit der Bereitschaft der Franzosen, ihr SECAM III-System zugunsten der sowjetischen Variante aufzugeben, hatten weder die Deutschen noch die Briten gerechnet. Der Vorschlag der Franzosen erfreute sich zudem der spontanen Unterstützung zweier wichtiger Persönlichkeiten, die als ständige Vertreter der EBU bzw. CCIR an den Sitzungen teilnahmen: EBU-Direktor George Hansen sowie der amerikanische CCIR-Direktor Leslie Hayes. Beide wiesen darauf hin, daß die Erreichung einer einheitlichen Norm - egal welche Systemvariante dafür in Frage komme - das oberste Ziel der gemeinsamen Bemühungen im Rahmen der CCIR-Vollversammlung sein sollte, »même si la solution n'est pas la meilleure [...] même s'il faut 5 mois pour essayer d'y arriver ${ }^{288}$.

Aufgrund der positiven Reaktionen wandte sich Studiengruppenleiter Eric Esping mit der Frage an die bundesdeutsche und britische Delegation, ob sie dazu bereit seien, die Einführung des Farbfernsehens in ihren Ländern zu-

285 Documents on CCIR Study Groups Period 1963-1966, Doc.Temp./179, 4.7.1966.

286 In einem Brief von Stanesby, dem Leiter der britischen Delegation in Oslo, an Merriman (FO), berichtet Stanesby von der geplanten Aktion der Dänen (in Absprache mit Deutschland und England), SEQUAM (Sequential European Quadrature Amplitude Memory Method) als Alternative einzubringen. Zitat: "I think it important that such a document be issued before the NIR/SECAM IV offensive gets underway «. In einem Telegramm vom 5.07. heißt es dazu: »British Delegation are lobbying hard in support of Danish proposal for general acceptance of PAL under face-saving formula (SEQUAM). They consider that Italy and to a lesser extent Austria, Spain, Belgium and Luxembourg may be key delegations and would appreciate any lobbying which can be carried out in capitals«, in: PRO, Signatur HO 256/388.

287 Siehe die 41 Seiten handschriftliche Aufzeichnungen über den Verlauf der Osloer Verhandlungen (ohne Angabe des Autors), in: Archives nationales, Signatur ORTF/Année 1999, Nr. 44, zukünftig zitiert als »Oslo-Tagebuch«. Das Manuskript ermöglicht eine bis ins kleinste Detail reichende Rekonstruktion der Verhandlungsabläufe in Oslo, da sowohl präzise Zeitangaben als auch die einzelnen Redebeiträge mit Angabe der entsprechenden Namen bzw. Delegation aufgefuihrt werden. Es muß von einem Mitglied der französischen Delegation verfaßt worden sein. Leider finden sich keine Hinweise auf den Autor.

288 Siehe Oslo-Tagebuch, S. 16, in: ibid. 
gunsten eines einheitlichen europäischen Farbfernsehstandards um ein halbes Jahr zu verschieben. Sowohl Hans Pressler als auch der Brite Stanesby erklärten, daB eine Entscheidung darüber, ob eine Verschiebung des Einführungstermins des Farbfernsehens möglich sei, außerhalb ihrer Kompetenz liege. Auch die von den Franzosen geforderte Forschungskonzentration auf das SECAM IV-System wurde von beiden Delegationsleitern als unmögliche Forderung zurückgewiesen, da man - so die Argumentation - der an der Farbfernsehtechnik wesentlich beteiligten Rundfunkindustrie nicht vorschreiben könne, an welchen Systemen sie zu arbeiten habe bzw. woran sie nicht arbeiten dürfe. Dieser Rückzug auf die Ebene rein formal-juristischer Argumentation kann aber als Zeichen dafür gedeutet werden, daß sich die bundesdeutsche und britische Delegation erheblichem "moralischen « Druck ausgesetzt sahen. Denn, wie auch Stanesby am Abend des 7. Juli nach London telegrafierte, standen er und seine Kollege Hans Pressler ziemlich alleine in ihrer harten pro-PAL-Haltung da:

Unfortunately the French proposal appeared to gain a large measure of support and of those delegations represented at the meeting only the F.R.G., the U.K. and - in a luke-warm measure - the Netherlands indicated their continued support for PAL. It is an unfortunate fact that the Chairman of the meeting, Eric Esping, and, particularly, the Director a.i. of the CCIR [Leslie Hayes, A.d.V.], adopted attitudes which were in favour of the French proposals. [...] Unfortunately, it appears that the activities of the broadcasting organizations in the EBU have seriously prejudiced the position ${ }^{289}$.

Auch Hans Pressler telegrafierte am Morgen des 8. Juli einen ausführlichen Bericht über die Sitzung des Vortages an Staatssekretär Bornemann vom Bundespostministerium. Pressler berichtete, da $B$ er im Anschluß an die lebhafte Sitzung Besuch von Philippe Olivier bekommen habe, der ihm seine Enttäuschung darüber mitgeteilt habe, daß der von Staatssekretär von Hase gegenüber Informationsminister Peyrefitte immer wieder geäußerte und nun in Form des SECAM IV-Systems realisierte Wunsch, alles zu unternehmen, um eine technische Kompromißlösung zwischen PAL und SECAM zu erreichen, von deutscher Seite nun zurückgewiesen werde ${ }^{290}$. Wie Werner Nestel in einem später verfaßten Reisebericht der Osloer Konferenz berichtete, sollen Stanesby und Pressler jedesmal sehr angeschlagen aus diesen Sitzungen herausgekommen sein. »Thre Überlegungen gingen dahin«, so Nestel, »ob es nicht durch einen Kompromiß irgendwelcher Art gelingen könnte, den sschwarzen Peter، abzuwenden ${ }^{291}$.

289 Telegramm von H. Stanesby an das General Post Office, Oslo, 7.07.1966, in: PRO, Signatur HO 256/388.

290 Telegramm von Hans Pressler an Staatssekretär Bornemann, Oslo, 8.07.1966, in: Bundeszwischenarchiv Bonn, Signatur B 145/4513.

291 Siehe den von Werner Nestel verfaBten "Reisebericht, CCIR-Tagung in Oslo vom 22.06. bis 16.07. 1966«, Ulm, 18.07.1966, 6 maschinegeschriebene Seiten, hier S. 5, in: Bundeszwischenarchiv Bonn, Signatur B 145/4513. 
So überraschend der französische Vorstoß am Morgen des 7. Juli gekommen war, so verwunderlich war der noch am gleichen Tag erfolgte Widerruf des "Angebots" am Ende dieses durch langwierige und unfruchtbare Diskussionen gezeichneten Tages. Da weder die deutsche noch die britische Delegation bereit war, das SECAM IV-System in der dafür erforderlichen Zeitspanne zu studieren und die Einführung des Farbfernsehbetriebs in ihren Ländern entsprechend zu retardieren, zog die französische Delegation ihr »Kompromißangebot « zurück und hielt an der Einführung des SECAM III-Systems fest. Kam dieser plötzliche Rückzug den PAL-Anhängern ohne Frage entgegen, hinterließ er bei zahlreichen Delegationen, die der französischen Initiative erwartungsvoll zugestimmt hatten, einen bitteren Nachgeschmack. Wie Hans Pressler bemerkte, lag die Vermutung nahe, »daß der Vermittlungsvorschlag vorwiegend aus Gründen der Optik gemacht wurde ${ }^{292}$. Auch H. Stanesby deutete den unerwarteten Rückzug der Franzosen, der - wie er betont - »in a quietly dramatic way« inszeniert worden sei, als ein taktisches Manöver, auch wenn er, wie er in seinem Abschlußbericht gestand, über die ursächlichen Motive der französischen Delegation im unklaren war ${ }^{293}$.

Obwohl es Befürwortern eines einheitlichen europäischen Standards - allen voran den bereits genannten Persönlichkeiten Hayes und Hansen und der im Hintergrund sehr aktiven belgischen Delegation - gelang, die Franzosen am darauffolgenden Tag zu einer erneuten Zusage ihres Angebots vom Vortag zu bewegen, hielten die Briten und Deutschen an ihren Positionen fest. In einer hitzigen Diskussion versuchten nun beide Lager, sich gegenseitig die Schuld am Scheitern einer Kompromißlösung zu geben. Während die Franzosen den Briten und Deutschen eine "anti-europäische « Haltung vorwarfen und verlangten, deren Weigerung SECAM IV als einheitlichen europäischen Standard zu akzeptieren in das offizielle Protokoll des CCIR-Konferenzberichts aufzunehmen, warfen Stanesby und Pressler den Franzosen eine Politisierung der Farbfernsehfrage und damit eine Mißachtung der CCIR-Statuten vor. Nach acht Stunden vergeblicher Diskussion brach Gruppenleiter Erik Esping die Sitzung erfolglos ab und beauftragte eine Redaktionsgruppe mit dem Verfassen eines unparteiischen Berichtes über die beiden letzten Verhandlungstage. Doch selbst dort setzten sich die teilweise polemischen Wortgefechte zwischen Franzosen, Deutschen und Briten fort, so daß der Vorsitzende Esping den Bericht alleine verfassen mußte ${ }^{294}$. Dieser beschränkte

292 Ibid.

293 Siehe den 4 seitigen, von $H$. Stanesby am 22.08. verfaßten »Report to TAC/TSC on CCIR $\mathrm{XI}^{\text {th }}$ Plenary Assembly, Oslo, 1966《, in: PRO, Signatur HO 256/388.

294 Am 11.07. schickte Hans Pressler ein 2 seitiges Telegramm an Staatssekretär Bornemann vom Postministerium, in dem er über den Fortgang der Verhandlungen berichtete. Dort hieß es: "Die Verhandlungen in dieser Redaktionsgruppe waren unerfreulich wegen der nervösen Reaktion des französischen Vertreters auf sachliche Fragen des englischen und deutschen Vertreters, 
sich auf die bloße Wiederholung der unterschiedlichen Positionen und vermied es tunlichst, eine zusammenfassende Aussage zu treffen, die als Wertung des Geschehens gedeutet werden konnte ${ }^{295}$.

Damit waren die Bemühungen gescheitert, in der kleinen Runde der Delegationsleiter der wichtigsten europäischen Fernsehnationen zu einer Einigung über die Farbfernsehfrage zu gelangen. Als am 13. Juli die Diskussion in der größeren Studiengruppe wieder aufgenommen wurde, drängte vor allem die belgische Delegation darauf, die Chance eines einheitlichen europäischen Farbfernsehsystems nicht leichtfertig zu vergeben. Doch muBten gerade die Vertreter kleinerer Länder bald einsehen, daß sie an den Entscheidungen der »big four « - Frankreich, Bundesrepublik Deutschland, Großbritannien und Sowjetunion - wenig zu ändern vermochten. Sowohl in Frankreich als auch in der Bundesrepublik und Großbritannien waren es in erster Linie industrielle Interessen, die ein Abweichen von der SECAM III- bzw. PAL-Linie verhinderten.

Von Prof. Nestel ständig über den Lauf der Verhandlungen in Oslo unterrichtet, versuchte der Telefunken-Vorstandsvorsitzende Dr. Felix Herriger in Bonn Druck auszuüben, damit der bundesdeutsche Delegationsleiter weiterhin unbeirrt an seiner pro-PAL-Haltung festhalte ${ }^{296}$. Ähnliche Stimmen wurden von der britischen Rundfunkindustrie auf einer »Krisensitzung « im Postministerium am 14. Juli geäußert, auf der Delegationsleiter Stanesby sowie weitere Delegationsmitglieder über den Verlauf der Osloer Verhandlungen Bericht erstatteten. Der Vorsitzende der BREMA, Sir Jules Thorne, zeigte sich bei diesem Treffen sehr besorgt über die Möglichkeit eines erneuten Aufschubs des Farbfernseheinführungstermins. Außerdem habe die britische Industrie bereits eine Menge Geld in die Untersuchung des NTSC- und PAL-

die beide den Vorsitzenden um Schutz gegen beleidigende Äußerungen des französischen Vertreters bitten mußten«, in: Bundeszwischenarchiv Bonn, Signatur B 145/4513.

295 »Report by Sub-Group XI-A-2«, Doc.Temp./276 (XI)-E, 11.07. 1966.

296 In einer Gesprächsnotiz von Dr. Herriger über Telefonate mit Werner Nestel in Oslo und Dr. Siewert in Bonn - beide am 12.07.1966 - heiBt es: „Es wurde mit Prof. Nestel verabredet, daß wir versuchen, über Bonn zu erreichen, daB die deutsche Kommission, insbesondere Herr Pressler, eine Rückenstärkung bekommt. [...] Siewert wurde über Telefonat mit Nestel berichtet und gebeten, über AA bzw. Botschaft in Oslo pro PAL aktiv zu werden. Siewert berichtet, daB ein Gespräch mit Dr. Frank [vom Auswärtigen Amt, A.d.V.] ergeben habe, daß noch heute ein Telegramm an die Botschaft in Oslo mit entsprechender Weisung abgehen würde«, in: AEG-Telefunken-Archiv, Deutsches Technikmuseum Berlin, Signatur GS 1649. Einen Tag später, am 13. Juli, telefonierte Herriger auch mit dem Geschäftsführer der Fachgruppe 13 des ZVEI, Dr. Hücking. »Herr Dr. Hücking teilte meine Meinung, daß es sich die deutsche Industrie nicht leisten könne, in der Frage des Farbfernsehsystems noch weitere $11 / 2$ bis 2 Jahre zu warten, bis ein neuer Normvorschlag für NIR gemacht und erprobt sei. Aus diesem Grund müsse die deutsche Industrie darauf drängen, daB das PAL-System zur Einführung käme«. Siehe Gesprächsnotiz von Dr. Herriger über Telefonat mit Dr. Hücking, 13.07.1966, in: AEG-Telefunken-Archiv, Deutsches Technikmuseum Berlin, Signatur GS 1646. 
Systems investiert, so daß eine erneute Investition für eine weitere Systemvariante nicht in Frage komme. Obwohl Sir Hugh Carleton Greene und sein Chefingenieur McLean aus Sicht der BBC die Vorteile eines einheitlichen europäischen Farbfernsehsystems erneut hervorhoben, beschloß der Generaldirektor im britischen Postministerium und Leiter der Sitzung, Sir Ronald German, daß die britische Delegation in Oslo an der eindeutigen pro-PALHaltung festhalten solle ${ }^{297}$. Bereits einen Tag später informierte Stanesby, nach Oslo zurückgekehrt, seinen deutschen Kollegen Pressler über das Resultat der Besprechung in London, das dieser mit Freude nach Bonn weiterleite$\mathrm{te}^{298}$.

Hielt das britische Postministerium demnach an der Befürwortung des PAL-Systems fest, hatte vor allem BBC-Chefingenieur Francis McLean auch in Oslo nichts unversucht gelassen, seinen Einfluß zugunsten der Propagierung des SECAM IV-Systems geltend zu machen. Wie immer geschah dies sehr zum Ärger des Foreign Office sowie der britischen Rundfunkindustrie. Bereits zu Beginn der Osloer Verhandlungen beschwerte sich Delegationsleiter Stanesby über die eigenmächtigen Aktionen des BBC-Chefingenieurs: »I am sorry to say that the PAL position has been seriously undermined by the widely publicised BBC work on NIR/SECAM IV-work which was reported to the EBU and which is frequently mentioned during this Conference. The BBC's favourable opinion on NIR/SECAM IV is widely known and seriously embarrasses us, and I am afraid that McLean, in casual conversation, makes no effort to support the PAL point of view « ${ }^{299}$.

Während McLean seine pro-SECAM IV-Position demnach in Oslo außerhalb der offiziellen Sitzungen mehr oder minder ungehindert verbreiten konnte $^{300}$, wurden potentielle französische Initiativen auf seiten der Ingenieure der ORTF bereits im Keim erstickt. Wie mehrere Interviewpartner berichten, hatten die Ingenieure der ORTF das SECAM IV-System in ihren Laboratorien soweit entwickelt, daß sie in der Lage waren, entsprechende Vorfüh-

297 "Note of a meeting held in room 109, Post Office Headquarters Building on 14 th July, 1966«, in: PRO, Signatur HO 256/387. Auf fünf maschinegeschriebenen Seiten wird hier der Stand der Verhandlungen in Oslo zusammengefaßt. Neben Vertretern der Rundfunkindustrie und der BBC nahmen an der Sitzung auch Vertreter des Außenministeriums, des Privatfernsehsenders ITA, des Postministeriums, des Ministeriums für Technologie sowie des Finanzministeriums teil. 298 Telegramm von Pressler an das Bundespostministerium, Oslo, 15.07.1966, in: Bundeszwischenarchiv Bonn, Signatur B 145/4513.

299 Mitteilung von Stanesby an Merriman (FO), in: PRO, Signatur HO 256/388.

300 Die BBC-Aktivitäten für SECAM IV werden auch in einem Aufsatz von Jacques Fagot erwähnt. Dort heißt es: »Pour ajouter au ssuspense< la BBC, à Londres, avait même sorti de ses cartons des notes techniques montrant que des solutions analogues au SECAM IV avaient été envisagées dans le secret de ses laboratoires«. Siehe Jacques FAGot, La télévision en couleurs, in: Technique, Art et Science (1969) S. $71 \mathrm{f}$. 


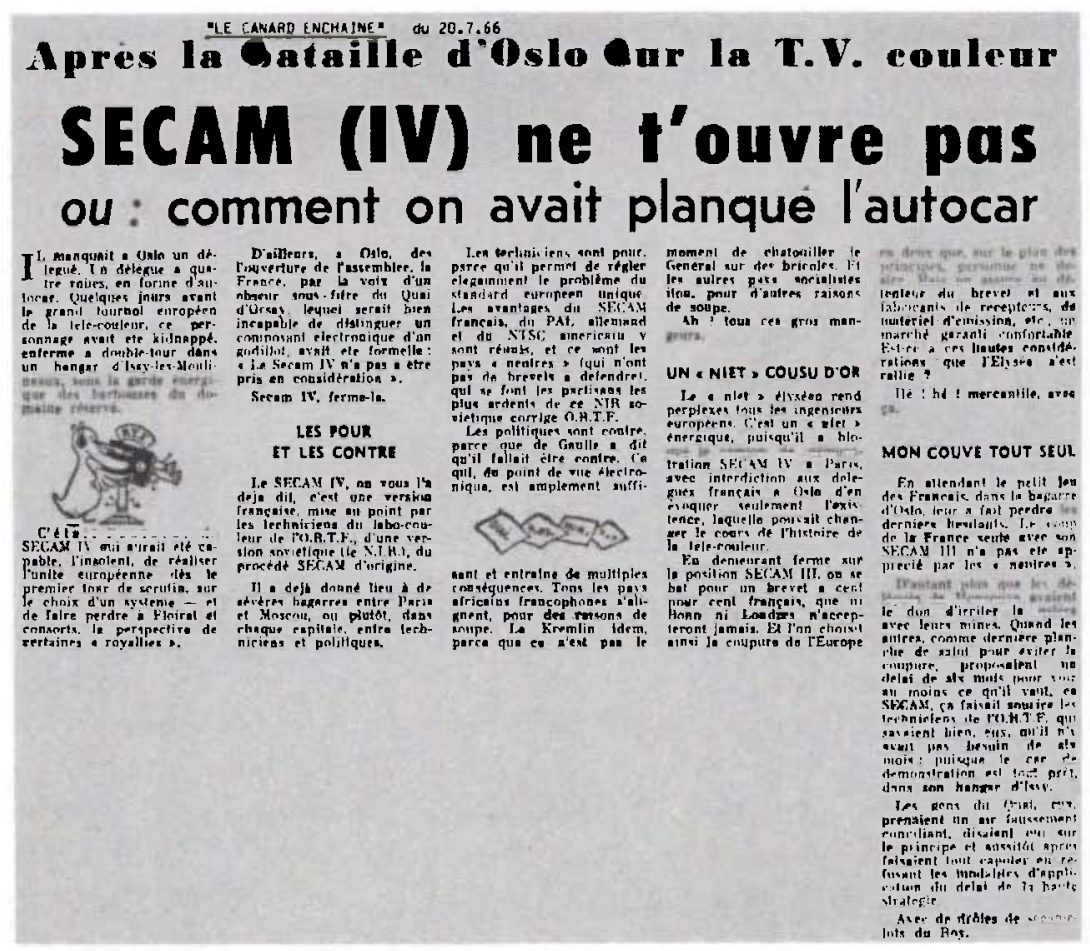

'Abb. 23: „SECAM (IV) ne t'ouvre pas«, aus: Le Canard Enchainé, 20. Juli 1966.

rungen in Oslo zu machen ${ }^{301}$. Zu diesem Zweck war bereits ein Lastwagen mit den benötigten Apparaturen bestückt und die erforderlichen Genehmigungen (Zollpapiere, Reisepässe) eingeholt worden. Nachdem die französische Delegation das SECAM IV-Angebot unterbreitet hatte, stand in Paris alles bereit zum Aufbruch nach Oslo, als wenige Stunden später das kategorische Verbot zur Abreise eintraf. Da sich die Lage in Oslo geändert hatte, kam eine Demonstration des Systems unter keinen Umständen mehr in Frage - sehr zum Ärgernis der ORTF-Ingenieure. Wie Yves Angel überliefert, soll der französische Delegationsleiter Rodocanachi die Entscheidung mit den Worten begründet haben: »La France a tendu la main et n'a rencontré que le

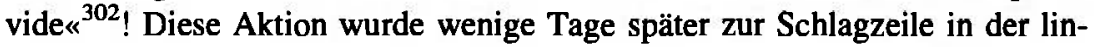

301 ORTF-Chefingenieur Louis Goussot schrieb wenig später in einem längeren Aufsatz zum Thema Farbfernsèhen gar, daB man das NIR-System in den Laboratorien der ORTF so weit entwickelt habe, daß man mit der Fertigung von Prototypen für die Serienfertigung hätte beginnen können (»en le poussant jusqu'à la réalisation de prototypes reproductibles en série«). Siehe Louis Goussot, L'équipement de la télévision en couleur à l'ORTF, in: L'Onde électrique 48 (1967) S. 1017-1028, hier S. 1017.

302 ANGel, Brève histoire des débuts de la télévision française. 

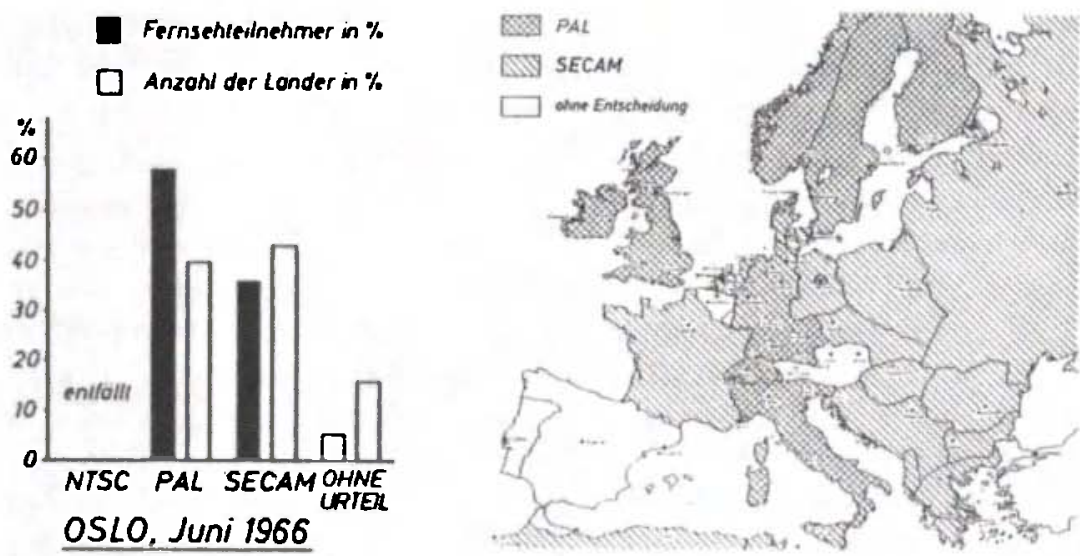

Abb. 24/25: Diagramm und Karte der Ergebnisse der CCIR-Tagung in Oslo vom Juni/Juli 1966, aus: MüLLER, Die internationalen Bemühungen, S. $247 f$.

ken französischen Tageszeitung "Le Canard Enchaîné«, die am 20. Juli titelte: »SECAM (IV) ne t'ouvre pas - ou: comment on avait planque l'autocar «.

Obwohl Frankreich seinen diplomatischen Druck in Oslo durch die Anreise des ehemaligen Kabinettsdirektors von Alain Peyrefitte, Jean-Jacques de Bresson, der nunmehr Direktor der juristischen Abteilung des Quai d'Orsay war, noch verstärkte, änderte sich in der letzten Woche der Beratungen in Oslo an den entscheidenden Positionen der zentralen Verhandlungsakteure nichts mehr. In recht nüchternen Worten faßte der britische Delegationsleiter Stanesby das Ende der Konferenz in seinem Abschlußbericht zusammen:

The final result of all these discussions was a report from the Study Group XI to the Plenary Assembly setting out the technical characteristics of the various colour television systems and appending to it the report that had originated in Sub-Group XI A 2. When this report was finally presented at the Plenary Assembly there was a tense moment and no-one at all discussed $\mathrm{it}^{303}$.

Wie schon in Wien war die CCIR auch in Oslo nicht in der Lage, eine Empfehlung für einen einheitlichen europäischen Farbfernsehstandard zu formulieren. Von seiten der technischen Experten wurde dieses Scheitern sehr bedauert. Die internationale Presse schloB sich diesem Bedauern weitestgehend an, auch wenn gewisse regierungsnahe Blätter in beiden Lagern keine Probleme hatten, den »Schuldigen« im jeweils anderen Lager auszumachen. In Frankreich war es vor allem der "Figaro $-\mathrm{zu}$ dessen Herausgebern und politischen Leitartiklern später auch Alain Peyrefitte zählen sollte -, der die

303 »Report to T.A.C./T.S.C. on C.C.I.R. XI ${ }^{\text {th }}$ Plenary Assembly, Oslo, 1966«, in: PRO, Signatur HO 256/388. 
verpaßte Chance eines »esperanto électronique« Deutschland und Großbritannien ankreidete: "Ainsi«, so heißt es in einem Artikel von Pierre de Latil vom 18. Juli 1966, „des décisions unilatérales avaient été prises à Bonn et à Londres avant la conférence qui devait faire un choix technique! Décidément, au moment où l'on parle tant de collaboration européenne, on n'a jamais tellement bafoué qu'aujourd'hui les bases saines des négociations internationales ${ }^{304}$. Radio \& Télévision-Chefredakteur Eugène Aisberg, der vor Oslo noch den Schlachtruf »unité avant tout« ausgegeben hatte, mußte sich nach Oslo eingestehen, daß seine hoffnungsvollen Erwartungen enttäuscht worden waren. Resigniert schrieb er: "Jamais, décidément, les destinées de la couleur ne nous ont paru aussi sombres! $\aleph^{305}$

Bereits vor dem offiziellen Ende der Vollversammlung in Oslo (22. Juli) trafen sich in Bonn die Spitzen von Telefunken mit den Staatssekretären von Hase und Bornemann sowie mit dem Ministerialdirigenten Dr. Frank vom Auswärtigen Amt, um die Ergebnisse der Osloer Verhandlungen auszuwerten. Da am 21. Juli der französische Staatspräsident zu Besuch in Bonn war, wollte man im Informationsministerium argumentativ gerüstet sein, falls de Gaulle das Gespräch auf das Thema Farbfernsehen bringen würde - auch wenn dies im Protokoll nicht vorgesehen war. Vor allem Felix Herriger machte deutlich, daß man möglichen »französischen Wünschen nach >Opfern und der Vertagung der Entscheidung « auf keinen Fall nachgeben dürfe. »Wir sollten stolz darauf sein«, so der Telefunken-Vorstandsvorsitzende, »daß ein deutsches System eine derartige internationale Anerkennung bei Fachleuten erhalten hat und dieses mühsam errungene Prestige nicht preisgeben ${ }^{306}$.

Auch der Vorsitzende des Fachverbandes Rundfunk und Fernsehen im ZVEI, Dr. Meyer, gab zu bedenken, daß die französischen Interessen nun unberücksichtigt bleiben müßten - »es muß auf jeden überraschenden Kuhhandel mit den Franzosen verzichtet werden, wenn nicht ein ganzer Industriezweig erheblich geschädigt werden soll«. Nachdem Karl-Günther von Hase die Ausführungen der anwesenden Industriellen gehört hatte, zog auch er ein Fazit aus Sicht des Bundespresse- und Informationsamtes:

304 Pierre DE LATIL, TV-Couleurs: La division technique de l'Europe est irrémédiable, in: Le Figaro, 18.07.1966.

305 Eugène AIsBerg, L'Europe écartelée, in: Radio \& Télévision 166 (1966) S. 203.

306 Vermerk über drei Besprechungen mit den Herren Staatssekretär von Hase, Bundespresseamt, Staatssekretär Bornemann, Bundespostministerium und Mininisterialdirigent Dr. Frank, Auswärtiges Amt, am 19.07.1966 in Bonn über das Ergebnis von Oslo und die Haltung der Bundesregierung beim de Gaulle-Besuch am 21.07.1966, verfaBt von Dr. Siewert (Telefunken), Bonn, 22.07.1966, 6 maschinegeschriebene Seiten, in: AEG-Telefunken-Archiv, Deutsches Technikmuseum Berlin, Signatur GS 1647. 
Die Bundesregierung [bleibt] bei ihrer bisherigen pro-PAL-Haltung, die stets bewuBt unpolitisch und >keine nationale Frage war und sich ausschließlich auf der Grundlage der technischen Leistung bewegt hat. Die vor allem von Frankreich betriebene Entwicklung ist in politischer Sicht unerfreulich. Man hätte sich durchaus eine optimalere Gestaltung des Problems vorstellen können. Die Schuld liegt aber eindeutig nicht bei uns. Immer wieder habe er den Franzosen angeboten, den Versuch zu machen, beide Systeme zu kombinieren. Frankreich hat darauf überhaupt nicht reagiert, sondern wie ein >deus ex machinar vor Wien den französisch-russischen Vertrag geschlossen. Wir befinden uns also in einer guten Situation und haben ein Alibi ${ }^{307}$.

Staatssekretär Bornemann vom Bundespostministerium zeigte sich über die erreichte Position in Oslo sehr zufrieden: »Wie könnte die Bundesregierung PAL aufgeben«, so fragte er, "wenn England eine so großartige Haltung in Oslo bewiesen hat «? Tatsächlich wurde die enge deutsch-englische Kooperation sowohl von bundesdeutscher als auch von britischer Seite als Erfolg und vielversprechendes Zeichen für eine weitere Zusammenarbeit im europäischen Kontext gedeutet. In einem Rundschreiben unterrichtete Sir Frank Roberts vom britischen Außenministerium seine Kollegen über ein Gespräch mit Karl-Günther von Hase am 21. Juli 1966, bei dem dieser ihm zu der festen Haltung für PAL in Oslo gedankt habe:

State Secretary von Hase told me last night how pleased the Ferderal Government were over the close Anglo-German cooperation which had developed over international colour television. They highly appreciated our support for PAL which had been decisive. [...] He was most critical of French behaviour. He claimed that the Germans had made great efforts over a long period to come to some compromise solution but the French apart from their initial action at Vienna had been entirely uncompromising until Oslo when they had put forward their SECAM IV proposal which was quite unrealistic and obviously a mere tactical device ${ }^{308}$.

Obwohl man im Quai d'Orsay das Scheitern der SECAM IV-Initiative im Gegensatz zur CFT/CSF bedauerte, widmete man sich bald den praktischen Folgen, welche die Spaltung Europas für die Fernsehwelt und vor allem für die französisch-sowjetische Kooperation bedeutete. Zwar äußerte auch Gwishiani im Gespräch mit dem französischen Botschaftsmitglied Baudet in Moskau sein Bedauern über das Scheitern der NIR-Offerte, doch gab Gwishiani zu verstehen, daß man sich nun den praktischen Fragen des Aufbaus des Farbfernsehens in der Sowjetunion und Frankreich widmen müsse ${ }^{309}$. In gegenseitigem Einverständnis zwischen de Bresson und Gwishiani wurde am 29. Juli ein französisch-sowjetisches Pressecommuniqué veröffentlicht, in dem beide Länder ihren nunmehr definitiven Beschluß bekannt gaben, das

307 Ibid.

308 Rundschreiben von Sir F. Roberts (FO) vom 21.07.1966, in: PRO, Signatur FO 371/181315, General Department, Akte GT 41/39.

309 Telegramm von Baudet, französische Botschaft in Moskau, an Jean-Jacques de Bresson, Quai d'Orsay, Moskau, 23.07.1966, in: Archives du MAE, Affaires Économiques et Financières, Affaires Générales, Nr. 220d. 
SECAM III-System einzuführen - allerdings nicht, ohne nochmals auf die Kompromißbereitschaft beider Länder in Oslo hinzuweisen:

Constatant que l'accord sur un procédé unique de télévision en couleur en Europe n'a pu être réalisé à la Conférence d'Oslo, malgré les propositions de compromis avancées par les délégations française et soviétique, le Gouvernement français, en plein accord avec le Gouvernement de l'URSS, a décidé de choisir définitivement le système SECAM III et de préparer dès à présent la mise en exploitation sur le plan industriel de ce procéde $e^{310}$.

310 Telegramm von Jean-Jacques de Bresson an Rodocanachi, französische Botschaft Moskau, Paris, 25.07. 1966, in: Archives du MAE, Affaires Economiques et Financières, Affaires Générales, Nr. $220 \mathrm{~d}$. 


\subsection{Farbfernsehpolitik zwischen industriepolitischem Kalkül und nationalem Prestige - zusammenfassende \\ Betrachtung des »terrain politique«}

Bevor in Kapitel 5 eine systematische Analyse des Scheiterns der Bemühungen um einen einheitlichen europäischen Farbfernsehstandard vorgenommen wird, sollen die grundlegenden Aspekte der politischen Dimension der Farbfernsehkontroverse noch einmal zusammengefaßt werden.

$\mathrm{Ab}$ Mitte der fünfziger Jahre stieg das Fernsehen in den westeuropäischen Ländern zum neuen Leitmedium der medialen Öffentlichkeit auf. Allerdings wurde die Bedeutung des neuen audiovisuellen Mediums für die Gestaltung der politischen Öffentlichkeit einer Nation dies- und jenseits des Rheins unterschiedlich eingeschätzt. Dieser unterschiedlichen Einschätzung entsprechend kam es zu divergierenden institutionellen und strukturellen Ausbildungen des Fernsehrundfunks in beiden Ländern. Während das Fernsehen in Frankreich ganz selbstverständlich in der Tradition des zentralistischen Hörrundfunks als Instrument regierungspolitischer Meinungsbildung eingesetzt wurde (Télécratie), setzte sich in der Bundesrepublik mittels alliierter Nachhilfe das föderale Modell vom Bund unabhängiger Landesrundfunkanstalten durch, das eine regierungspolitische Monopolisierung des Fernsehrundfunks trotz entsprechender Versuche (Adenauer-Fernsehen) erfolgreich verhinderte. Dementsprechend groß war der politische Zugriff auf das neue Medium auf der französischen Seite, während er auf bundesdeutscher Seite durch das Karlsruher Fernsehurteil vom Februar 1961 verfassungsrechtlich beschränkt wurde. Diese strukturellen Unterschiede sind der Grund dafür, daß die zentralen politischen Akteure auf französischer Seite einen viel direkteren und unmittelbareren Zugriff auf rundfunkpolitische oder rundfunktechnische Entscheidungen ausüben konnten als ihre deutschen Kollegen.

Neben den strukturellen Unterschieden gab es zudem unterschiedliche Einschätzungen der politischen Wirkmächtigkeit des neuen Mediums Fernsehen. Während weder Adenauer noch Erhard die suggestive Kraft des bewegten Bildes - das im Gegensatz zum Kino in jedes Haus dringen konnte - richtig einschätzten, war sich Charles de Gaulle dieser Bedeutung von Anfang an bewuBt. Seine Rundfunkerfahrungen des Zweiten Weltkriegs (»Voix de la France «) setzte er nahtlos in die Fernsehwelt um. Diese im Vergleich zu deutschen Politikern wesentlich höhere Sensibilität für das neue Leitmedium Fernsehen machte de Gaulle aufmerksam für rundfunktechnische Entwicklungen, die er umgehend als nationale Prestigeobjekte (»champions nationaux «) deutete und dementsprechend politisch auflud.

Glaubte man zu Beginn des Jahres 1963 sowohl in Frankreich als auch in der Bundesrepublik daran, das Thema Farbfernsehen zu einem beispielhaften Objekt der gerade vertraglich festgelegten deutsch-französischen »Freund- 
schaft« machen zu können, sorgte die rasche Abkühlung des deutsch-französischen Verhältnisses nach dem Amtsantritt Erhards für eine Kursänderung de Gaulles in dieser Frage. Schritt für Schritt avancierte das SECAM-Projekt für den französischen Staatspräsidenten zum Präzendenzfall der französischsowjetischen Annäherung und war damit Ausdruck seiner neuen europapolitischen Vision (»Europa vom Atlantik bis zum Ural«). Während man auf bundesdeutscher Seite - zumindest im Bundespresse- und Informationsamt weiter an einer Annäherung der beiden Positionen im Sinne des deutsch-französischen Vertrages arbeitete, hatte de Gaulle das SECAM-System zur »Concorde franco-russe« erklärt. Resultat dieser neuen außenpolitischen Strategie de Gaulles, die keineswegs immer auf Gegenliebe im Quai d'Orsay stieß, war die Unterzeichnung des französisch-sowjetischen Farbfernsehvertrags am 22. März 1965 in Paris.

Die Bekanntmachung des französisch-sowjetischen Farbfernsehvertrags drei Tage vor Beginn der CCIR-Zwischentagung in Wien, auf der die Fernsehexperten der Welt einen einheitlichen europäischen Farbfernsehstandard zu definieren suchten, löste in Expertenkreisen eine Welle der Entrüstung aus. Ist die Unterzeichnung und Veröffentlichung des Vertrages mit den Worten Alfred Grossers durchaus als Meisterleistung de Gaullescher »Schockdiplomatie zu bewerten, wurde sie von den technischen Experten, welche die zentralen Akteure der CCIR waren, als unerfreulicher Eingriff der Politik in das Feld der »neutralen Technik « gedeutet. Tatsächlich ging die Taktik der Franzosen trotz oder gerade wegen dieser diplomatischen Offensive nicht auf: Viele Delegationen, die sich bislang durchaus interessiert für die Technik des SECAM-Systems gezeigt hatten, wendeten sich aufgrund der Politisierung der Farbfernsehfrage eher von den Franzosen ab. Auch das Kalkül der Franzosen, die Bundesrepublik via UdSSR und Satellitenstaaten besonders durch eine SECAM-Übernahme in der DDR - für das SECAMSystem zu gewinnen, ging in Wien nicht auf. Die Wiener Konferenz endete vielmehr in einem Zusammenrücken der NTSC- und PAL-Verfechter zugunsten der letzteren.

Die Phase zwischen den beiden CCIR-Tagungen in Wien und Oslo kann als diejenige Phase beschrieben werden, in der es zur internationalen Politisierung der Farbfernsehfrage kam. Nach Wien formierten sich auch die PALund NTSC-Befürworter neu und es kam zur folgenreichen Annäherung der britischen und bundesdeutschen Position, die durch die PAL-Übernahme des Philips-Landes Niederlande noch verstärkt wurde. Während sich somit das PAL-Lager für die Osloer Verhandlungen wesentlich verstärkte, sorgte die sowjetische NIR-Entwicklung für ernsthafte Irritationen des französisch-sowjetischen Verhältnisses. Zwar gelang es der französischen Diplomatie unter großen Anstrengungen letztlich doch noch, die sowjetischen »Partner« auf die SECAM III-Linie festzulegen, doch sorgte das NIR-System, das schnell 
den Ruf eines technischen Kompromißsystems zwischen PAL und SECAM erlangte, für internationales Aufsehen. Vor allem die Ingenieure der BBC und ORTF sahen im NIR-System den schon unmöglich scheinenden europäischen Standard und investierten wider den Willen der zuständigen politischen Institutionen in die Erforschung des sowjetischen Systems.

Obschon alle zentralen Akteure mit klaren strategischen Weisungen in Oslo anreisten, kam es mit der französischen Offerte, das SECAM IV (NIRSystem) als möglichen europäischen Standard zu diskutieren, zu einer unerwarteten Wende in den Verhandlungen. Da der baldige Widerruf dieses als "großzügiges französisches Opfer« verkauften Angebots sowie der Rückzug der britischen und bundesdeutschen Argumentation auf formaljuristische Kriterien alle weiteren Verhandlungsbemühungen im Kern ersticken ließ, blieb es auch in Oslo bei der Spaltung der Delegierten in ein PAL- und ein SECAM-Lager. Die CCIR-Vollversammlung war nicht in der Lage, eine Empfehlung für ein einheitliches europäisches Farbfernsehsystem auszusprechen.

Wie in Wien förderten die gescheiterten Bemühungen in Oslo auf beiden Seiten die publizistische Suche nach »Schuldigen « für dieses Scheitem. Verharrten diese »Beschuldigungen « meist in ideologischen oder nationalistischen Verzerrungen der Wirklichkeit, ist es auch aus heutiger Perspektive schwer, die Ernsthaftigkeit des französischen-sowjetischen SECAM IV-Angebots in Oslo einzuschätzen ${ }^{311}$. Tatsächlich hätte die Einführung dieses Systems, das - so die Meinung vieler damaliger Fernsehtechniker - dem PALSystem verwandter war als dem SECAM-System, für die Franzosen eine herbe Niederlage aus industriepolitischer und wirtschaftlicher (Lizenzgebühren) Perspektive bedeutet. Vieles deutet darauf hin, daß im Falle der bundesdeutschen und britischen Zustimmung, das NIR-System einer eingehenderen Untersuchung zu unterziehen und damit den Einführungstermin des Farbfernsehens um sechs bis maximal zwölf Monate zu verschieben, eine Einigung durchaus realistisch gewesen wäre. Wären die Bundesrepulik und Großbritannien zu dieser zeitlichen Verschiebung ihres ersten Farbfernsehbetriebs bereit gewesen, hätte dem SECAM IV-System als europäischem Standard wahrscheinlich nichts im Wege gestanden. Der Druck der britischen und bundesdeutschen Rundfunkindustrie, Ende 1967 unbedingt mit dem Farbfernsehen zu beginnen um das Absatztief im Bereich der s/w-Empfänger aufzufangen, war höher als der potentielle politische und kulturelle Mehrwert einer einheitlichen europäischen Lösung.

311 Im Interview mit dem Autor äußerte sich Jean-Jacques de Bresson selbstkritisch über die verpaßte Chance in Oslo: „J'ai été beaucoup critiqué par les délégations a Oslo. Ils me rapprochaient d'avoir torpédié la possibilité d'un accord technique - ce qui est vrai d'ailleurs. Mais c'était mes instructions«. Interview mit Jean-Jacques de Bresson, Paris, 17.09.1999. 
